\title{
Spatial scale, plant identity and management effects on the diversity-productivity relationship in a semi-natural grassland
}

\author{
Dissertation \\ to obtain the $\mathrm{Ph}$. D. degree \\ in the International Ph. D. Program for \\ Agricultural Sciences in Goettingen (IPAG) \\ at the Faculty of Agricultural Sciences, \\ Georg-August-University Göttingen, Germany
}

presented by

Tatiana From

born in Moscow, Russia

Göttingen, May 2013 
D7

1. Supervisor: Prof. Dr. Johannes Isselstein

2. Co-supervisor: Prof. Dr. Christoph Leuschner

Date of dissertation defence: 16.05.2013 


\section{Contents}

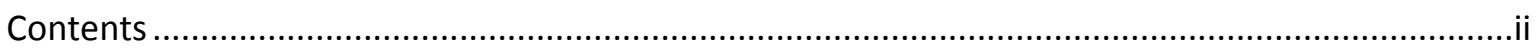

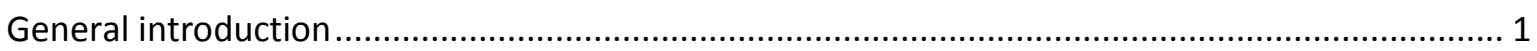

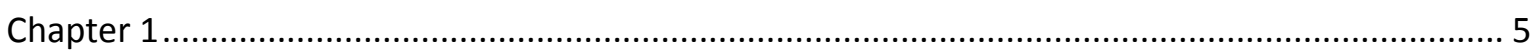

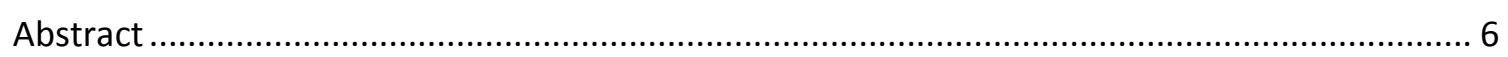

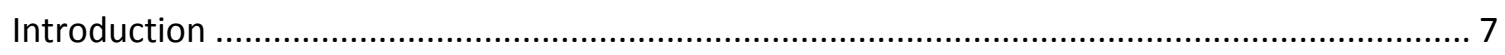

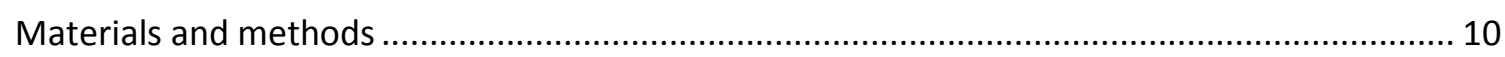

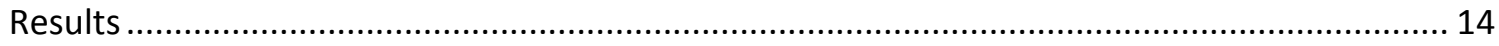

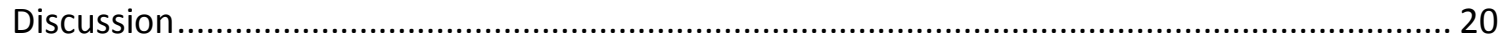

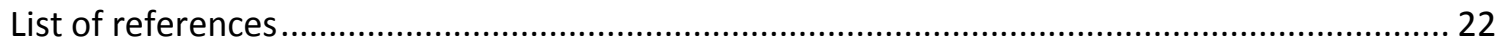

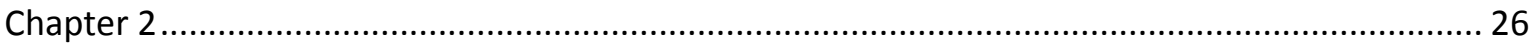

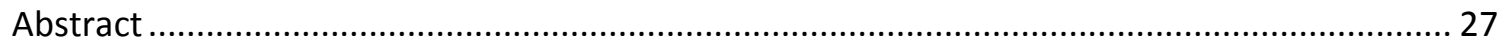

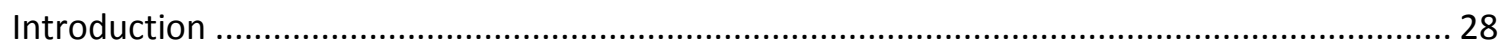

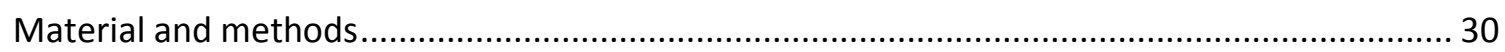

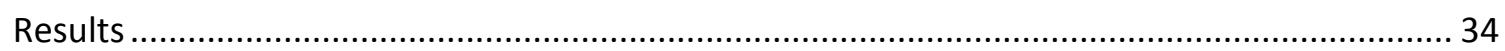

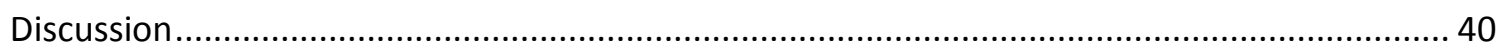

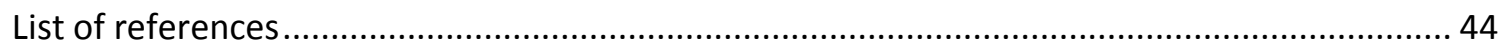

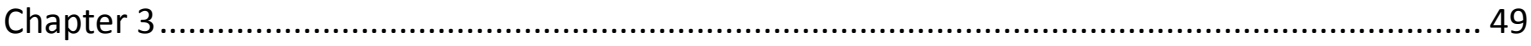

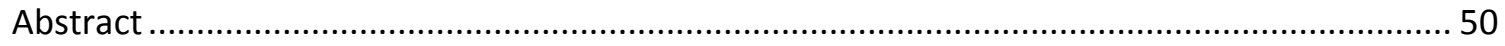

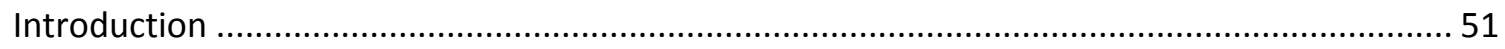

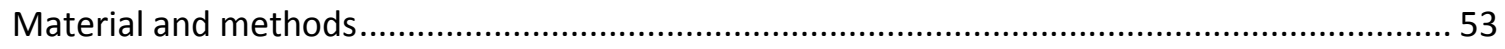

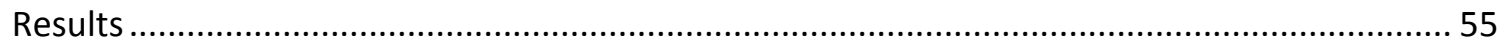

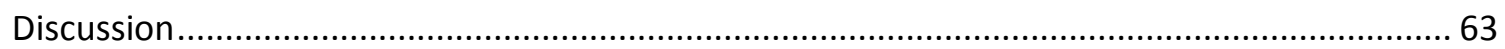

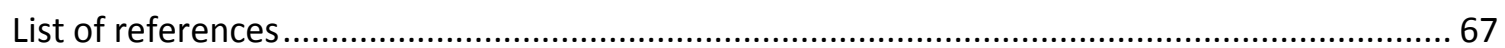

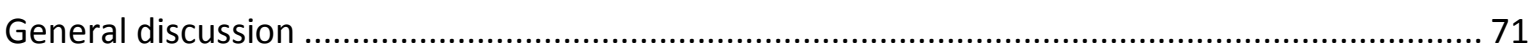

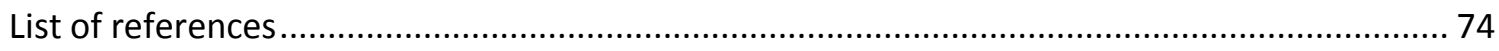

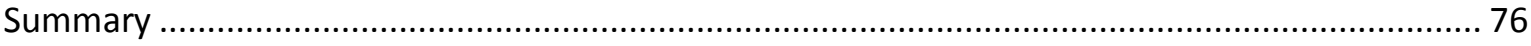

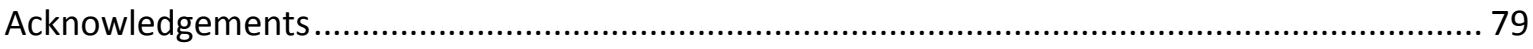

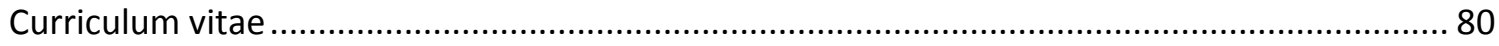

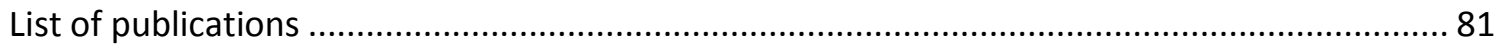


Appendix

Appendix 1. Supporting information for Chapter 1 (Supplementary table 1) ........................... 82

Appendix 2. Supporting information for Chapter 1 (Supplementary table 2). .83

Appendix 3. Supporting information for the Chapter 1 (Supplementary table 3). 


\section{General introduction}

Semi-natural temperate grasslands constitute important elements of European and North American landscapes and deliver a wide range of ecosystem services, providing multiple uses to human well-being (MA 2005). According to the EEA (2010b), agricultural areas with high biodiversity, such as extensive grasslands, still make up about $30 \%$ of European farmland and are among world biodiversity hotspots (Wilson et al. 2012). Intensification of agricultural activity and expansion of cities and infrastructure have contributed largely to biodiversity losses in grasslands (Tilman et al. 2001, Hopkins \& Holz 2006, de Snoo et al. 2012, Wesche et al. 2012) and to the decrease of grassland areas (MA 2005). Furthermore, intensification of agriculture continues to pose a threat both to biodiversity on farmland and to the farmland soil (EEA 2010a). Apart from land-use transformation processes, climate change impacts may deteriorate the delivery of ecosystem services by grasslands. For instance, changes in the intensity of rainfall and prolonged summer drought are likely to occur more frequently in future under projected climate change scenarios (IPCC 2007).

Biodiversity loss and its possible effects on ecosystem functioning have motivated researchers to conduct a vast number of studies in grassland communities, with a large variation in methodological issues as well as spatial and temporal aspects. So far, according to the meta-analysis of recent studies by Hooper et al. (2012) biodiversity loss in the $21^{\text {st }}$ century could rank among the major drivers of ecosystem change. Most of the studies reviewed by Balvanera et al. (2006) led the authors to the conclusion that biodiversity has positive effects on most ecosystem services, among others above-ground biomass production which is a highly important provisioning service of the grassland ecosystem. While some authors reported that dominant species largely influence ecosystem functioning (Grime 1998, Mokany et al. 2008) grassland multifunctionality was shown to require more species than found in recent experiments (Hector \& Bagchi 2007, Isbell et al. 2011).

So far, most of the studies in grassland ecosystems were conducted either using experimental manipulation of biodiversity (mostly in sown swards) or via observation (in diverse semi-natural and natural grasslands) (Diaz et al. 2003). The findings of the studies from the two groups, however, lacked consistency considering such ecosystem service as biomass production. Some authors found a positive relationship between species diversity and biomass production (among others Tilman et al. 2001, Roscher et al. 2005). These findings, however, came from experimental grassland communities (Sanderson et al. 2004) 
and may have underestimated the real effects of species losses on the ecosystem functioning (Cardinale et al. 2007). It sometimes also remained uncertain how results obtained in experimental studies could scale up to landscape and regional levels and be generalized across ecosystem types and processes (Loreau et al. 2001). In semi-natural grasslands, species richness, on the other hand, often only poorly explained the variation in productivity for managed grasslands (among others Assaf et al. 2011). Observational studies, in turn, were often criticized, for example for confounded site and diversity effects (Kahmen et al. 2005). More recently, several of so called „removal experiments“ have been established in different regions (Diaz et al. 2003, McLaren \& Turkington 2010, Petersen et al. 2012). Containing species composition in their natural abundances and allowing compensatory growth of the remaining species were named as their main advantages (Diaz et al. 2003). In removal experiments, biodiversity became both dependent and independent variable (Diaz et al. 2003, Petersen et al. 2012).

Although a number of biodiversity studies have tackled the most important aspects of ecosystem functioning, there are a lot of questions which need further research. For instance, greater attention should be paid to what individual species do in such experiments (Loreau et al. 2001). It also still remains unclear whether the effects of biodiversity found in experimental studies are the same in mature natural ecosystems where competitive feedbacks and complex environmental mechanisms affect diversity-productivity relationships (Grace et al. 2007). A major future challenge is also to determine how biodiversity dynamics, ecosystem processes, and abiotic factors interact (Loreau et al. 2001). More attention should also be paid to including agricultural management into biodiversity research (Wrage et al. 2011). Another important issue in the biodiversity experiments should include considering spatial scale at which different variables are obtained (Dolnik \& Breuer 1998, Grace et al. 2007, Šimova et al. 2013). It is important to know how biodiversity loss may affect the functions of plant community dynamics under more realistic conditions (Šmilauer \& Šmilauerová 2013), thus multiple measures of diversity might be of advantage for examining the role of biodiversity in the functioning of grassland ecosystems.

Our study was conducted in the framework of the Grassland Management (GrassMan) experiment which is one of the projects in the Excellence cluster „Functional Biodiversity Research" at the University of Goettingen, Germany. The experimental field is a seminatural permanent grassland of Lolio-Cynosuretum plant community with a more than hundred-year-old history of extensive agricultural use. The combination of three experimental factors (sward diversity, fertilization and cutting frequency) resulted in 12 
different treatments replicated 6 times and was established in a Latin rectangle in the year 2008. The project was aimed at studying plant functional groups removal, treated as response variable, as well as at studying diversity and management effects on many aspects of ecosystem functioning.

\section{List of references}

Assaf, T.A., Beyschlag, W., Isselstein, J., 2011. The relationship between diversity and productivity in natural and in managed grasslands. Applied Ecology and Environmental Research 9 (2), 157166.

Balvanera, P., Pfisterer, A.B., Buchmann, N., He, J.-S., Nakashizuka, T., Raffaelli, D., Schmid, B., 2006. Quantifying the evidence for biodiversity effects on ecosystem functioning and services. Ecology Letters 9 (10), 1146-1156.

de Snoo, G.R., Naus, N., Verhulst, J., van Ruijven, J., Schaffers, A., 2012. Longterm changes in plant diversity of grasslands under agricultural and conservation management. Applied Vegetation Science (15), 299-306.

Diaz, S., Symstad, A.J., Stuart Chapin, F., Wardle, D.A., Huenneke, L.F., 2003. Functional diversity revealed by removal experiments. Trends in Ecology \& Evolution 18 (3), 140-146.

Dolnik, C., Breuer, M., 2008. Scale Dependency in the Species-Area Relationship of Plant Communities. Folia Geobotanica 43 (3), 305-318.

EEA, 2010a. EU 2010 Biodiversity Baseline Post-2010 EU biodiversity policy. http://www.eea.europa.eu/publications/eu-2010-biodiversity-baseline/report-summary. EEA Report 2010, European Environmental Agency, Copenhagen.

EEA 2010b, The European environment - state and outlook 2010. http://www.eea.europa.eu/soer/synthesis/synthesis. EEA Report 2010, European Environmental Agency, Copenhagen.

Grace, J.B., Michael Anderson, T., Smith, M.D., Seabloom, E., Andelman, S.J., Meche, G., Weiher, E., Allain, L.K., Jutila, H., Sankaran, M., Knops, J., Ritchie, M., Willig, M.R., 2007. Does species diversity limit productivity in natural grassland communities? Ecology Letters 10 (8), 680-689.

Grime, J.P., 1998. Benefits of plant diversity to ecosystems: immediate, filter and founder effects. Journal of Ecology (86), 902-910.

Hector, A., Bagchi, R., 2007. Biodiversity and ecosystem multifunctionality. Nature 448 (7150), 188190.

Hooper, D.U., Adair, E.C., Cardinale, B.J., Byrnes, J.E.K., Hungate, B.A., Matulich, K.L., Gonzalez, A., Duffy, J.E., Gamfeldt, L., O'Connor, M.I., 2012. A global synthesis reveals biodiversity loss as a major driver of ecosystem change. Nature 486, 105-109.

Hopkins, A., Holz, B., 2006. Grassland for agriculture and nature conservation: production, quality and multi-functionality. Agronomy Research 4 (1), 3-20.

IPCC 2007. Contribution of Working Group I to the Fourth Assessment Report of the Intergovernmental Panel on Climate Change, 2007 Solomon, S., D. Qin, M. Manning, Z. Chen, M. Marquis, K.B. Averyt, M. Tignor and H.L. Miller (eds.) Cambridge University Press, Cambridge, United Kingdom and New York, NY, USA. 
Isbell, F., Calcagno, V., Hector, A., Connolly, J., Harpole, W.S., Reich, P.B., Scherer-Lorenzen, M., Schmid, B., Tilman, D., van Ruijven, J., Weigelt, A., Wilsey, B.J., Zavaleta, E.S., Loreau, M., 2011. High plant diversity is needed to maintain ecosystem services. Nature 477 (7363), 199-202.

Kahmen, A., Perner, J., Audorff, V., Weisser, W., Buchmann, N., 2005. Effects of plant diversity, community composition and environmental parameters on productivity in montane European grasslands. Oecologia 142, 606-615.

Loreau, M., Naeem, S., Inchausti, P., Bengtsson, J., Grime, J.P., Hector, A., Hooper, D.U., Huston, M.A., Raffaelli, D., Schmid, B., Tilman, D., Wardle, D.A., 2001. Biodiversity and ecosystem functioning: current knowledge and future challenges. Science 294, 804-808.

Millennium Ecosystem Assessment (MA) (2005). Ecosystems and human well-being. Synthesis report. http://www.unep.org/maweb/documents/document.354.aspx.pdf.

McLaren, J.R., Turkington, R., 2010. Ecosystem properties determined by plant functional group identity. Journal of Ecology 98 (2), 459-469.

Mokany, K., Ash, J., Roxburgh, S., 2008. Functional identity is more important than diversity in influencing ecosystem processes in a temperate native grassland. Journal of Ecology 96 (5), 884893.

Petersen, U., Wrage, N., Köhler, L., Leuschner, C., Isselstein, J., 2012. Manipulating the species composition of permanent grasslands-A new approach to biodiversity experiments. Basic and Applied Ecology 13 (1), 1-9.

Proulx, R., Wirth, C., Voigt, W., Weigelt, A., Roscher, C., et al., 2010. Diversity promotes temporal stability across levels of ecosystem organization in experimental grasslands. PLOS ONE 5 (10), e13382.

Roscher, C., Temperton, V.M., Scherer-Lorenzen, M., Schmitz, M., Schumacher, J., Schmid, B., Buchmann, N., Weisser, W.W., Schulze, E.-D., 2005. Overyielding in experimental grassland communities - irrespective of species pool or spatial scale. Ecology Letters 8 (4), 419-429.

Sanderson, M.A., Skinner, R.H., Barker, D.J., Edwards, G.R., Tracy, B.F., Wedin, D.A., 2004. Plant species diversity and management of temperate forage and grazing land ecosystems. Crop Science (44), 1132-1144.

Šimova, I., Li, Y.M., Storch, D., 2013. Relationship between species richness and productivity in plants: the role of sampling effect, heterogeneity and species pool. Journal of Ecology 101, 161-170.

Šmilauer, P., Šmilauerová, M., 2013. Asymmetric relationship between grasses and forbs: results from a field experiment under nutrient limitation. Grass and Forage Science 68(1), 186-198.

Tilman, D., Reich, P.B., Knops, J., Wedin, D., Mielke, T., Lehman, C., 2001. Diversity and productivity in a long-term grassland experiment. Science 294 (5543), 843-845.

Wesche, K., Krause, B., Culmsee, H., Leuschner, C., 2012. Fifty years of change in Central European grassland vegetation: Large losses in species richness and animal-pollinated plants. Biological Conservation 150 (1), 76-85.

Wilson, J.B., Peet, J.K., Dengler, J., Pärtel, M., 2012. Plant species richness: the world records. Journal of Vegetation Science 23, 796-802.

Wrage, N., Strodthoff, J., Cuchillo, H.M., Isselstein, J., Kayser, M., 2011. Phytodiversity of temperate permanent grasslands: ecosystem services for agriculture and livestock management for diversity conservation. Biodiversity Conservation 20 (14), 3317-3339. 


\section{Chapter 1}

Exploring the relationship between diversity and productivity in a semi-natural grassland at several spatial scales 


\section{Abstract}

There has been no consistent findings regarding the role that biodiversity plays for biomass production so far. The role of spatial scale for exploring the relationship between the two variables has been addressed in some studies but its importance and selection of the sizes varied a lot. Biodiversity experiments conducted in experimental grasslands have often reported inconsistent results regarding the role of sampling scale for ecosystem functioning. Particularly poorly the effects of spatial scale on diversity-productivity relationship were studied in semi-natural grasslands in a more systematic way. Our study explored the effects of sampling scale on this relationship (expressed in species richness and evenness) and above-ground biomass production by estimating yield shares of all plant species and harvesting at four different spatial scales: small $\left(0.04 \mathrm{~m}^{2}\right.$ and $\left.0.16 \mathrm{~m}^{2}\right)$, medium $\left(1 \mathrm{~m}^{2}\right)$, large $\left(9 \mathrm{~m}^{2}\right)$, and very large $\left(225 \mathrm{~m}^{2}\right)$. The effects of species identity on the above-ground biomass production were studied using multivariate analysis of vegetation composition. Harvesting at small sampling scales revealed the highest coefficient of variation in species diversity indicating the high importance of species identity at small scale whereas these effects were eliminated at larger sampling scales. Correlation strength between species richness and productivity differed across the harvesting dates in both years, scales, and at various management intensities. The most common plot size for vegetation surveys used in observational studies on semi-natural grasslands, $1 \mathrm{~m}^{2}$, rather poorly described the vegetation composition and biomass data varied a lot depending on management intensity. While it might be a representative size for collecting data on vegetation composition, the area for sampling biomass should take into consideration how homogenous the vegetation composition of each particular site is. We suggest that employing the scale of sampling as an additional variable in the analysis might increase the probability of meeting the correct conclusion on the presence or absence and character of relationship between species diversity and productivity or other ecosystem functions. Further studies are needed to understand the role of spatial vegetation patterns in semi-natural grasslands. Role of vegetation composition, species identity as well as management effects should be considered in the way they interact in heterogeneous semi-natural environments and contribute to biomass production. 


\section{Introduction}

Humans have induced changes in global biodiversity at an unprecedented rate (Vitousek et al. 1997; Sala et al. 2000; Chapin et al. 2000; Rosenzweig 2003). Concerns about agricultural intensification and biodiversity decline became one of the major driving forces for conducting biodiversity experiments (Hooper et al. 2005; Flynn et al. 2009). One of the most intensively studied questions was the functioning of ecosystems in relation to different aspects of diversity (Mittelbach et al. 2001, Roscher et al. 2004), and identifying the underlying mechanisms of ecosystem functioning (Loreau et al. 2001). Several biodiversity experiments conducted on sown grasslands showed that reducing species richness can lead to less efficient capture of resources in the ecosystem and reduce biomass production (Hector et al. 1999; Tilman et al. 2006). On the other hand, in a study on an old grassland in Minnesota, Gross et al. (2000) found a negative linear relationship between species richness and productivity. Assaf et al. (2011) explored the relationship between species diversity and productivity in natural and managed grasslands and found that higher biomass production was associated with higher species diversity in natural, low productive, species poor grasslands but was only poorly explained by species richness in managed grasslands. So far, there has been not much consensus regarding the relationship between diversity and productivity.

According to Addicott et al. (1987) scaling of ecological observations is extremely important to make appropriate comparisons between field studies and theoretical models. Transferability of results from experimental plant communities to natural ecosystems (Loreau et al. 2001, Cardinale et al. 2004), as well as the lack of studies on semi-natural grasslands (Sanderson et al. 2004) were mentioned as weaknesses of biodiversity research. Chapin et al. (2000) pointed out that much less is known about the impact of species diversity in species-rich, natural ecosystems than in experimental plant communities. Grace et al. (2007) conducted a meta-analysis of studies on the relationship between diversity and productivity across several natural grassland communities and found that small-scale diversity in mature natural systems had only a weak influence on productivity, in absolute and in relative terms (the size of the plots chosen in the study by Grace et al. (2007) varied from $0.5 \times 0.5 \mathrm{~m}^{2}$ to $10 \times 10 \mathrm{~m}^{2}$ ). While some investigators explained diversity in temperate grasslands without considering spatio-temporal factors (Herben et al. 1993), other studies reported that the relationship between diversity and productivity is independent of the scale of sampling (Roscher et al. 2005). Munzbergova (2004), for example, reported that data on seed and site availability and their role in species distribution could not be extrapolated to the scales other than measured, thus pointing at 
the importance of multiple-scale studies. Huber (1999) found that patterns of spatial species richness in a limestone grassland were correlated at larger scales $\left(0.25 \mathrm{~m}^{2}\right)$, but not at finer scales $\left(0.01\right.$ and $\left.0.0004 \mathrm{~m}^{2}\right)$, suggesting heterogeneous spatial and temporal distribution of species.

In later generations of biodiversity experiments, scale has become a more important issue (Scheiner et al. 2000; Schneider 2001; Sandel \& Smith 2009). Na et al. (2010), for instance, considered the uncertain relationship between diversity and ecosystem functioning to be attributed to variations in ecosystems and community composition. In a study on oak savannas, Weiher \& Howe (2003) compared the patterns of small-scale $\left(0.25 \mathrm{~m}^{2}\right)$ and largescale species richness $\left(1023 \mathrm{~m}^{2}\right)$ and found that they were not correlated. Sandel \& Smith (2009) suggested that a thorough consideration of scale could help resolve some debates on the topic by turning scale into a working variable. Adler \& Lauenroth (2003) and Dolnik $\&$ Breuer (2008) demonstrated the importance of considering scale range in analyzing species-area relationships. Byers \& Noonburg (2003) using a modelling approach to examine the effects of scale on the resistance to invasion and Waide et al. (1999) in the meta-analysis of diversity-productivity studies across ecosystems also stated that spatial scale should be considered more in future studies as many ecosystems processes show scale-dependent patterns of functioning. So far, there has been no systematic experimental study of the effect of sampling scale on the diversity-productivity relationship in semi-natural grasslands. Along with a need for larger spatial scale studies (Caliman et al. 2010), including agricultural management aspects (Hopkins \& Holz 2006, Wrage et al. 2011) and creating more natural species abundances gradients (Díaz et al. 2003) were mentioned as important issues to address in future studies on semi-natural grasslands. Whereas several diversityproductivity studies addressed the influence of management of semi-natural grasslands on the relationship at the small scale (Gross et al. 2009, Rose \& Leuschner 2012), it is uncertain whether these results can be generalized to other spatial scales.

In the present study, we focused on the role of spatial scale on the relationship between species diversity, expressed in species number (species richness) and evenness, and productivity in agriculturally managed grassland. In the set-up year of the Grassland Management experiment (GrassMan), it was found that a plot size of $9 \mathrm{~m}^{2}$ for vegetation surveys covers most of the species present and could thus adequately characterize the vegetation composition of each experimental plot. Therefore, there were two main relevé quadrat sizes established: 1 and $9 \mathrm{~m}^{2}$. According to Dolnik \& Breuer (2009), the most common scale size for vegetation analysis is often $1 \mathrm{~m}^{2}$. However, many experiments often work with smaller sampling areas which might be of advantage for exploring the patterns in 
more homogeneous experimental (sown) grasslands, but can be insufficient for exploring the general patterns between the species diversity and productivity in semi-natural systems. We therefore involved further sampling scales in our study (small: 0.04 and 0.16 as well as very large: $225 \mathrm{~m}^{2}$ ) in order to understand the role of spatial scale in the diversityproductivity relationship at the field level. We hypothesized that harvesting at the small scale does not always reflect the diversity patterns in this semi-natural grassland due to natural heterogeneity of vegetation cover and thus the results from harvesting at the small spatial scales should not be extrapolated to larger scales or generalized. 


\section{Materials and methods}

\section{Study site and climatic conditions}

The study was conducted on a semi-natural permanent grassland more than 130 years old at the Relliehausen experimental farm (514ㄴ $53^{\prime \prime} \mathrm{N}, 9^{\circ} 32^{\prime} 42^{\prime \prime} \mathrm{E}, 490 \mathrm{~m}$ a.s.I.) in the Solling Uplands, $60 \mathrm{~km}$ north of Goettingen (Germany). Before the start of the experiment, the site was used for light cattle grazing and hay cutting. The annual precipitation is 1028 $\mathrm{mm}$ and the average annual temperature is $6.9^{\circ} \mathrm{C}$ (German Weather Service 1960-1990). For detailed information on the distribution of precipitation and temperature during the study period, please refer to Supplementary Table 1 (Appendix 1 in this thesis). The vegetation community is a nutrient-poor, montane mesic-moist to moist Lolio-Cynosuretum with high shares of Festuca rubra and Agrostis capillaris. The soil is characterised as a haplic Cambisol with $\mathrm{pH} \mathrm{H}_{2} \mathrm{O}$ values of 5.2 - 5.6.

\section{Experimental design}

For detailed information on the set-up of the experiment, please see Petersen et al. (2012). Twelve different treatments were established by combinations of the following experimental factors: sward type, fertilization, and cutting regime (Table 1).

Table 1. Experimental factors, their levels and abbreviations

\begin{tabular}{ll}
\hline Factor & Level \\
\hline Sward type & Control (Co) \\
& Dicot-reduced (-Dic) \\
& Monocot-reduced (-Mon) \\
Cutting frequency & One cut per year (1x) \\
& Three cuts (3x) \\
Fertilization & No fertilizer (no) \\
& $180-30-100$ kg of N-P-K ha-1 year ${ }^{-1}$ (NPK) \\
\hline
\end{tabular}

Herbicides against dicot species (Starane and Duplosan KV (active components Fluroxypyr/ Triclopyr and Duplosan KV; both $3 \mathrm{~L} \mathrm{ha}^{-1}$ ) and monocot species (Select $240 \mathrm{EC}$, Stähler Int., Stade, Germany; $\left.0.5 \mathrm{~L} \mathrm{ha}^{-1}\right)$ were applied on July $31^{\text {st }} 2008$, resulting in immediate significant changes in sward composition (Petersen et al. 2012). One third of the plots were left untreated (control sward). Cutting regime was intensive, with three cuts (middle of May, middle of July and late September), or extensive with one cut in the middle of July. Half of the plots did not receive any fertilizer since the start of the experiment. The other half of the plots received $90 \mathrm{~kg}$ of $\mathrm{N}$ applied at the beginning of April and $90 \mathrm{~kg} \mathrm{~N}, 30 \mathrm{~kg} \mathrm{P}$ and $100 \mathrm{~kg}$ $\mathrm{K}$ applied in the beginning of June each year (all corresponding amounts of fertilizer given per ha). The 72 plots resulting from six replications of each treatment, $15 \mathrm{~m} \times 15 \mathrm{~m}$ each, were arranged in a Latin square of six rows and six blocks (each block consisting of two columns). The combination of fertilization level and cutting frequency (" 1 xno" standing for 
plots cut once not fertilized, "1xNPK" - for plots cut once fertilized, "3xno" - for plots cut three times not fertilized, and " 3 XNPK" - for plots cut three times fertilized) is referred to as "management system" further on and used to explore the effects of different management strategies on the relationship between diversity and productivity.

\section{Sampling scale and harvesting}

The study was conducted over two experimental years starting in May 2010. Above-ground biomass was harvested at four different spatial scales: small $\left(0.16 \mathrm{~m}^{2}\right.$ in 2010 and $0.04 \mathrm{~m}^{2}$ in 2011); medium $\left(1 \mathrm{~m}^{2}\right)$, large $\left(9 \mathrm{~m}^{2}\right)$ and very large $\left(225 \mathrm{~m}^{2}\right)$ at each mowing event. Harvesting at small, medium and large sampling scales was conducted 5-6 days prior to the harvest of the whole plots for logistic reasons. At both small sampling scales $\left(0.04 \mathrm{~m}^{2}\right.$ in 2011 and $0.16 \mathrm{~m}^{2}$ in 2010), biomass was cut by hand and taken to the institute for weighing and drying. Cutting of medium and large plots was performed with a bar mower. Fresh biomass cut at medium, large and very large sampling scales was weighed in the field to determine the fresh weight and subsamples of 200-300 g were taken to the institute and dried at $60^{\circ} \mathrm{C}$ for 48 hours to correct the fresh weight for water content. As a standard measure of above-ground biomass production at the plot level (very large scale) a Haldrup $\circledR$ forage harvester was used to determine the weight of fresh biomass.

\section{Vegetation composition}

Vegetation surveys were performed twice a year by the same specialists for medium, large and very large (overall species richness) sampling scales after Klapp \& Stählin (1936) in the beginning of May and end of August to account for temporal changes in species composition. Along with species richness (defined as number of all species found per sampling plot), we calculated the Shannon diversity and species evenness ((Shannon evenness $\mathrm{H}^{\prime} / \log (\mathrm{n})$ where $\mathrm{H}^{\prime}$ is the Shannon index and $\mathrm{n}$ is species richness). At the small scale (both for 0.04 and $0.16 \mathrm{~m}^{2}$ ) vegetation surveys were conducted directly before each cutting event.

\section{Data analysis}

Turboveg for Windows 2.91d (Alterra, Wageningen) was used for processing vegetation data and calculating Shannon diversity. Statistical analysis of the data was performed using the $\mathrm{R}$ software, Version 2.14.0 (2011). We expressed all biomass data in $\mathrm{g}$ per $\mathrm{m}^{2}$ to receive comparable values for each plot and scale of sampling. We started analyzing the effects of spatial scale on the relationship between diversity and productivity by implementing the scale variable in the linear mixed-effect models (Pinheiro \& Bates 2009) for the whole dataset, with fertilization, cutting frequency and sward type as explanatory variables and 
species richness or evenness as covariables and included the spatial factors in the random structure of the model. Weather conditions were considered in the main models as year effects and included as fixed effects to account for temporal variation. Adjustments of nonlinearity were performed as needed. The best fitting models including the significant predictive variables were selected by comparison of the Akaike Information Criteria (AIC) and were selected using the marginality principle by not deleting the main effects if the higher-order interactions of the respective factors were significant. Residuals of the models were inspected for normality of distribution and homogeneity of variance in groups of according factors and adjustments for heterogeneity of the variance were performed if needed using the varldent structure. A significant interaction term of scale and other factors indicated that the effects of management on the dependent variable depended on spatial scale. We therefore calculated parameters for each model at all harvest dates, across scales and management systems.

To explore diversity effects in more detail, separate models for both years at all scales were calculated for each of the four management systems. We further proceeded with additional analyses of relationships between yield and species richness and yield and species evenness separately for each year, as the largest variation of the data was found at all three harvest dates in both of the years cutting event and management system as the response of yield varied among experimental years, harvest dates and main experimental factors (fertilization and cutting frequency). We used linear regressions to explore the relationship between above-ground biomass production and diversity (for species richness and evenness separately) and in case of significance of spatial effects (block or row effects) we included these factors in the linear models as well. To inspect the differences of the variances of average yields, species richness and evenness across scales we used all pairwise comparison procedure based on Tukey contrasts for mixed effects model with yield (species richness or evenness respectively) as response variable and spatial structure employed as random effects. We referred in the description of the results to the "small spatial scale" keeping in mind that the sampling scales were different in the two experimental years (0.04 $\mathrm{m}^{2}$ in 2011 and $0.16 \mathrm{~m}^{2}$ in 2011 respectively). As we included in the analysis year factor and explored the relationship between species richness and biomass production, as well as species evenness and biomass production separately for all harvesting dates and management systems, it seemed to be legitimate.

Multivariate analysis of the data was performed with Canoco for Windows, version 4.53 (ter Braak \& Šmilauer 1997-2004). Species data were log-transformed. To explore the effects of species composition on above-ground biomass production, we performed a detrended 
correspondence analysis (DCA) to find the appropriate method for further processing the data. According to Lepš \& Šmilauer (2003), unimodal methods should be used if the longest gradient of ordination axis is larger than 4. Thus, we performed the constrained correspondence analysis (CCA) - a unimodal method of constrained ordination on the data from July 2011 as we found significant effects of species richness on productivity at this cut at several spatial scales. Block and row were used as covariables to account for the variation caused by the design of the experiment. We used CanoDraw (Version 4.12, written by Petr Šmilauer (1999-2003)) to graphically explore the data. Treatments and scale level variables were used as nominal environmental variables. 


\section{Results}

Species richness was correlated with the sampling area and was found to be the lowest at the smallest harvesting scale, but with a high coefficient of variation (Table 2). The highest coefficients of variation in species richness were found at both small spatial scales. With increasing harvesting area, the coefficient of variation decreased and was found to be the smallest at the very large sampling scale (11.3\%).

Table 2. Means with standard deviation, minimum and maximum species richness and coefficient of variation for five experimental scales (average of two years, 0.04 and $0.16 \mathrm{~m}^{2}$ : average from three cuts of 2011 and 2010 respectively). Further scale levels: medium: $1 \mathrm{~m}^{2}$, large: $9 \mathrm{~m}^{2}$, very large: 225 $\mathrm{m}^{2}$. Letters indicate significant differences among the spatial scales based on linear mixed-effect models with species richness as response variable (no significant differences between the two years at medium, large and very large scales)

\begin{tabular}{|c|c|c|c|c|c|c|}
\hline Scale & & $\mathrm{N}$ & $\begin{array}{l}\text { Mean species } \\
\text { richness }\end{array}$ & $\begin{array}{l}\text { Minimum } \\
\text { species } \\
\text { richness }\end{array}$ & $\begin{array}{l}\text { Maximum } \\
\text { species } \\
\text { richness }\end{array}$ & $\begin{array}{l}\text { Coefficient of } \\
\text { variation, \% }\end{array}$ \\
\hline \multirow[t]{2}{*}{ Small } & $0.04 \mathrm{~m}^{2}$ & 144 & $5 \pm 2^{a}$ & 2 & 9.7 & 34.9 \\
\hline & $0.16 \mathrm{~m}^{2}$ & 144 & $6 \pm 2^{b}$ & 2.3 & 11 & 36.6 \\
\hline Medium & & 288 & $11 \pm 2^{c}$ & 7.2 & 15.5 & 18.2 \\
\hline Large & & 288 & $15 \pm 2^{d}$ & 11.3 & 19.8 & 13.2 \\
\hline Very large & & 288 & $23 \pm 3^{e}$ & 16.3 & 28.2 & 11.3 \\
\hline
\end{tabular}

Species evenness did not differ among the two experimental years (thus average values for the two years are shown) and was not significantly different between the both small spatial scales (shown separately in Fig. 1) disregarding of management systems.

While the differences across scales were not significant between large and very large scales, management intensity had significant effects on species evenness: cutting plots three times a year increased species evenness (plots became more homogeneous) compared to plots cut once a year (see the third chapter for overview) and fertilization decreased evenness (increasing heterogeneity) of plots compared to non-fertilized ones.

Above-ground biomass production had a rather high coefficient of variation if viewed disregarding of management systems (Table 3). The relationship between species diversity and biomass as well as species evenness and biomass is therefore further on presented across scales and within scales to explore the effects of the management systems as well. 


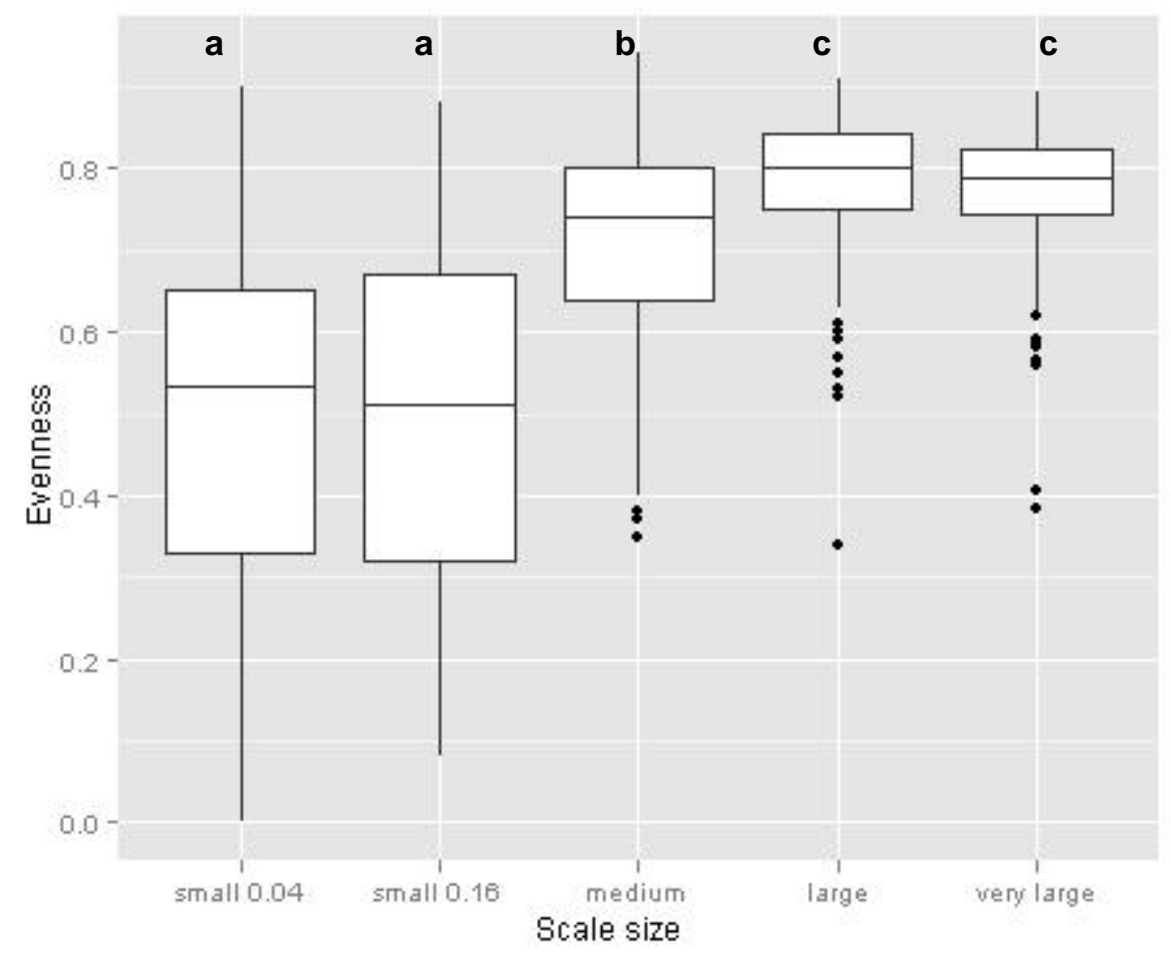

Fig. 1. Species evenness at five different spatial scales. Letters indicate significant differences among the spatial scales based on linear mixed-effect models with species richness as response variable (no significant differences between the two years at medium, large and very large scales)). Small scale is presented separately $\left(0.04 \mathrm{~m}^{2}\right.$ in 2011 and $0.16 \mathrm{~m}^{2}$ in 2010); further scale levels are: medium: $1 \mathrm{~m}^{2}$, large: $9 \mathrm{~m}^{2}$, very large: $225 \mathrm{~m}^{2} . \mathrm{n}=144$ for both small scales, $\mathrm{n}=288$ for medium, large and very large scales.

Lowest coefficients of variation for yield were found the small sampling scale at May and September harvests in the second experimental year (30.2\% and $29.7 \%$, respectively). The highest coefficients of variation were found at the medium sampling scale in May 2010 $(68.8 \%)$ and at the largest sampling scale in September $2011(61.2 \%)$.

Table 3. Mean dry yields and coefficients of variation for five experimental scales (small: 0.04 and $0.16 \mathrm{~m}^{2}$ in 2011 and 2010 respectively; medium: $1 \mathrm{~m}^{2}$; large: $9 \mathrm{~m}^{2}$; very large: $225 \mathrm{~m}^{2}$ ) at three harvests. $n=36$ in May and September and $n=72$ in July

\begin{tabular}{|c|c|c|c|c|c|c|c|}
\hline \multirow[t]{2}{*}{ Year } & \multirow[t]{2}{*}{ Scale } & \multicolumn{2}{|c|}{ May } & \multicolumn{2}{|c|}{ July } & \multicolumn{2}{|c|}{ September } \\
\hline & & $\begin{array}{l}\text { Mean } \\
\text { yield } \\
{\left[\mathrm{g} / \mathrm{m}^{2}\right]}\end{array}$ & $\begin{array}{l}\text { Coefficient } \\
\text { of variation } \\
\text { [\%] }\end{array}$ & $\begin{array}{l}\text { Mean } \\
\text { yield } \\
{\left[\mathrm{g} / \mathrm{m}^{2}\right]}\end{array}$ & $\begin{array}{l}\text { Coefficient } \\
\text { of variation } \\
\text { [\%] }\end{array}$ & $\begin{array}{l}\text { Mean } \\
\text { yield } \\
{\left[\mathrm{g} / \mathrm{m}^{2}\right]}\end{array}$ & $\begin{array}{l}\text { Coefficient } \\
\text { of variation, } \\
\text { [\%] }\end{array}$ \\
\hline \multirow[t]{4}{*}{2010} & Small & 200.9 & 38.1 & 291.9 & 42.6 & 95.7 & 40.2 \\
\hline & medium & 192.7 & 68.8 & 524.0 & 43.3 & 230.6 & 52.1 \\
\hline & Large & 265.2 & 56.9 & 360.4 & 33.0 & 155.2 & 52.33 \\
\hline & very large & 152.8 & 41.9 & 357.2 & 33.9 & 255.2 & 51.2 \\
\hline \multirow[t]{4}{*}{2011} & Small & 235.0 & 30.2 & 488.3 & 46.4 & 263.4 & 29.7 \\
\hline & medium & 295.1 & 43.9 & 621.6 & 50.6 & 216.0 & 35.9 \\
\hline & Large & 148.6 & 42.4 & 469.7 & 50.0 & 163.6 & 40.0 \\
\hline & very large & 222.1 & 52.8 & 479.5 & 43.0 & 83.1 & 61.2 \\
\hline
\end{tabular}


Harvesting at four different sampling scales, we found no consistent pattern in the relationship between species richness and above-ground biomass production (Table 5), however, significant relationships between the two variables at the corresponding scales and cutting events were negative in both experimental years.

Table 5. Determination coefficient $\left(\mathrm{R}^{2}\right), p$-value $(p)$ and slope direction for linear regression of yield and species richness (block and row included as fixed effect if found significant). Small scale in 2010: $0.16 \mathrm{~m}^{2}$, in 2011: $0.04 \mathrm{~m}^{2}$. Further scale levels: medium: $1 \mathrm{~m}^{2}$, large: $9 \mathrm{~m}^{2}$, very large: $225 \mathrm{~m}^{2} . \mathrm{n}=36$ in May and September, $\mathrm{n}=72$ at July harvest

\begin{tabular}{clcccccc}
\hline Cut & Scale & \multicolumn{3}{c}{$\mathbf{2 0 1 0}$} & \multicolumn{3}{c}{$\mathbf{2 0 1 1}$} \\
\cline { 3 - 8 } & & Slope & $\boldsymbol{P}$ & $\mathbf{R}^{\mathbf{2}}$ & Slope & $\boldsymbol{p}$ & $\mathbf{R}^{\mathbf{2}}$ \\
\hline May & small & - & 0.42 & 0.02 & - & 0.11 & 0.07 \\
& medium & - & 0.18 & 0.36 & - & 0.53 & 0.01 \\
& large & - & 0.46 & 0.01 & - & 0.47 & 0.02 \\
& very large & - & 0.51 & 0.01 & + & 0.29 & 0.03 \\
\multirow{5}{*}{ July } & small & - & $<\mathbf{0 . 0 0 1}$ & 0.35 & - & $<\mathbf{0 . 0 1}$ & 0.18 \\
& medium & - & $\mathbf{0 . 0 5}$ & 0.02 & - & $<\mathbf{0 . 0 0 1}$ & 0.15 \\
& large & - & 0.14 & 0.03 & - & $<\mathbf{0 . 0 0 1}$ & 0.21 \\
& very large & - & $\mathbf{0 . 0 9}$ & 0.04 & - & 0.58 & 0.04 \\
& small & - & 0.14 & 0.24 & - & $\mathbf{0 . 0 9}$ & 0.08 \\
& medium & - & 0.11 & 0.07 & - & $\mathbf{0 . 0 5}$ & 0.12 \\
& large & - & 0.13 & 0.10 & - & 0.13 & 0.07 \\
& very large & - & 0.62 & 0.007 & - & 0.84 & 0.004 \\
\hline
\end{tabular}

At the small spatial scale a negative relationship between species richness and aboveground biomass production was found only at July harvests and a marginal effect in September 2011. At the medium harvesting scale there were significant correlations between species richness and biomass found in July and September of the second year.

At both large and very large scales significant relationship between productivity and species evenness were detected only twice. Testing the correlation of above-ground biomass production and evenness partly showed similar patterns as for the relationship of species richness and productivity, but also revealed significant negative correlations at all cutting events at further sampling scales (Table 6).

Table 6. Determination coefficient $\left(\mathrm{R}^{2}\right), p$-value $(p)$ and slope direction for linear regression of yield and species evenness (block and row included as fixed effect if found significant). Small scale in 2010: $0.16 \mathrm{~m}^{2}$, in 2011: $0.04 \mathrm{~m}^{2}$. Further scale levels: medium: $1 \mathrm{~m}^{2}$, large: $9 \mathrm{~m}^{2}$, very large: $225 \mathrm{~m}^{2}$. $\mathrm{n}=36$ in May and September, $\mathrm{n}=72$ at July harvest

\begin{tabular}{llcccccc}
\hline & & \multicolumn{3}{c}{$\mathbf{2 0 1 0}$} & \multicolumn{3}{c}{$\mathbf{2 0 1 1}$} \\
\cline { 3 - 8 } Cut & Scale & Slope & $\boldsymbol{p}$ & $\mathbf{R}^{\mathbf{2}}$ & Slope & $\boldsymbol{p}$ & $\mathbf{R}^{\mathbf{2}}$ \\
\hline May & Small & $\mathbf{+}$ & $\mathbf{0 . 0 3}$ & 0.13 & - & $\mathbf{0 . 0 3}$ & 0.31 \\
& medium & + & 0.32 & 0.03 & - & 0.32 & 0.03
\end{tabular}




\begin{tabular}{clcccccc} 
& Large & + & 0.69 & 0.001 & - & 0.20 & 0.05 \\
\multirow{4}{*}{ July } & very large & + & 0.24 & 0.04 & - & 0.42 & 0.002 \\
& Small & - & 0.25 & 0.02 & - & $<0.01$ & 0.10 \\
& medium & - & $\mathbf{0 . 0 6}$ & 0.05 & - & $<\mathbf{0 . 0 5}$ & 0.25 \\
& Large & - & $\mathbf{0 . 0 2}$ & 0.07 & - & $<\mathbf{0 . 0 0 1}$ & 0.28 \\
& very large & - & $\mathbf{0 . 0 6}$ & 0.13 & - & $<\mathbf{0 . 0 0 1}$ & 0.35 \\
\multirow{3}{*}{ Sept } & Small & - & 0.62 & 0.20 & - & $\mathbf{0 . 0 6}$ & 0.09 \\
& medium & - & 0.29 & 0.03 & - & $<\mathbf{0 . 0 0 1}$ & 0.31 \\
& Large & - & 0.23 & 0.04 & - & $\mathbf{0 . 0 9}$ & 0.08 \\
& very large & - & $\mathbf{0 . 0 4}$ & 0.18 & - & 0.14 & 0.06 \\
\hline
\end{tabular}

Results of testing the data for the effects of management systems on the relationship between species richness and above-ground biomass and evenness and above-ground biomass are shown in the Supplementary Tables $2 \& 3$ (in this thesis Appendix 2 and 3). The relationship between species richness and productivity varied (slope found being both positive and negative) in the four different management systems established at the experimental site.

A negative significant relationship between species richness and productivity in plots cut once a year and not fertilized was found at several spatial scales. At the medium spatial scale there was a positive relationship between the two variables only in one management system: in plots cut three times a year and not fertilized. Regarding the relationship between species richness and productivity in different management systems irrespective of scale size, in plots cut three times a year and not fertilized this relationship was mostly found to be positive while at plots cut three times a year and fertilized it varied, as it also did in plots cut once a year and fertilized.

At plots cut once a year and not fertilized a significantly negative relationship between species richness and above-ground biomass production was found only at the small spatial scale. A significantly positive relationship between species evenness and above-ground biomass production in plots cut three times a year and not fertilized was found more often than a negative relationship while in plots cut three times and fertilized it varied. While in some management systems at different cutting events the relationship between species evenness and productivity varied among the spatial scales regarding the direction and the strength of this relationship, some of the management systems had similar patterns to the relationship between species richness and productivity, such as plots cut three times and not fertilized.

In an ordination diagram of the vegetation data for the July harvest 2011 , the first two axes 
of the canonical correspondence analysis (CCA) explained up to $49.4 \%$ of the speciesenvironment relation (Fig. 2). A high number of samples with species such as Agrostis capillaris, Veronica chamaedrys and Festuca rubra constituted the species composition at the small harvesting scale and thus were found to be grouped close to the small harvesting scale gradient arrow. The length of the arrow for the medium-sized plots $\left(1 \mathrm{~m}^{2}\right)$ is short, indicating that there are few samples having a unique species composition characteristic only for the medium-sized plots. The majority of the samples at the large and very large scale showed a more diverse species composition and were thus more scattered over the diagram. The increasing biomass shares of one of the most productive species at the field, Dactylis glomerata, was associated with fertilization and can thus be seen close to the intrinsic variable "NPK".

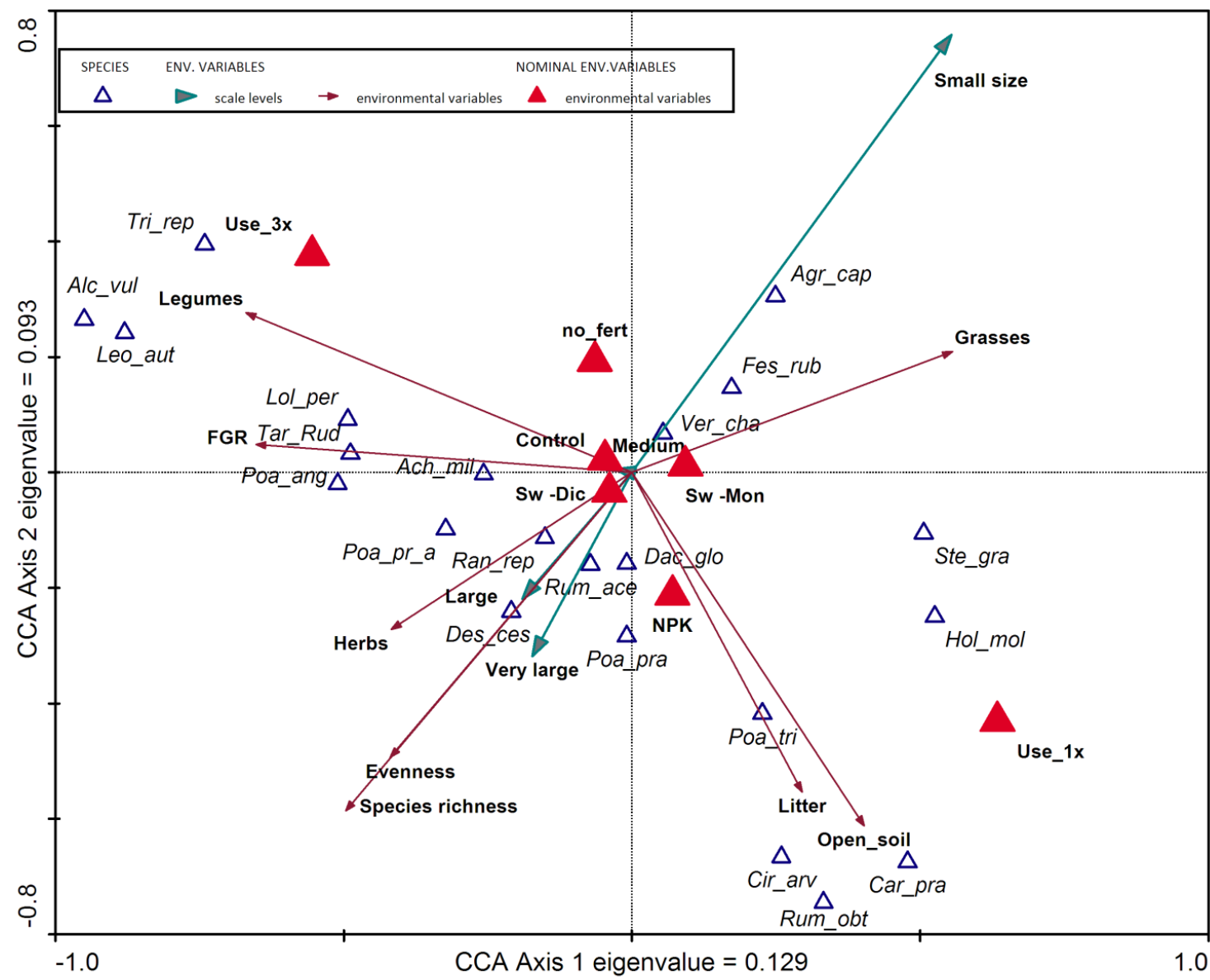

Fig. 2. Ordination diagram based on the canonical correspondence analysis (CCA) of the vegetation composition at four different experimental scales in July 2011 (row and block as covariables). Species data log-transformed. Presented are species with a fit $>3 \%$. Abbreviations of species names: Alc_vul: Alchemilla vulgaris, Ach_mil: Achillea millefolium, Agr_cap: Agrostis capillaris, Cra_pra: Cardamine pratensis, Cir_arv: Cirsium arvense, Dac_glo: Dactylis glomerata, Des_ces: Deschampsia cespitosa, Hol_mol: Holcus mollis, Leo_aut: Leontodon autumnalis, Lol_per: Lolium perenne, Poa_ang: Poa angustifolia, Poa_pra: Poa pratensis, Poa_pra_a: P. humilis + P. pratensis aggregated, Poa_tri: P. trivialis, Ran_rep: Ranunculus repens, Rum_ace: Rumex acetosa, Rum_obt: Rumex obtusifolius, Car_pra: Cardamine pratensis, Tar_Rud: Taraxacum Sect. Ruderalia, Tri_rep: 
Trifolium repens, Ver_cha: Veronica chamaedrys. Nominal environmental variables: Control: control sward, Sw -Mon: monocot-reduced, Sw -Dic: dicot-reduced. no fert: no fertilization, NPK: fertilized, Use_1x: cut once a year, Use_3x: cut three times a year, small: Small size $\left(0.04 \mathrm{~m}^{2}\right)$, Medium: $1 \mathrm{~m}^{2}$, Large: $9 \mathrm{~m}^{2}$, Very large: $225 \mathrm{~m}^{2}$. Environmental variables: Grasses: share of grass species in the relevé [\%], Herbs: share of herb species [\%], Legumes: share of legume species [\%], FGR: number of functional groups (grasses, herbs, legumes), Litter: \% of litter per relevé, Open soil: \% of bare soil per relevé, Species richness: species number per sampling area, Evenness: Shannon Evenness. 


\section{Discussion}

The present study analyzed the effects of sampling scale on the relationship between diversity (expressed in species richness and evenness) and above-ground biomass production of a semi-natural permanent grassland. The relationship between species diversity and productivity differed across sampling scales and management systems. The direction of the relationship (positive or negative) also varied, with positive relationship found often at plots cut three times a year and not fertilized compared to plots fertilized and cut three times where it was more often also positive. Species identity effects were important at smaller spatial scales.

We found that increasing the harvesting scale reduced the coefficient of variation of species richness. Crawley \& Harral (2001) and Sandel \& Smith (2009) suggested that the number of individuals generally increases with the size of the plot sampled, leading to an increased probability of finding the most characteristic species reflecting the typical vegetation composition of a semi-natural grassland, so that a larger plot could provide a better basis for measuring productivity. Our results are in line with these findings. On the small scale not species richness, but species identity can have stronger effects on biomass production depending on the size of the species. Several tall and productive grasses can have more biomass and additional species do not contribute significantly to biomass. Thus a negative relationship between species richness and productivity can be detected. According to the multivariate analysis of the vegetation data from our study, samples from the small harvesting scale of $0.04 \mathrm{~m}^{2}$ in July 2011 often had short herbs such as Veronica chamaedrys and several low-productive grasses such as Agrostis capillaris and Festuca rubra. Such patches had higher species richness, but did not perform well in terms of above-ground biomass production. At the same time we had samples with only one or two species, particularly Dactylis glomerata, which produced high yields, but had low species richness due to the size of the plants in the vegetation quadrat.

At both larger sampling scales heterogeneity of the vegetation cover can reduce the strength of the relationship between diversity and productivity even more or turn it into less significant otherwise depending on the size and identity of species. Oksanen (1996) explained a decline in species richness at higher productivity levels with an increase in the size of plant individuals. The same space at the small-scale plots could be occupied by few productive species such as Dactylis glomerata, or several less productive ones, such as Veronica chamaedrys or Agrostis capillaris. 
Recent observational study by Šimova et al. (2013) on several herbaceous communities in the Czech Republic demonstrated that at small spatial scale the relationship between species richness and productivity was negatively significant while at larger spatial scales it turned into a non-significant relationship. In our study there was quite often no significant relationship detected between the two variables. We therefore suggest that species identity plays an important role at the small sampling scale in the relationship between species diversity and productivity. Weiher (1999) also reported that small-scale species richness was not a good indicator of larger-scale species richness. In our study sampling at small spatial scales in some of the management systems did not reflect the relationship between diversity and productivity or species evenness and productivity found at the larger spatial scales.

Commonly used area for describing vegetation composition is $1 \mathrm{~m}^{2}$ (Dolnik \& Breuer 2008). In our study, the plots of $1 \mathrm{~m}^{2}$ showed high coefficients of variation in species richness and presence of the relationship between diversity and productivity. We suggest that in seminatural grasslands the plot size should not only cover the minimum species area, which reflects most of the species present in the area of interest but should be optimized to include possible heterogeneity effects, both in terms of species diversity measures and biomass. While in sown grasslands sampling at the small-scale seems to be sufficient to draw general conclusions on the mechanisms of ecosystem functioning due to larger homogeneity of the vegetation, we suggest that in studies in semi-natural grasslands researchers should consider sampling across several spatial scales to take into account the possible heterogeneity of vegetation composition.

At two larger scales (in our case $9 \mathrm{~m}^{2}$ and $225 \mathrm{~m}^{2}$ ) the relationship between species diversity and productivity was also rather inconsistent across both experimental years and management systems. Year effects could be partly explained by dry weather conditions in the year 2010 (fertilization effects might have been weaker due to summer drought, see Supplementary Table 1) and the distribution of rainfall over the vegetation period in both years, as previously found by Bernhardt-Römermann et al. (2011). Further reasons could lie in the seasonal changes of species richness. Bischoff et al. (2005), for example, argued that the effects of species richness on productivity disappeared in late summer due to the reduction of species richness at high productivity levels.

Generally vegetation structure of this experimental site could be characterized by a certain patchiness due to a matrix of large grass tussocks (Dactylis glomerata and Festuca rubra) interspersed with smaller herbs and grasses that might have reacted differently to nutrient 
addition and mowing. Increasing cutting frequency, for instance, may reduce the proportion of tall herbs and grasses (Fenner \& Palmer 1998). Wilsey \& Stirling (2007) and Jiang et al. (2009) suggested that species diversity in non-synthetic communities is particularly likely to be affected by the abiotic and biotic properties of local habitats. We suggest that in our study above-ground biomass production and vegetation diversity parameters at the plot level might have been affected by this structure of the vegetation composition thus turning into non-significant relationship. Kirwan et al. (2007) mentioned that in order to explain observed responses of above-ground biomass production to diversity, information on site environments, contribution of individual species to total yields, as well as temporal dynamics are needed. Species composition seems to contain more useful data for exploring the ecosystem processes than species richness alone.

We could see in our study that the relationship between species richness and productivity varied across the sampling scales. Most importantly, it seemed that management system and species composition and identity played a role in it to higher extent. Considering the scale variable is an important initial step in selecting the minimum species area. We suggest that an appropriate spatial scale should be selected especially to consider heterogeneity of vegetation composition. A small sampling scale may be more often influenced by the identity of common species present on the plot (due to the selection effect according to which more common species are likely to be present in the sample), while at larger scales these effects can be eliminated, but the sampling effort can become more significant. While in more homogenous environments spatial scale may be rather irrelevant, in more heterogeneous habitats it is important to consider the patchiness of vegetation composition to be able to draw conclusions on the presence or absence of the relationship between diversity and productivity.

\section{List of references}

Addicott, J.F., Aho, J.M., Antolin, M.F., Padilla, D.K., Richardson, J.S., Soluk, D.A., 1987. Ecological neighborhoods: scaling environmental patterns. OIKOS 49, 340-346.

Adler, P.B., Lauenroth, W.K., 2003. The power of time: spatiotemporal scaling of species diversity. Ecology Letters 6 (8), 749-756.

Assaf, T.A., Beyschlag, W., Isselstein, J., 2011. The relationship between diversity and productivity in natural and in managed grasslands. Applied Ecology and Environmental Research 9 (2), 157166. 
Bernhardt-Römermann, M., Römermann, C., Sperlich, S., Schmidt, W., 2011. Explaining grassland biomass - the contribution of climate, species and functional diversity depends on fertilization and mowing frequency. Journal of Applied Ecology 48 (5), 1088-1097.

Bischoff, A., Auge, H. \& Mahn, E.-G.. 2005. Seasonal changes in the relationship between plant species richness and community biomass in early succession. Basic and Applied Ecology 6, 385394.

Caliman, A., Pires, A.F., Esteves, F.A., Bozelli, R.L., Farjalla, V.F., 2010. The prominence of and biases in biodiversity and ecosystem functioning research. Biodiversity and Conservation 19 (3), 651-664.

Cardinale, B.J., Ives, A.R., Inchausti, P., 2004. Effects of species diversity on the primary productivity of ecosystems: extending our spatial and temporal scales of inference. OIKOS 104, 437-450.

Chapin, S.F. III, Zavaleta, E.S., Eviner, V.T., Naylor, R.L., Vitousek, P.M., Reynolds, H.L., Hooper, D.U., Lavorel, S., Sala, O.E., Hobbie, S.E., Mack, M.C., Diaz, S., 2000. Consequences of changing biodiversity. Nature 405, 234-242.

Crawley, M.J., Harral, J.E., 2001. Scale dependence in plant biodiversity. Science 291, 864-868.

Díaz, S., Symstad, A.J., Stuart Chapin, F., Wardle, D.A., Huenneke, L.F., 2003. Functional diversity revealed by removal experiments. Trends in Ecology \& Evolution 18 (3), 140-146.

Dolnik, C., Breuer, M., 2008. Scale dependency in the species-area relationship of plant communities. Folia Geobotanica 43, 305-318.

Fenner, M., Palmer, L., 1998. Grassland management to promote diversity: creation of a patchy sward by mowing and fertiliser regimes. Field Studies 9, 313-324.

Flynn, D.F.B., Gogol-Prokurat, M., Nogeire, T., Mollinari, N., Trautman Richers, B., Lin, B.B., Simpson, N., Mayfield, M.M. DeClerck, F., 2009. Loss of functional diversity under land use intensification across multiple taxa. Ecology Letters 12, 22-33.

Grace, J.B., Anderson, M.T., Smith, M.D., Seabloom, E., Andelman, S.J., Meche, G., Weiher, E., Allain, L.K., Jutila, H., Sankaran, M., Knops, J., Ritchie, M., Willig, M.B., 2007. Does species diversity limit productivity in natural grassland communities? Ecology Letters 10, 680-689.

Gross, K.L., Willig, M.R., Gough, L., Inouye, R., Cox, S.B., 2000. Patterns of species density and productivity at different spatial scales in herbaceous plant communities. OIKOS 89 (3), 417-427.

Gross, N., Bloor, J.M., Frédérique, L., Maire, V., Soussana, J.-F., 2009. Effects of land-use change on productivity depend on small-scale plant species diversity. Basic and Applied Ecology 10, 687696.

Hector, A., Schmid, B., Beierkuhnlein, C., Caldeira, M.C., Diemer, M., Dimitrakopoulos, P.G., Finn, J.A., Freitas, H., Giller, P.S., Good, J., Harris, R., Högberg, P., Huss-Danell, K., Joshi, J., Jumpponen, A., Körner, C., Leadly, P.W., Loreau, M., Minns, A., Mulder, C.P.H., O'Donovan, G., Otway, S.J., Pereira, J.S., Prinz, A., Read, D.J., Scherer-Lorenzen, M., Schulze, E.-D., Siamantziouras, A.-S.D., Spehn E., M., Terry, A.C., Troumbis, A.Y., Woodward, F.I., Yachi, S., Lawton, J.H., 1999. Plant diversity and productivity experiments in European grasslands. Science 286, 1123-1127.

Herben, T., Krahulec, F., Hadincová, V., Kovářová, M., 1993. Small-scale spatial dynamics of plant species in a grassland community over six years. Journal of Vegetation Science 4, 171-178.

Hopkins, A., Holz, B., 2006. Grassland for agriculture and nature conservation: production, quality and multi-functionality. Agronomy Research 4 (1), 3-20.

Huber, R., 1999. Patterns of species richness in a limestone grassland under different treatments in relation to spatial scale. Applied Vegetation Science 2, 257-266. 
Jiang, L., Wan, S., Li, L., 2009. Species diversity and productivity: why do results of diversitymanipulation experiments differ from natural patterns? Journal of Ecology 97, 603-608.

Kirwan, L., Lüscher, A., Sebastià, M.T., Finn, J.A., Collins, R.P., Porqueddu, C., Helgadottir, A., Baadschaug, O.H., Brophy, C., Coran, C., Dalmannsdóttir, S., Delgado, I., Elgersma, A., Fothergill, M., Frankow-Lindberg, B.E., Golinski, P., Grieu, P., Gustavsson, A.M., Höglind, M., Huguenin-Elie, O., lliadis, C., Jørgensen, M., Kadziuliene, Z., Karyotis, T., Lunnan, T., Malengier, M., Maltoni, S., Meyer, V., Nyfeler, D., Nykanen-Kurki, P., Parente, J., Smit, H.J., Thumm, U., Connoly, J., 2007. Evenness drives consistent diversity effects in intensive grassland systems across 28 European sites. Journal of Ecology 95, 530-539.

Klapp, E., Stählin, A., 1936. Standorte, Pflanzengesellschaften und Leistung des Grünlandes. Ulmer, Stuttgart.

Lepš, J., Šmilauer, P., 2003. Multivariate analysis of ecological data using CANOCO. Cambridge University Press, Cambridge.

Loreau, M., Naeem, S., Inchausti, P., Bengtsson, J., Grime, J.P., Hector, A., Hooper, D.U., Huston, M.A., Raffaelli, D., Schmid, B., Tilman, D., Wardle, D.A., 2001. Biodiversity and Ecosystem Functioning: Current Knowledge and Future Challenges. Science 294, 804-808.

Mittelbach, G.G., Steiner, C.F., Scheiner, S.M., Gross, K.L., Reynolds, H.L., Waide, R.B., Willig, M.R., Dodson, S.I., Gough, L., 2001. What is the observed relationship between species richness and productivity? Ecology 82 (9), 2381-2396.

Munzbergova, Z., 2004. Effect of spatial scale on factors limiting species distributions in dry grassland fragments. Journal of Ecology 92 (5), 854-867.

$\mathrm{Na}$, Z., Zhengwen, W., Jinying, L., Kun, W., 2010. Relationship between plant diversity and spatial stability of aboveground net primary productivity (ANPP) across different grassland ecosystems. African Journal of Biotechnology 9, 6708-6715.

Oksanen, J., 1996. Is the humped relationship between species richness and biomass an artefact due to plot size? Journal of Ecology 84 (2), 293-295.

Petersen, U., Wrage, N., Köhler, L., Leuschner, C., Isselstein, J., 2012. Manipulating the species composition of permanent grasslands-A new approach to biodiversity experiments. Basic and Applied Ecology, 13 (1), 1-9.

Pinheiro, J., Bates, D., DebRoy, S., Sarkar, D., The R Core team, 2009. nlme: Linear and nonlinear mixed effects models. $R$ package version 3, 1-96.

$\mathrm{R}$ Development Core Team, 2011. R: A language and environment for statistical computing. $\mathrm{R}$ Foundation for Statistical Computing, Vienna.

Roscher, C., Schumacher, J., Baade, J., Wilcke, W., Gleixner, G., Weisser, W.W., Schmid, B., Schulze, E.-D., 2004. The role of biodiversity for element cycling and trophic interactions: an experimental approach in a grassland community. Basic and Applied Ecology 5, 107-121.

Roscher, C., Temperton, V.M., Scherer-Lorenzen, M., Schmitz, M., Schumacher, J., Schmid, B., Buchmann, N., Weisser, W.W., Schulze, E.-D., 2005. Overyielding in experimental grassland communities - irrespective of species pool or spatial sale. Ecology Letters 8, 419-429.

Rose, L., Leuschner, C., 2012. The diversity-productivity relationship in a permanent temperate grassland: negative diversity effect, dominant influence of management regime. Plant Ecology \& Diversity 5, 265-274.

Rosenzweig, M.L., 2003. Reconciliation ecology and the future of species diversity. Oryx 37, 194205. 
Sala, O.E., Chapin, S.F. III, Armesto, J.J., Berlow, E., Bloomfield, J., Dirzo, R., Huber-Sanwald, E., Huenneke, L.F., Jackson, R.B., Kinzig, A., Leemans, R., Lodge, D.M., Mooney, H.A., Oesterheld, M., Poff, L.N., Sykes, M.T., Walker, B.H., Walker, M., Wall, D.H., 2000. Global biodiversity scenarios for the year 2100. Science 287, 1770-1774.

Sandel, B., Smith, A.B.. 2009. Scale as a lurking factor: incorporating scale-dependence in experimental ecology. OIKOS 118, 1284-1291.

Sanderson, M.A., Skinner, R.H., Barker, D.J., Edwards, G.R., Tracy, B.F., Wedin, D.A., 2004. Plant species diversity and management of temperate forage and grazing land ecosystems. Crop Science 44, 1132-1144.

Scheiner, S.M., Cox, S.B., Willig, M., Mittelbach, G.G., Osenberg, C., Kaspari, M., 2000. Species richness, species-area curves and Simpson's paradox. Evolutionary Ecology Research 2, 791-802.

Schneider, D.C., 2001. The rise of the concept of scale in ecology. BioScience 51 (7), 545-553.

Šimova, I., Yue, L.M., Storch, D., 2013. Relationship between species richness and productivity in plants: the role of sampling effect, heterogeneity and species pool. Journal of Ecology 101 (1), 161-170.

Ter Braak, C. J. F., Šmilauer, P., 1997-2004. Canoco for Windows. Plant Research International, Wageningen.

Ter Braak, C. J. F., Šmilauer, P., 2002. Canoco reference manual an CanoDraw for Windows User's guide: Software for Canonical Community Ordination (version 4.5). Microcomputer Power, Ithaca, NY.

Tilman, D., Reich, P.B., Knops, J.M.H., 2006. Biodiversity and ecosystem stability in a decadelong grassland experiment. Nature 441, 629-932.

Vitousek, P.M., Mooney, H.A., Lubchenco, J., Melillo, J.M., 1997. Human domination of Earth's ecosystems. Science 277, 494-499.

Waide, R.B., Willig, M.R., Steiner, C.F., Mittelbach, G., Gough, L., Dodson, S.I., Juday, G.P., Parmenter, R., 1999. The relationship between productivity and species richness. Annual Review of Ecology and Systematics 30 (1), 257-300.

Weiher, E., 1999. The combined effects of scale and productivity on species richness. Journal of Ecology 87, 1005-1011.

Weiher, E., Howe, A., 2003. Scale-dependence of environmental effects on species richness in oak savannas. Journal of Vegetation Science 14, 917-920.

Wilsey, B.J., Stirling, G., 2007. Species richness and evenness respond in a different manner to propagule density in developing prairie microcosm communities. Plant Ecology 190, 259-273.

Wrage, N., Strodthoff, J., Cuchillo, H.M., Isselstein, J., Kayser, M., 2011. Phytodiversity of temperate permanent grasslands: ecosystem services for agriculture and livestock management for diversity conservation. Biodiversity Conservation 20, 3317-3339. 


\section{Chapter 2}

Plant functional traits and dominant species diversity in a semi-natural grassland along a management intensity gradient 


\begin{abstract}
Species richness, dominant species and their plant functional traits have rarely been addressed together in biodiversity experiments on agriculturally relevant semi-natural grasslands. We present the results of a study on the effects of management intensification in a permanent grassland and the response of overall and dominant species diversity. A removal experiment in the Solling uplands, Germany (three sward types: control, dicotreduced and monocot-reduced) employed four different levels of management intensity resulting from a combination of two factors: fertilization (no and $180-30-100 \mathrm{~kg} \mathrm{ha}^{-1}$ year $^{-1}$ of N-P-K, respectively) and cutting frequency (cut once and three times a year). This study was conducted over two years $(2010,2011)$, starting with a third year after introducing the management treatments. We defined species diversity by species number per plot as well as evenness and identified dominant species, making up about $80 \%$ of the yield share. We collected information on several plant functional traits for each of the dominant species: plant height, leaf dry matter content, stem dry matter content, leaf specific area, green leaves / total leaves ratio, stem specific density, and calculated additionally the ratio of stem specific density and plant height. Further measures of functional diversity included functional groups shares, functional diversity index, defined as the total branch length of the traits-species cluster diagram, and aggregated plant functional traits for each plot. We found that management intensification did not affect the total species number, but affected species evenness and functional diversity of dominant species, including their number and identity. Correlations of above-ground biomass and several dominant species' traits were underlining reasons for fertilization effects on above-ground productivity in this grassland rather than overall species number. This indicates the importance of monitoring not only species richness but also other measures of diversity, as well as including management aspects in studies of plant functional traits in grasslands.
\end{abstract}




\section{Introduction}

Agricultural intensification and other land use transformation processes have considerably affected the state of biodiversity and ecosystem functioning in the European and North American grasslands (Tilman et al. 2001, Hooper et al. 2005, Hopkins \& Holz 2006, Wesche et al. 2012). A lot of biodiversity research has been concentrated on various aspects of ecosystem functioning, such as productivity, nutrient cycling, and resistance of ecosystems to invasive species (Tilman et al. 1996, Hector et al. 1999, Spehn et al. 2005, Campbell et al. 2011). Biodiversity has been shown to support ecosystem multifunctionality and stability (Hector \& Bagchi 2007, Proulx et al. 2010). Many studies supplied evidence for a positive relationship between phytodiversity and productivity (Loreau et al. 2001, Naeem et al. 2002, Hooper et al. 2005), but these findings were based mainly on experiments with sown grassland (Sanderson et al. 2004, Caliman et al. 2010) and included species richness as the only measure of biodiversity (Balvanera et al. 2006). In natural and semi-natural grasslands such a relationship was often found to be weak or even absent (Huston et al. 2000, Adler et al. 2011). Long-term effects of biodiversity and effects of its loss on provision of ecosystem services also often remained unclear (Laliberté et al. 2010).

Apart from species richness, more recent studies involved other measurements of diversity, such as plant functional traits, and linked them to the concept of ecosystem functioning (Petchey \& Gaston 2002, Mason et al. 2005, Violle et al. 2007, Diaz et al. 2007, Lavorel et al. 2008, Duru et al. 2012, Garnier \& Navas 2012). Among those new multiple measures of diversity were functional diversity index (Petchey \& Gaston 2002) and functional attribute diversity indices (Mason et al. 2005, Mouillot et al. 2005). Some studies explored the responses of plant functional traits to changes in management practices using data from field measurements (Duru et al. 2012), whereas a number of studies investigated data on functional traits that were derived from species traits databases (Liira et al. 2008). Multiple plant trait analysis was used to assess grassland management effects such as grazing and mowing (Louault 2005, Fortunel 2009, Klimešová et al. 2008), grassland succession and land-use change (Kahmen \& Poschlod 2004, Lindborg \& Eriksson 2005) and was also implemented in studies on synthetic communities (Roscher et al. 2012). However, the question how dominant species and their functional traits may influence productivity under different land-use management practices still needs further research (Flynn et al. 2009).

It is important to know how biodiversity loss may affect the functions of natural ecosystems (Caliman et al. 2010), especially under realistic long-term conditions (Šmilauer \& 
Šmilauerová 2013). Thus, using multiple measures of diversity might be of advantage for exploring the role of biodiversity in ecosystem processes in semi-natural grasslands. So far, such experimental studies on semi-natural grasslands have been rare. More attention should be given to the role of the dominant species in this relationship as well. Yang et al. (2011), for instance, found that the presence of highly productive species, which tend to be dominant and have stabilizing properties, might enhance ecosystem stability, but this aspect has not been well studied. According the EEA (2010), agricultural areas with high biodiversity, such as extensive grasslands, still make up about $30 \%$ of European farmland, but the intensification of agriculture poses a threat to this biodiversity. To understand this threat better, agricultural management has to be included into biodiversity research (Wrage et al. 2011, Schellberg \& Pontes 2012).

The present study explores the effects of management intensification on the relationship between productivity and different measures of dominant and overall species diversity. Species richness and evenness, as well as the number of dominant species and their functional diversity defined by the aggregated plant functional traits (after Garnier et al. 2004) and the functional diversity index, as described by Petchey \& Gaston $(2002,2006)$ were examined along a management intensity gradient. Use of the functional diversity index allowed us to incorporate several plant traits into the analysis and to account for differences in the number and identity of dominant species. We hypothesized that in an old semi-natural grassland not species diversity (expressed in the number of species per plot and evenness), but the different aspects of functional diversity such as dominant species number and their plant functional traits matter more for productivity and that management intensification affects all of the components of diversity. We also discuss the findings in terms of relevance for intensification of grassland management for biomass production and conservation of its diversity. 


\section{Material and methods}

\section{Study site}

The study site is situated in the Solling uplands, $60 \mathrm{~km}$ from Goettingen, Germany, at an elevation of $490 \mathrm{~m}$ a.s.I. $\left(51^{\circ} 44^{\prime} 53^{\prime \prime} \mathrm{N}, 9^{\circ} 32^{\prime} 42^{\prime \prime} \mathrm{E}\right)$. It was established in 2008 on a permanent semi-natural Lolio-Cynosuretum grassland with high shares of Festuca rubra and Agrostis capillaris. The soil is a nutrient-poor shallow stony haplic Cambisol with a mean $\mathrm{pH}_{\mathrm{H}_{2} \mathrm{O}}$ of 5.34 . The long-term annual temperature is $6.9^{\circ} \mathrm{C}$, the annual precipitation 1028 mm (Deutscher Wetterdienst 1960-1991, station Silberborn-Holzminden, 440 m a.s.I.). Before the start of the experiment the site was extensively used for permanent pasture by cattle or hay cutting (for detailed description see Petersen et al. 2012).

\section{Experimental design}

In June 2008,72 plots of $15 \mathrm{~m} \times 15 \mathrm{~m}$ were established at the study site. The combination of three management factors (three sward types, two fertilization levels and two cutting frequencies) resulted in 12 different treatments replicated 6 times, which were assigned to the experimental plots in a Latin rectangle design. Spatial variation is represented by two factors: row and block. The three sward types were: control (Co), dicot-reduced (-Dic) and monocot-reduced (-Mon). The dicot-reduced sward type was established via application of herbicide in June 2008 (active components Fluoroxypyr + Triclopyr and Mecoprop-P (3 L $\left.\left.\mathrm{ha}^{-1}\right)\right)$. The monocot-reduced sward type was achieved by application of Clethodim $(0.5 \mathrm{~L}$ $\left.\mathrm{ha}^{-1}\right)$. The control sward was not treated by herbicide. Fertilization levels were as follows: no fertilization (no) and 180-30-100 kg of N, P, K ha-1 year $^{-1}$, respectively (NPK). Half of the experimental plots were cut once a year $(1 \mathrm{x})$ in the middle of July. The other half was cut three times (3x) a year (in the middle of May, middle of July and end of September). The combination of fertilization level and cutting frequency ("1no" standing for cut once not fertilized, "1NPK" - for plots cut once fertilized, "3no" - for plots cut three times not fertilized, and "3NPK" - for plots cut three times fertilized) is referred to as management system further on.

\section{Vegetation composition}

Vegetation surveys were conducted twice a year in early May and late August. Overall species number (which we refer to as species richness) was recorded at the plot scale (225 $\mathrm{m}^{2}$ ), as well as in two $3 \mathrm{~m} \times 3 \mathrm{~m}$ permanent vegetation relevé squares per plot. In both of the $9 \mathrm{~m}^{2}$ relevé plots we additionally estimated yield proportions of each species according to Klapp and Stählin (1936) and shares of three functional groups (grasses, herbs and legumes). Shannon Evenness was calculated as $\mathrm{H}^{\prime} / \log e(n)$ and is hereafter referred to as 
evenness (where $\mathrm{H}^{\prime}$ is the Shannon diversity index and $\mathrm{n}$ is the number of species found on the corresponding plot).

\section{Dominant species and their plant functional traits}

Based on the results of the vegetation surveys in 2010, we selected for the further analysis dominant species that made up about $80 \%$ of the yield (as suggested by Garnier et al. 2004) on each of the $15 \mathrm{~m} \times 15 \mathrm{~m}$ plots. In the following growing season, in the year 2011, before each sampling of plant functional traits, we conducted an additional estimation of the dominant species proportions at the plot level. Plant samples were randomly collected in the field ( 2 individuals of each species per plot, replicated 6 times). Sampling took place one week before each cutting event: in the beginning of May, beginning of July and middle of September. We collected material by cutting the plant at the ground level and transported it to the lab in sealed plastic bags with wet tissue inside. Plant samples were stored in the cool dark chamber $\left(9^{\circ} \mathrm{C}\right)$ prior to the analysis.

Plant functional traits were chosen based on their possible reaction to different management techniques applied at the study site (Lavorel \& Garnier 2002, Cornelissen et al. 2003, Louault et al. 2005, Garnier et al. 2007). The following traits were measured for each of the species: plant height, leaf dry matter content, stem specific density, green leaves/total leaves ratio, leaf specific area, stem dry matter content and the ratio of stem specific density and plant height. We concentrated on above-ground traits and did not account for the traits from species databases to explore the effects of management.

Plant height (expressed in $\mathrm{cm}$ ) was measured as the difference between the height of the highest photosynthetic tissue and the base of the shoot. We counted the total number of leaves and the number of green leaves to receive the green leaves/total leaves ratio. Leaf dry matter content was measured as the ratio of leaf dry weight and fresh weight (expressed in $\mathrm{mg} / \mathrm{g}$ ). Leaves were weighed with the precision of $1 / 10 \mu \mathrm{g}$. The dry weight of the leaves was obtained by drying them for 48 hours at $60^{\circ} \mathrm{C}$. The leaf area was measured on fresh leaves that were scanned fully exposed and analyzed with the WinRhizo scanning software (Version 2007 d, Regent Instruments Inc., Quebec, Canada). The same software was further used for the surface analysis of the surface area of the leaves and the volume of the main part of the stem and used (these values were used to calculate stem specific density (expressed in $\left.\mathrm{g} / \mathrm{m}^{3}\right)$ ). The specific leaf area was calculated as leaf area divided by the dry weight of the leaf. For Ranunculus repens, the petioles were not removed from the leaves for this analysis. The stem dry matter content of each plant was expressed as the weight of 
the dry stem (after drying for 48 hours at $60^{\circ} \mathrm{C}$ ) divided by the weight of the fresh stem ( $\mathrm{mg}$ $\left.g^{-1}\right)$.

\section{Aggregated traits and functional diversity index}

Aggregated traits for each plot were calculated as described in Garnier et al. (2004). This measure allowed us to incorporate plant yield shares of the dominant species and test the contribution of each aggregated trait separately to the above-ground biomass production. Functional diversity index is a measure of functional diversity proposed by Petchey \& Gaston (2002). It is defined as the total branch length of a functional dendrogram of a species-traits matrix. An increase of the index implies an increase in functional diversity of the vegetation composition. Use of the functional diversity index allowed to incorporate several plant traits into the analysis and to account for variation in the number and identity of dominant species. The functional diversity index can be a substantial improvement over using functional groupings to describe the functional diversity of a community (Flynn et al. 2009). The addition of a species can increase or not change the functional diversity index of the community but not decrease (Flynn et al. 2009).

\section{Measurement of above-ground biomass}

Above-ground biomass production was estimated for each of the 72 plots by collecting fresh biomass with a Haldrup $®$ forage combine harvester (cutting height $7 \mathrm{~cm}$ ). $10 \%$ of the total biomass from each plot was weighed in the field and 100-200 $\mathrm{g}$ sub-samples were taken to the lab for water content analysis after drying at $60^{\circ} \mathrm{C}$ for $48 \mathrm{~h}$.

\section{Data analyses}

Univariate data analyses were performed in R Version 2.14.0 (R Core Development Team 2012). Overall species richness was explored as a predictor of biomass in each of the four experimental years and as no significant effects of species richness on aboveground biomass production were found, further analysis of the different measures of functional diversity was performed in the year 2011, three years after the removal of the functional groups. We tested the differences in yield treated as response variable using linear mixed effects models (Pinheiro et al. 2009) and incorporated spatial structure as random effects, comparing the means of the data using the all pair-wise multiple comparison procedure ("cld" algorithm by Piepho 2004). In case of variance heterogeneity of the residuals in the factor groups of selected models, we adjusted the variance for the corresponding group by factor level (details in the corresponding result tables). Then we calculated the functional diversity index for each plot at all three sampling dates. Functional diversity index was calculated as described by Petchey \& Gaston (2002) using the XTree 
function as described by Schumacher (XTree function for calculating functional diversity index, 2003). Correlations between species richness, evenness, share of grasses, number of dominant species, functional diversity index, and aggregated plant functional traits and productivity were tested using Spearman rank correlation coefficient.

To explore the effects of species identity on functional diversity, we conducted a multiple regression analysis with the functional diversity index as a response variable and shares of the dominant species as explaining variables, reducing the final adequate linear model to the species having a significant effect on the response variable. Multivariate analysis of the vegetation composition was performed with CANOCO (version 4.5 for Windows, Ter Braak C. J. F. \& Šmilauer P. 1997-2004. Canoco for Windows. Plant Research International, Wageningen). Species scores were log-transformed. We performed Monte-Carlo permutation test to check the explanatory power of the main experimental factors for vegetation composition. Row and block were used as covariables to account for the spatial variation of vegetation composition. We used the "spatial distribution of experimental plots" option to assign the plots to the experimental Latin rectangle design. We performed indirect gradient analysis (partial RDA - Redundancy analysis) and standardized the samples by species to define most common dominant species. If not stated otherwise, we used the default settings of Canoco. 


\section{Results}

Impacts of management intensification on different diversity measures

In the year 2011, three years after the swards had been modified in their functional composition by the use of herbicides, we found that overall species richness did not differ significantly among the different management systems (Table 1) nor among the three sward types $(p=0.95)$, Table 2. Species evenness, however, responded to the intensification of management and was significantly different among three of four management systems.

Table 1. Means and standard deviations of species richness (overall for the whole plot) and evenness (mean of two vegetation relevés, $9 \mathrm{~m}^{2}$ each) in four management systems in $2011(\mathrm{~N}=72)$. Spatial structure was incorporated in linear mixed-effect models as random effects and the main experimental factors (sward type, fertilization and cutting frequency) as fixed effects. Letters indicate significant differences based on all pair-wise comparison procedure using Tukey contrasts.

\begin{tabular}{lllll}
\hline Management system & $1 \mathrm{no}$ & 1NPK & 3no & 3NPK \\
\hline Species richness & & & & \\
Mean & $26.7 \pm 2.4^{\mathrm{a}}$ & $26.8 \pm 1.7^{\mathrm{a}}$ & $26.4 \pm 3^{\mathrm{a}}$ & $26.6 \pm 2.9^{\mathrm{a}}$ \\
Min & 23 & 23 & 21 & 21 \\
Max & 32 & 30 & 33 & 32 \\
CV, \% & 9 & 6.3 & 11.4 & 10.9 \\
Species evenness & & & & \\
Mean & $0.76 \pm 0.04^{\mathrm{b}}$ & $0.70 \pm 0.07^{\mathrm{a}}$ & $0.82 \pm 0.04^{\mathrm{c}}$ & $0.78 \pm 0.06^{\mathrm{b}}$ \\
Min & 0.69 & 0.53 & 0.77 & 0.60 \\
Max & 0.82 & 0.80 & 0.88 & 0.86 \\
CV, \% & 5.8 & 9.6 & 4.5 & 7.8 \\
\hline
\end{tabular}

Fertilization reduced species evenness compared to not fertilized plots while a higher cutting frequency increased species evenness. Coefficients of variation for evenness were smaller than for species richness in the corresponding management systems, except for the plots cut once and fertilized, where species evenness had a higher coefficient of variation than species richness. Fertilization increased the shares of grasses compared to herb shares $(p<0.0001)$ while cutting frequency decreased the shares of grasses through promoting herbs' shares $(p<0.0001)$ (Table 2$)$.

Table 2. Means and standard deviations of overall species richness (per plot), evenness (mean of two vegetation relevées, $9 \mathrm{~m}^{2}$ each) and functional group shares in three sward types $(\mathrm{N}=72)$, average for 2011. Spatial structure was incorporated in linear mixed-effect models as random effects and the main experimental factors (sward type, fertilization and cutting frequency) as fixed effects. Asterisks indicate significant differences from the control sward with the following significance values: . $p<0.05,{ }^{*} p<0.01,{ }^{* *} p<0.001,{ }^{* * *} p<0.0001$. 


\begin{tabular}{llll}
\hline & Control & $\begin{array}{l}\text { Dicot-reduced } \\
(-\mathrm{Dic})\end{array}$ & $\begin{array}{l}\text { Monocot-reduced } \\
(- \text { Mon })\end{array}$ \\
\hline $\begin{array}{l}\text { Overall species } \\
\text { number }\end{array}$ & $26.5 \pm 2$ & $26 \pm 2.7$ & $27 \pm 2.5$ \\
$\begin{array}{l}\text { Species } \\
\text { evenness }\end{array}$ & $0.78 \pm 0.06$ & $0.76 \pm 0.08$ & $0.76 \pm 0.08$ \\
$\begin{array}{l}\text { Grasses, \% } \\
\text { Herbs, \% }\end{array}$ & $71.7 \pm 9.9$ & $75.9 \pm 10.7$. & $68.1 \pm 11.6 *$ \\
Legumes, \% & $26.9 \pm 9.0$ & $25.3 \pm 9.7$ & $29.9 \pm 10.1$. \\
\hline
\end{tabular}

The species number over the four experimental years differed slightly among the management systems in the year 2010 (Figure 1) following the removal of functional groups, while in the first year (2009) the variation in species richness was due to sward effects (Mon sward had 1.6 species more than the control sward ( $p=0.01)$; -Dic sward had 1.3 species less than the control sward $(p=0.05))$. A description of further effects of herbicide application can be found in Petersen et al. (2012).

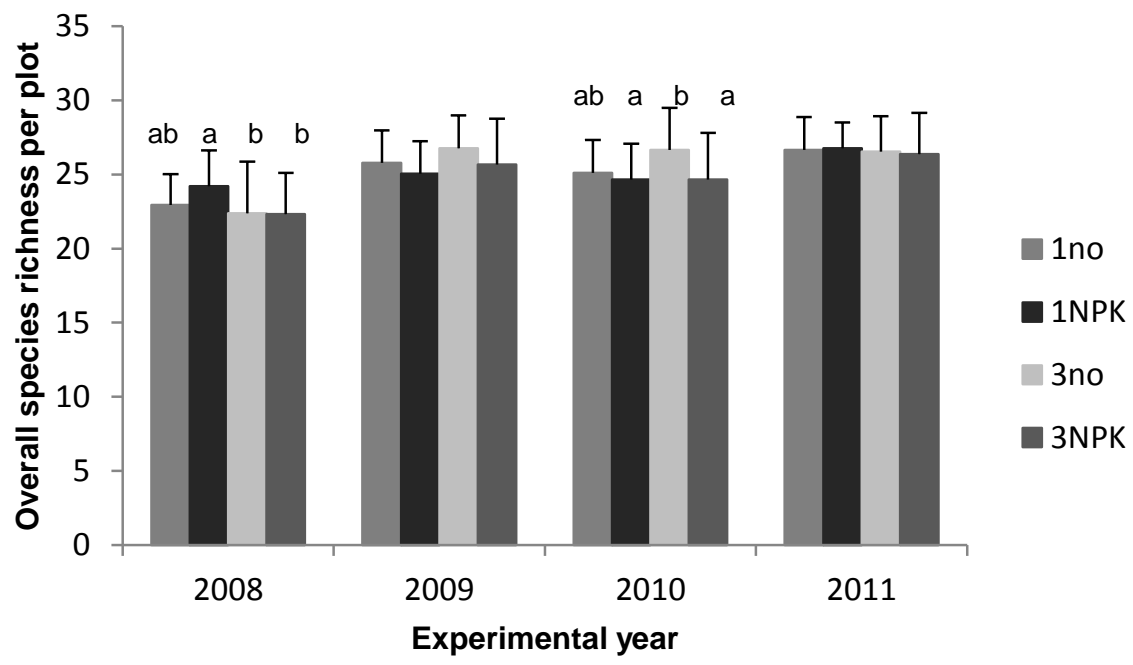

Figure 1. Overall species richness (mean of two vegetation surveys) in corresponding management systems (1no, 1NPK, 3no, 3NPK, see Table 1) in the four experimental years. Letters indicate significant differences in the years 2008 and 2010 among the management systems based on linear mixed-effect models with the three main experimental factors (sward, fertilization and cutting frequency) as fixed effects and spatial structure incorporated as random effects (no significant differences in 2009 and 2011).

Both the number of dominant species and the functional diversity index responded to the changes in management and were significantly smallest in plots cut once and fertilized, intermediate in 1 no or 3 NPK plots and significantly largest in plots cut three times and unfertilized (Table 3). Cutting frequency increased both number and functional diversity index $(p<0.001)$, whereas fertilization decreased them $(p<0.01)$. The number of dominant species varied between four and eight in all management systems (Table 3). The smallest 
coefficient of variation in the functional diversity index (12.8\%) was characteristic for plots cut three times and fertilized.

Table 3. Mean, minimum and maximum number and coefficient of variation of dominant species and functional diversity index per management system (mean of three sampling dates, $N=72$ ). Spatial and temporal effects were incorporated in linear mixed-effect models as random effects and the main experimental factors (sward type, fertilization and cutting frequency) as fixed effects. Letters indicate significant differences based on all pair-wise multiple comparison procedure using Tukey contrasts.

\begin{tabular}{lllll}
\hline Management system & $1 \mathrm{no}$ & 1NPK & 3 no & 3NPK \\
\hline Dominant species & & & & \\
Mean & $5.6 \pm 0.98 \mathrm{~b}$ & $4.9 \pm 0.79 \mathrm{a}$ & $6.17 \pm 1.02^{\mathrm{c}}$ & $5.67 \pm 0.95^{\mathrm{b}}$ \\
Min & 4 & 4 & 4 & 4 \\
Max & 8 & 7 & 8 & 8 \\
CV, \% & 17.45 & 15.92 & 16.59 & 16.79 \\
Functional diversity index & & & \\
Mean & $18.53 \pm 2.78 \mathrm{~b}$ & $16.83 \pm 2.53^{\mathrm{a}}$ & $19.91 \pm 2.73^{\mathrm{c}}$ & $18.44 \pm 2.35 \mathrm{~b}$ \\
Min & 13.5 & 13.05 & 14.5 & 13.51 \\
Max & 25.6 & 23.67 & 25.66 & 24.13 \\
CV, \% & 15.01 & 15.02 & 13.73 & 12.77 \\
\hline
\end{tabular}

Sampling date had significant effects on most of the studied plant functional traits $(p<$ 0.0001 ) (Table 4), therefore the data are presented separately. Management system had significant effects on several aggregated traits (Table 4).

Table 4. Aggregated traits (means and standard deviations) for each management system per sampling date $(\mathrm{N}=18)$. Spatial effects were incorporated in linear mixed-effect models as random effects and the main experimental factors (sward type, fertilization and cutting frequency) as fixed effects. Letters indicate significant differences based on all pair-wise multiple comparison procedure using Tukey contrasts at corresponding sampling dates. LDMC stands for leaf dry matter content, SLA - for specific leaf area, Stem DMC -for stem dry matter content, Stem SpDens - for stem specific density, Ratio Dens/Height represents the ratio between stem specific density and plant height.

\begin{tabular}{|c|c|c|c|c|}
\hline Aggregated traits & 1no & 1NPK & 3 no & $3 \mathrm{NPK}$ \\
\hline \multicolumn{5}{|l|}{ May } \\
\hline Heightagg & $12.04 \pm 2.02 \mathrm{ab}$ & $12.5 \pm 3.01 \mathrm{a}$ & $9.94 \pm 2.05^{b}$ & $10.62 \pm 2.49 a b$ \\
\hline Leaves ratioagg & $0.78 \pm 0.15 \mathrm{ab}$ & $0.82 \pm 0.02$ a & $0.81 \pm 0.04 a b$ & $0.72 \pm 0.15^{b}$ \\
\hline LDMC $_{\text {agg }}$ & $0.23 \pm 0.03 \mathrm{~b}$ & $0.23 \pm 0.02 \mathrm{ab}$ & $0.24 \pm 0.02 \mathrm{~b}$ & $0.21 \pm 0.03$ a \\
\hline SLAagg & $0.015 \pm 0.001 \mathrm{a}$ & $0.017 \pm 0.002 \mathrm{ab}$ & $0.016 \pm 0.02 \mathrm{ab}$ & $0.017 \pm 0.004 \mathrm{~b}$ \\
\hline Stem $\mathrm{DMC}_{\mathrm{agg}}$ & $0.20 \pm 0.02 \mathrm{~b}$ & $0.17 \pm 0.03 \mathrm{a}$ & $0.20 \pm 0.03 \mathrm{~b}$ & $0.16 \pm 0.03$ a \\
\hline Stem SpDensagg & $0.17 \pm 0.03 \mathrm{~b}$ & $0.14 \pm 0.031^{a}$ & $0.18 \pm 0.029 \mathrm{~b}$ & $0.12 \pm 0.03$ a \\
\hline $\begin{array}{l}\text { Ratio Dens/Heightagg } \\
\text { July }\end{array}$ & $0.01 \pm 0.003 a$ & $0.01 \pm 0.003 a b$ & $0.017 \pm 0.003^{c}$ & $0.01 \pm 0.004^{b}$ \\
\hline Heightagg & $41.88 \pm 5.5^{c}$ & $50.06 \pm 7.0^{a}$ & $31.79 \pm 5.08^{b}$ & $38.63 \pm 4.49 \mathrm{c}$ \\
\hline Leaves ratioagg & $0.54 \pm 0.12^{b}$ & $0.69 \pm 0.13^{b}$ & $0.57 \pm 0.21 \mathrm{ab}$ & $0.67 \pm 0.09 \mathrm{ab}$ \\
\hline LDMC $_{\text {agg }}$ & $0.28 \pm 0.08$ a & $0.25 \pm 0.06^{a}$ & $0.25 \pm 0.03$ a & $0.25 \pm 0.04$ a \\
\hline SLAagg & $0.015 \pm 0.002{ }^{a}$ & $0.02 \pm 0.002 \mathrm{ab}$ & $0.02 \pm 0.003 a b$ & $0.018 \pm 0.003^{b}$ \\
\hline Stem DMCagg & $0.27 \pm 0.03^{a}$ & $0.25 \pm 0.028^{a}$ & $0.26 \pm 0.03^{a}$ & $0.26 \pm 0.018^{b}$ \\
\hline Stem SpDensagg & $0.27 \pm 0.03 \mathrm{~b}$ & $0.24 \pm 0.03 \mathrm{ab}$ & $0.26 \pm 0.03 \mathrm{~b}$ & $0.22 \pm 0.035$ a \\
\hline Ratio Dens/Heightagg & $0.006 \pm 0.0009^{c}$ & $0.004 \pm 0.0007^{a}$ & $0.008 \pm 0.002^{b}$ & $0.005 \pm 0.001 \mathrm{ac}$ \\
\hline
\end{tabular}




\begin{tabular}{lllll} 
September & & & & \\
Heightagg & $10.65 \pm 2.43^{\mathrm{b}}$ & $17.32 \pm 4.27^{\mathrm{a}}$ & $10.16 \pm 2.09^{\mathrm{b}}$ & $16.06 \pm 4.13^{\mathrm{a}}$ \\
Leaves ratioagg $^{\mathrm{a}}$ & $0.78 \pm 0.06^{\mathrm{a}}$ & $0.76 \pm 0.08^{\mathrm{a}}$ & $0.77 \pm 0.04^{\mathrm{a}}$ & $0.74 \pm 0.09^{\mathrm{a}}$ \\
LDMC $_{\text {agg }}$ & $0.20 \pm 0.039^{\mathrm{a}}$ & $0.22 \pm 0.13^{\mathrm{a}}$ & $0.20 \pm 0.02^{\mathrm{a}}$ & $0.19 \pm 0.03^{\mathrm{a}}$ \\
SLAagg $^{\mathrm{a}}$ & $0.02 \pm 0.003^{\mathrm{b}}$ & $0.03 \pm 0.01^{\mathrm{a}}$ & $0.18 \pm 0.04^{\mathrm{b}}$ & $0.25 \pm 0.005^{\mathrm{ab}}$ \\
Stem DMC $_{\text {agg }}$ & $0.18 \pm 0.04^{\mathrm{a}}$ & $0.16 \pm 0.03^{\mathrm{a}}$ & $0.20 \pm 0.01^{\mathrm{a}}$ & $0.17 \pm 0.03^{\mathrm{a}}$ \\
Stem SpDensagg $_{\text {Ratio Dens/Heightagg }}$ & $0.167 \pm 0.03^{\mathrm{ab}}$ & $0.14 \pm 0.03^{\mathrm{a}}$ & $0.18 \pm 0.04^{\mathrm{b}}$ & $0.16 \pm 0.03^{\mathrm{ab}}$ \\
Rat $^{\mathrm{a}}$ & $0.015 \pm 0.005^{\mathrm{ab}}$ & $0.01 \pm 0.01^{\mathrm{ab}}$ & $0.017 \pm 0.007^{\mathrm{a}}$ & $0.009 \pm 0.003^{\mathrm{b}}$ \\
\hline
\end{tabular}

Aggregated plant height, apart from the seasonal variation, was found to be significantly different among most management systems, with the largest differences characteristic for plots fertilized and not fertilized. Aggregated leaf dry matter content was only significantly different between the plots cut once and fertilized and the other management treatments at the first sampling date whereas in July and September, there were no differences among management treatments. Aggregated stem dry matter content responded to the management treatments in a similar way as the aggregated leaf dry matter content. The strongest differences among the four management systems were found for the aggregated ratio of stem specific density and height.

\section{Biomass prediction}

The overall dry matter yield was significantly different among the fertilized and not fertilized plots with the smallest above-ground biomass characteristic for plots cut three times a year and not fertilized (Figure 2).

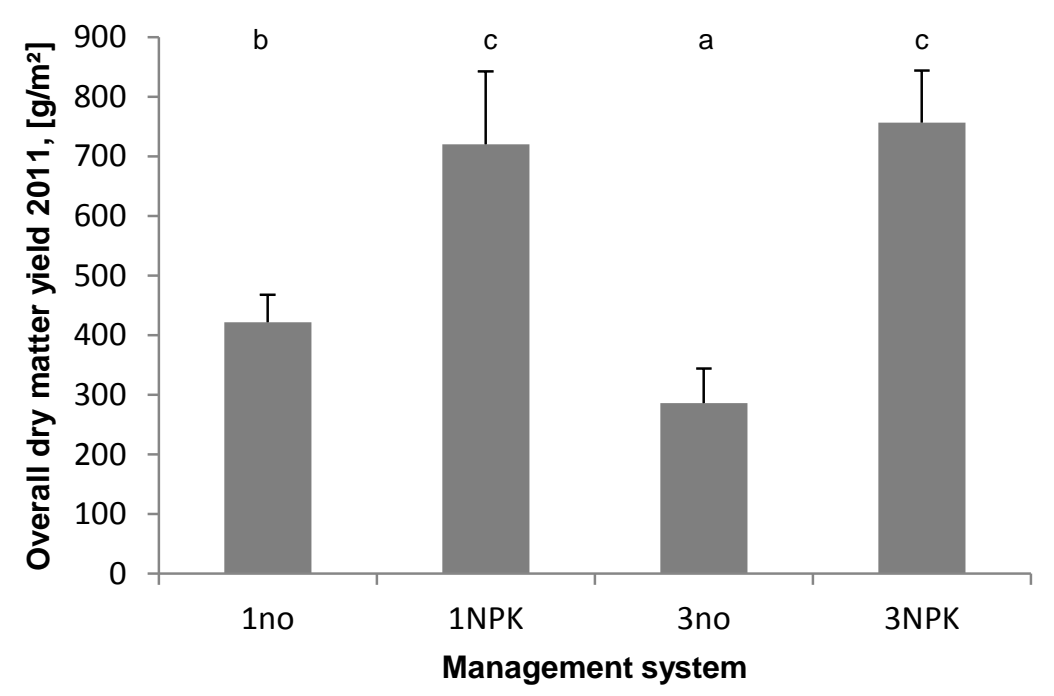

Figure 2. Overall dry matter yield in four management systems (1no, 1NPK, 3no, 3NPK) in 2011 $\left[\mathrm{g} / \mathrm{m}^{2}\right]$. Letters indicate significant differences among the management systems based on linear mixed-effect model with the three main experimental factors (sward, fertilization and cutting frequency) as fixed effects and spatial structure incorporated as random effects. 
In 2011, biomass production was highly influenced by fertilization (up to $80 \%$ of biomass production was explained by nutrient input regarding the main experimental factors). We did not find any significant relationship between the overall species number and productivity in the year $2011(p=0.61)$.

Correlations between yield and evenness and yield and functional diversity measures were larger than with species richness (Table 5). Functional group shares correlated positively with biomass production. The number of dominant species was negatively correlated with above-ground biomass, similarly to the functional diversity index, which had a slightly weaker but also highly significant correlation with above-ground biomass. We found that aggregated traits correlated differently with biomass production. While the smallest correlation coefficients were found between the aggregated specific leaf area and aboveground biomass, and aggregated stem specific density and yield, the strongest correlation was found between the ratio of stem specific density to height and biomass.

Table 5. Spearman rank correlation coefficients between yield and corresponding measures of diversity and aggregated traits (agg). FGR ratio stands for the ratio of grasses / (herbs+legumes). Height stands for plant height, LDMC stands for leaf dry matter content, SLA - for specific leaf area, Ratio leaves - for the ratio between green leaves and total leaves number, Stem DMC -for stem dry matter content, Stem SpDens - for stem specific density, Ratio Dens/Height represents the ratio between stem specific density and plant height

\begin{tabular}{|c|c|c|c|c|c|}
\hline \multicolumn{3}{|c|}{ Diversity measures } & \multicolumn{3}{|c|}{ Aggregated traits } \\
\hline $\begin{array}{l}\text { Diversity } \\
\text { measure }\end{array}$ & $\begin{array}{l}\text { Correlation } \\
\text { coefficient }\end{array}$ & $\begin{array}{l}\text { Significance } \\
\text { level }\end{array}$ & Aggregated trait & $\begin{array}{l}\text { Correlation } \\
\text { coefficient }\end{array}$ & $\begin{array}{l}\text { Significance } \\
\text { level }\end{array}$ \\
\hline \multicolumn{2}{|c|}{ Overall species diversity } & & Heightagg & 0.68 & $p<0.0001$ \\
\hline $\begin{array}{l}\text { Species } \\
\text { richness }\end{array}$ & 0.04 & $p=0.64$ & LDMC $_{\text {agg }}$ & 0.28 & $p<0.001$ \\
\hline $\begin{array}{l}\text { Species } \\
\text { evenness }\end{array}$ & -0.40 & $p<0.001$ & SLAagg & -0.18 & $p<0.05$ \\
\hline \multicolumn{2}{|c|}{ Functional diversity } & & Ratio leavesagg & -0.3 & $p<0.001$ \\
\hline $\begin{array}{l}\text { Functional } \\
\text { group shar }\end{array}$ & 0.64 & $p<0.001$ & Stem $\mathrm{DMC}_{\mathrm{agg}}$ & 0.26 & $p<0.01$ \\
\hline $\begin{array}{l}\text { Dominant } \\
\text { species }\end{array}$ & -0.39 & $p<0.001$ & Stem SpDensagg & 0.21 & $p<0.05$ \\
\hline FD index & -0.36 & $p<0.001$ & $\begin{array}{l}\text { Ratio } \\
\text { Dens/Heightagg }\end{array}$ & -0.75 & $p<0.0001$ \\
\hline
\end{tabular}

Role of dominant species identity for functional diversity of vegetation composition In an ordination diagram of vegetation data from the year 2011, the first two axes of the RDA explained $23.8 \%$ of the species-environment relation (Figure 3 ). The functional diversity index arrow was close to the arrow of the dominant species number, showing a high correlation between the two variables. The dry biomass arrow on the diagram was close to the arrow of the share of grasses, which is showing the strong effects of functional 
group composition on the above-ground biomass production in the year 2011. Agrostis capillaris, Festuca rubra, Dactylis glomerata, and Rumex acetosa were the most common species that made up $80 \%$ of the yield on the majority of the experimental plots.

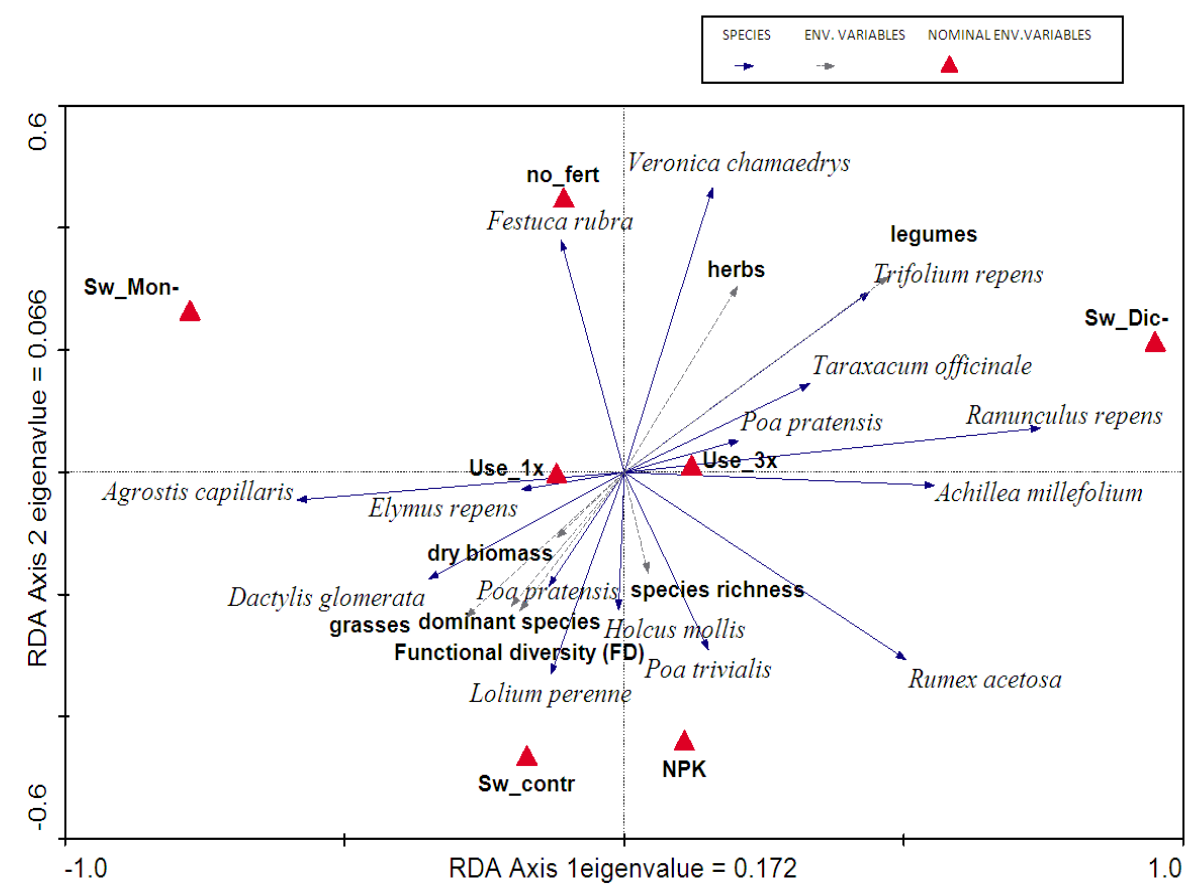

Figure 3. Ordination diagram of the vegetation data 2011 based on the Redundancy Analysis (RDA). Included the species with a fit of better than $3 \%$ (row and block as covariables). Species data logtransformed. Nominal environmental variables were: Sw_contr: control sward, Sw_Mon-: monocotreduced, Sw_Dic-: dicot-reduced. no_fert: no fertilization, NPK: fertilized, Use_1x: cut once a year, Use_3x: cut three times a year. Environmental variables were: grasses: share of grass species in the relevé [\%], herbs: share of herb species [\%], legumes: share of legume species [\%], species richness: species number per sampling area, Functional diversity (FD): functional diversity index, dominant species: number of dominant species per plot, dry biomass: overall yield per year $\left[\mathrm{g} / \mathrm{m}^{2}\right]$. 


\section{Discussion}

This study examined different aspects of grassland diversity including plant species richness and functional diversity in relation to management and productivity. We could show that in an old permanent grassland management intensity did not negatively affect the total species richness in the mid-term, but it did alter species evenness and the functional diversity of the vegetation composition. The increase in the above-ground biomass production, primarily associated with an increase in fertilizer application, was correlated with several aggregated plant functional traits as well as functional diversity measures rather than the overall species diversity. Nutrient input led to a decrease of species evenness and the functional diversity of dominant species while increasing cutting frequency positively affected the functional diversity of the sward and increased species evenness.

\section{Overall species and functional group diversity}

Three years after the manipulation of the sward by applying herbicides we found that species richness did not differ significantly among the four management systems. Furthermore, we did not find any significant relationship between species number and productivity in any of the study years. Our results are thus in contrast to the findings of several biodiversity experiments (Tilman et al. 2001, Hooper et al. 2005, Roscher et al. 2004 ) that showed that high species richness leads to an increase in biomass production. Chapin et al. (2000) stated that in most cases however, species richness correlates with rates of ecosystem processes when species numbers are small. In our case, the mean number of species present on the plots was 12 species per $\mathrm{m}^{2}$, which is larger than in most biodiversity experiments and may better reflect the "real-world" semi-natural grassland communities across Europe. In a review of recent studies on temperate permanent grasslands, Wrage et al. (2011) stated that the initial species diversity is determined by the available niches and is manipulated by management. It seems that at our site the four established levels of management did not greatly interfere with the available niches as the occurrence of most species did not change greatly in the investigated time period.

In our study, fertilization and cutting frequency were the main factors to explain productivity best. These effects were apparent through reaction of species evenness and functional diversity (aggregated plant traits) as well as species evenness to management intensification. Evenness was lower in fertilized plots than in unfertilized plots, and might thus have correlated better with the above-ground biomass production as the dominance patterns of vegetation were influenced by nutrient input through promoting better growth of larger dominant grasses, such as Dactylis glomerata. Higher shares of grasses and lower 
shares of herbs were characteristic for the fertilized plots. Some authors reported similar results regarding the effects of species evenness on productivity: Mokany et al. (2008) found that species identity was more important than species richness and in the study by Wilsey \& Potvin (2000) the relationship between aboveground biomass and species evenness varied and depended on the identity of the dominant species. In a study on a Kansas prairie by Foster et al. (2010) fertilization negatively influenced species evenness in plots which were not cut for hay while cutting for hay increased species evenness of the plots where no fertilizer was applied. Schaffers (2002) also reported that increasing mowing frequency increased species evenness. These findings are similar to our results, as the largest average species evenness was typical for plots cut three times and not fertilized and the lowest average species evenness was characteristic for fertilized plots cut once a year. According to Louault et al. (2005) major factors influencing the vegetation dynamics are nutrient availability and disturbance which reflect at the same time the most common agricultural activities, and the combination, as well as intensity of both are important.

In the year 2011, although the differences in functional group composition between the three sward types were significant, we found that these differences were no longer as pronounced as they were in the first two years after herbicide application. Petersen et al. (2012) showed that herbicide application significantly changed the shares of functional groups in the year following herbicide application. Apparently, a rather high resilience of the vegetation composition along with management contributed to the fact that the shares of grasses, for instance, almost regained the initial state with about $70 \%$ of the functional composition of the sward. This might also explain the high correlation between the functional group diversity, i.e. the ratio between grasses and herbs plus legumes, and above-ground biomass production. Other authors found a higher explanatory power of functional group diversity than species richness in a number of diversity-productivity studies (Diaz et al. 2003, Roscher et al. 2004). Šmilauer \& Šmilauerová (2013) conducted a removal experiment in the Czech Republic in a semi-natural grassland and reported that under nutrient-poor conditions both functional groups, herbs and grasses, contributed to maintaining grassland stability and productivity. We suggest that the functional group diversity may therefore play an important role in securing sustainable biomass yields. In the year with dry summer conditions (2010), for instance, overall biomass production in the control sward was better than in the two other sward types supporting this suggestion as the reduced effect of fertilizer application was apparently partly substituted by better performance of the control sward regarding the above-ground yield. 
The different measures of functional diversity, such as number of dominant species and functional diversity index, had stronger correlations with the above-ground biomass than overall species richness and explained similar parts of the variation in productivity as did species evenness. It seems that plant functional traits reacted to different management through changes seen in aggregated traits as well as the number and functional diversity of the dominant species. It therefore led to more pronounced effects of fertilization and cutting frequency on biomass formation. According to the mass-ratio hypothesis (Grime 1998), dominant species largely influence ecosystem functioning. Spehn et al. (2005) and Mokany et al. (2008) also reported that ecosystem processes were mostly influenced by the traits of dominant species. These results are in accordance with our findings.

Some of the aggregated traits showed strong correlations with above-ground biomass which is in line with previous findings (Garnier et al. 2004, Westoby \& Wright 2006, Duru et al. 2012). Although some species, especially grasses, may show a large plasticity regarding certain plant functional traits, such as leaf dry matter content and specific leaf area, some studies have incorporated plant functional traits from species databases only. However, in studies like ours, this would have been a limitation due to plastic responses to management (among others Rose et al. 2012, Duru et al. 2012). We did not measure the leaf N-content, but we suggest that some other traits that have been reported to respond to management, such as height or the ratio between stem specific density and height, can also be used as indicators of management impacts. Klimešova et al. (2008) reported that some traits that used in combination with height to assess the reaction of species to mowing or grazing are related to shoot architecture.

The functional diversity index has been reported to be insensitive to the number of species entering the analysis (Petchey \& Gaston 2002, Mason et al. 2005), but in our case this was not a limitation as we calculated the index for the dominant species only and this number even differed slightly among the plots, reflecting management effects. The fact that not only the number of dominant species, but also the functional diversity index differed among the treatments indicates that both these components of functional diversity were important and responded to the management intensification. Along with the number of dominant species, we also found that their identity mattered for functional diversity. Plots cut once a year often had species showing stronger dominance such as Dactylis glomerata, which could outshade other species. Kahmen \& Poschlod (2004) found that without biomass being removed, the plant height increased due to a larger share of tall species that out-compete small species in the competition for light. We suggest that this might also explain the increase of the functional diversity index in plots cut three times a year as more species 
have a chance for light competition on these plots. It seems that optimization of management intensity can play a crucial role in biomass production and preserving species diversity as fertilization was found to reduce species evenness and functional diversity of dominant species, at the same time increasing the ratio of grasses over herbs and legumes, producing higher yields. On the other hand, increasing cutting frequency promoted higher species evenness and was found to increase the functional diversity.

\section{Implications for agricultural land use}

In our study management intensification did not have dramatic effects on species losses, at least on the short to mid-term period, three years after the removal of functional groups to create different sward types. According to Wellstein et al. (2011), environmental change alters the trait composition indicating potential shifts in key ecosystem functions such as productivity, carbon storage, and hydrology over an ecologically short time period. Thus, after a change in management, effects on trait composition should be measurable before changes in species composition can be detected. It is therefore important to measure diversity not only in species number but look beyond that, including other diversity parameters.

In our study, the difference in functional diversity of dominant species resulted from the differences in management of the experimental plots which in turn came through response of plant traits to management suggesting that agricultural activities, optimizing and balancing nutrient input and cutting frequency, in semi-natural grasslands are of high importance when considering species conservation issues. Increasing cutting frequency even promoted slightly higher diversity of dominant species while fertilization led to decrease of the functional diversity. While dominant species may explain a large share of biomass production (Loreau et al. 2001), it is important to consider other ecosystem functions for which the minor species would play an important role. Schwartz et al. (2000), for example, argued that as ecosystem functions do not saturate at low species richness, diverse communities are important for ecosystem functioning. In a study on a Festuca rubra grassland by Pavlů et al. (2012) moderate application of NPK fertilizer did not generate irreversible structural and compositional changes. It seems that the vegetation diversity of a semi-natural grassland, its resilience and provision of further ecosystem functions such as better nutrient and water retention (Wrage et al. 2011) can be important arguments for farming on permanent swards rather than reseeding keeping monitoring of vegetation composition to make sure the changes in it are not threatened by too intensive nutrient input or intensive use. 


\section{List of references}

Adler, P.B., Seabloom, E.W., Borer, E.T., Hillebrand, H., Hautier, Y., Hector, A., Harpole, W.S., O'Halloran, L.R., Grace, J.B., Anderson, T.M., Bakker, J.D., Biederman, L.A., Brown, C.S., Buckley, Y.M., Calabrese, L.B., Chu, C.-J., Cleland, E.E., Collins, S.L., Cottingham, K.L., Crawley, M.J., Damschen, E.I., Davies, K.F., DeCrappeo, N.M., Fay, P.A., Firn, J., Frater, P., Gasarch, E.I., Gruner, D.S., Hagenah, N., Hille Ris Lambers, J., Humphries, H., Jin, V.L., Kay, A.D., Kirkman, K.P., Klein, J.A., Knops, J.M.H., La Pierre, K.J., Lambrinos, J.G., Li, W., MacDougall, A.S., McCulley, R.L., Melbourne, B.A., Mitchell, C.E., Moore, J.L., Morgan, J.W., Mortensen, B., Orrock, J.L., Prober, S.M., Pyke, D.A., Risch, A.C., Schuetz, M., Smith, M.D., Stevens, C.J., Sullivan, L.L., Wang, G., Wragg, P.D., Wright, J.P., Yang, L.H., 2011. Productivity is a poor predictor of plant species richness. Science 333 (6050), 1750-1753.

Balvanera, P., Pfisterer, A.B., Buchmann, N., He, J.-S., Nakashizuka, T., Raffaelli, D., Schmid, B., 2006. Quantifying the evidence for biodiversity effects on ecosystem functioning and services. Ecology Letters 9 (10), 1146-1156.

Campbell, V., Murphy, G., Romanuk, T.N., 2011. Experimental design and the outcome and interpretation of diversity-stability relations. OIKOS 120 (3), 399-408.

Chapin, S.F. III, Zavaleta, E.S., Eviner, V.T., Naylor, R.L., Vitousek, P.M., Reynolds, H.L., Hooper, D.U., Lavorel, S., Sala, O.E., Hobbie, S.E., Mack, M.C., Díaz, S., 2000. Consequences of changing biodiversity. Nature 405, 234-242.

Cornelissen, J.H.C., Lavorel, S., Garnier, E., Díaz, S., Buchmann, N., Gurvich, D.E., Reich, P.B., Steege, H.t., Morgan, H.D., van der Heijden, M.G.A., Pausas, J.G., Poorter, H., 2003. A handbook of protocols for standardised and easy measurement of plant functional traits worldwide. Australian Journal of Botany 51 (4), 335-380.

Díaz, S., Lavorel, S., de Bello, F., Quétier, F., Grigulis, K., Robson, M.T., 2007. Incorporating plant functional diversity effects in ecosystem service assessments. Proceedings of the National Academy of Sciences of the USA 104 (52), 20684-20689.

Díaz, S., Symstad, A.J., Stuart Chapin, F., Wardle, D.A., Huenneke, L.F., 2003. Functional diversity revealed by removal experiments. Trends in Ecology \& Evolution 18 (3), 140-146.

Duru, M., Theau, J.P., Cruz, P., 2012. Functional diversity of species-rich managed grasslands in response to fertility, defoliation and temperature. Basic and Applied Ecology 13, 20-31.

EEA 2010, The European environment - state and outlook 2010. EEA Report 2010, European Environmental Agency, Copenhagen. http://www.eea.europa.eu/soer/synthesis/synthesis.

Flynn, D.F. B., Gogol-Prokurat, M., Nogeire, T., Molinari, N., Trautman Richards, B., Lin, B.B., Simpson, N., Mayfield, M.M., DeClerck, F., 2009. Loss of functional diversity under land use intensification across multiple taxa. Ecology Letters 12, 22-33.

Foster, B.L., Khavin, I.S., Murphy, C.A., Smith, V.H., Ramspott M.E., Price, K.P., Kindscher, K., 2010. Transactions of the Kansas Academy of Science 113 (1/2), 103-119.

Garnier, E., Cortez, J., Billès, G., Navas, M.-L., Roumet, C., Debussche, M., Laurent, G., Blanchard, A., Aubry, D., Bellmann, A., Neill, C., Toussaint, J.-P., 2004. Plant functional markers capture ecosystem properties during secondary succession. Ecology 85 (9), 2630-2637.

Garnier, E., Lavorel, S., Ansquer, P., Castro, H., Cruz, P., Dolezal, J., Eriksson, O., Fortunel, C., Freitas, H., Kigel, J., Kleyer, M., Lehsten, V., Lepš, J., Meier, T., Pakeman, R., Papadimitriou, M., Papanastasis, V.P., Quested, H., Quétier, F., Robson, M., Roumet, C., Rusch, G., Skarpe, C., Sternberg, M., Theau, J.-P., Thébault, A., Vile, D., Zarovali, M.P., 2007. Assessing the Effects of Land-use Change on Plant Traits, Communities and Ecosystem functioning in grasslands: A 
standardized methodology and lessons from an Application to 11 European sites. Annals of Botany 99, 967-985.

Garnier, E., Navas, M.-L., 2012. A trait-based approach to comparative functional plant ecology: concepts, methods and applications for agroecology. A review. Agronomy for Sustainable Development 32 (2), 365-399.

Grime, P.J., 1998. Benefits of plant diversity to ecosystems: immediate, filter and founder effects. Journal of Ecology 86, 902-910.

Hector, A., Schmid, B., Beierkuhnlein, C., Caldeira, M.C., Diemer, M., Dimitrakopoulos, P.G., Finn, J.A., Freitas, H., Giller, P.S., Good, J., Harris, R., Högberg, P., Huss-Danell, K., Joshi, J., Jumpponen, A., Körner, C., Leadley, P.W., Loreau, M., Minns, A., Mulder, C.P. H., O'Donovan, G., Otway, S.J., Pereira, J.S., Prinz, A., Read, D.J., Scherer-Lorenzen, M., Schulze, E.-D., Siamantziouras, A.-S.D., Spehn, E.M., Terry, A.C., Troumbis, A.Y., Woodward, F.I., Yachi, S., Lawton, J.H., 1999. Plant diversity and productivity experiments in European grasslands. Science 286, 1123-1127.

Hector, A., Bagchi, R., 2007. Biodiversity and ecosystem multifunctionality. Nature 448 (7150), 188190.

Hooper, D.U., Chapin, F.S. III, Hector, A., Inchausti, P., Lavorel, S., Lawton, J.H., Lodge, D.M., Naeem, S., Schmid, B., Setälä, H., Symstad, A.J., Vandermeer, J., Wardle, D.A., 2005. Effects of biodiversity on ecosystem functioning: a consensus of current knowledge. Ecological Monographs 75 (1), 3-35.

Hopkins, A., Holz, B., 2006. Grassland for agriculture and nature conservation: production, quality and multi-functionality. Agronomy Research 4 (1), 3-20.

Huston, M.A., Aarsen, L.W., Austin, M.P., Cade, B.S., Fridley, J.D., Garnier, E., Grime, J.P., Hodgson, J., Lauenroth, W.K., Thompson, K., Vandermeer, J.H., Wardle, D.A., 2000. No consistent effect of plant diversity on productivity. Science 289 (5483), 1255a.

Kahmen, S., Poschlod, P., 2004. Plant functional trait responses to grassland succession over 25 years. Journal of Vegetation Science 15, 21-32.

Klapp, E., Stählin, A., 1936. Standorte, Pflanzengesellschaften und Leistung des Grünlandes. Ulmer, Stuttgart.

Klimešová, J., Latzel, V., de Bello, F., van Groenendael, J.M., 2008. Plant functional traits in studies of vegetation changes in response to grazing and mowing: towards a use of more specific traits. Preslia 80, 245-253.

Laliberté, E., Wells, J.A., DeClerck, F., Metcalfe, D.J., Catterall, C.P., Queiroz, C., Aubin, I., Bonser, S.P., Ding, Y., Fraterrigo, J.M., McNamara, S., Morgan, J.W., Merlos, D.S., Vesk, P.A., Mayfield, M.M., 2010. Land-use intensification reduces functional redundancy and response diversity in plant communities. Ecology Letters 13 (1), 76-86.

Lavorel, S., Garnier, E., 2002. Predicting changes in community composition and ecosystem functioning from plant traits: revisiting the Holy Grail. Functional Ecology 16, 545-556.

Lavorel, S., Grigulis, K., McIntyre, S., Williams, N.S.G., Garden, D., Dorrough, J., Berman, S., Quétier, F., Thébault, A., Bonis, A., 2008. Assessing functional diversity in the field - methodology matters! Functional Ecology 22, 137-147.

Lepš, J., Šmilauer, P., 2003. Multivariate analysis of ecological data using CANOCO. Cambridge University Press, Cambridge.

Liira, J., Schmidt, T., Aavik, T., Arens, P., Augenstein, I., Bailey, D., Billeter, R., Bukáček, R., Burel, F., Blust, G., Cock, R., Dirksen, J., Edwards, P.J., Hamerský, R., Herzog, F., Klotz, S., Kühn, I., Le Coeur, D., Miklová, P., Roubalova, M., Schweiger, O., Smulders, M.J., Wingerden, W.K., Bugter, R., 
Zobel, M., 2008. Plant functional group composition and large-scale species richness in European agricultural landscapes. Journal of Vegetation Science 19 (1), 3-14.

Lindborg, R., Eriksson, O., 2005. Functional response to land use change in grasslands: Comparing species and trait data. Ecoscience 12 (2), 183-191.

Loreau, M., Naeem, S., Inchausti, P., Bengtsson, J., Grime, J.P., Hector, A., Hooper, D.U., Huston, M.A., Raffaelli, D., Schmid, B., Tilman, D., Wardle, D.A., 2001. Biodiversity and Ecosystem Functioning: Current Knowledge and Future Challenges. Science 294, 804-808.

Louault, F., Pillar, V.D., Aufrère, J., Garnier, E., Sousanna, J.-F., 2005. Plant traits and functional types in response to reduced disturbance in a seminatural grassland. Journal of Vegetation Science $16,151-160$.

Mason, N.W. H., Mouillot, D., Lee, W.G., Wilson, B.J., 2005. Functional richness, functional evenness and functional divergence: the primary components of functional diversity. OIKOS 111, $112-118$.

Mokany, K., Ash, J., Roxburgh, S., 2008. Functional identity is more important than diversity in influencing ecosystem processes in a temperate native grassland. Journal of Ecology 96 (5), 884893.

Mouillot, D., Mason, W.H.N., Dumay, O., Wilson, J.B., 2005. Functional regularity: a neglected aspect of functional diversity. Oecologia 142 (3), 353-359.

Pavlů, V., Gaisler, J., Pavlů, L., Hejcman, M., Ludvíková, V., 2012. Effect of fertiliser application and abandonment on plant species composition of Festuca rubra grassland. Acta Oecologica 45, 42-49.

Petchey, O.L., Gaston, K.J., 2002. Functional diversity (FD), species richness and community composition. Ecology Letters 5, 402-411.

Petchey, O.L., Gaston, K.J., 2006. Functional diversity: back to basics and looking forward. Ecology Letters 9, 741-758.

Petersen, U., Wrage, N., Köhler, L., Leuschner, C., Isselstein, J., 2012. Manipulating the species composition of permanent grasslands-A new approach to biodiversity experiments. Basic and Applied Ecology 13 (1), 1-9.

Piepho, H-P., 2004. An Algorithm for a Letter-Based Representation of All-Pairwise Comparisons,

Journal of Computational and Graphical Statistics 13 (2), 456-466.

Pinheiro, J., Bates, D., DebRoy, S., Sarkar, D., The R Core team, 2009. nlme: Linear and nonlinear mixed effects models. $R$ package version 3, 1-96.

Proulx, R., Wirth, C., Voigt, W., Weigelt, A., Roscher, C., Attinger, S., Baade, J., Barnard, R.L., Buchmann, N., Buscot, F., Eisenhauer, N., Fischer, M., Gleixner, G., Halle, S., Hildebrandt, A., Kowalski, E., Annely, K., Lange, M., Milcu, A., Niklaus, P.A., Oelmann, Y., Rosenkranz, S., Sabais, A., Scherber, C., Scherer-Lorenzen, M., Scheu, S., Schulze, E.-D., Schumacher, J., Schwichtenberg, G., Soussana, J.-F., Temperton, V.M., Weisser, W.W., Wilcke, W., Schmid, B., 2010. Diversity Promotes Temporal Stability across Levels of Ecosystem Organization in Experimental Grasslands. PLOS ONE 5 (10), 1-8.

R Development Core Team, 2011. R: A language and environment for statistical computing. $R$ Foundation for Statistical Computing, Vienna.

Roscher, C., Schumacher, J., Baade, J., Wilcke, W., Gleixner, G., Weisser, W.W., Schmid, B., Schulze, E.-D., 2004. The role of biodiversity for element cycling and trophic interactions: an experimental approach in a grassland community. Basic and Applied Ecology 5, 107-121. 
Roscher, C., Schumacher, J., Gubsch, M., Lipowsky, A., Weigelt, A., Buchmann, N., Schmid, B., Schulze, E.-D., Chen, H.Y., 2012. Using plant functional traits to explain diversity-productivity relationships. PLOS ONE 7 (5), e36760.

Rose, L., Rubarth, M.C., Hertel, D., Leuschner, C., 2012. Management alters interspecific leaf trait relationships and trait-based species rankings in permanent meadows. Journal of Vegetation Science 24 (2), 239-250.

Sanderson, M.A., Skinner, H.R., Barker, D.J., Edwards, G.R., Tracy, B.F., Wedin, D.A., 2004. Plant Species Diversity and Management of Temperate Forage and Grazing Land Ecosystems. Crop Science 44, 1132-1144.

Schaffers, A.P., 2002. Soil, biomass, and management of semi-natural vegetation. Part II. Factors controlling species diversity. Plant Ecology 158, 247-268.

Schellberg, J., Pontes, L.D., 2012. Plant functional traits and nutrient gradients on grassland. Grass and Forage Science 67 (3), 305-319.

Schumacher, J., 2003. Xtree function for calculating functional diversity index. URL: http://owenpetchey.staff.shef.ac.uk/Code/Code/calculatingfd_assets/Xtree.r

Schwartz, M.W., Brigham, C.A., Hoeksema, J.D., Lyons, K.G., Mills, M.H., van Mantgem, P.J., 2000. Linking biodiversity to ecosystem function: implications for conservation ecology. New Phytologist 122, 297-305.

Šmilauer, P., Šmilauerová, M., 2013. Asymmetric relationship between grasses and forbs: results from a field experiment under nutrient limitation. Grass and Forage Science 68 (1), 186-198.

Spehn, E.M., Hector, A., Joshi, J., Scherer-Lorenzen, M., Schmid, B., Bazeley-White, E., Beierkuhnlein, C., Caldeira, M.C., Diemer, M., Dimitrakopoulos, P.G., Finn, J.A., Freitas, H., Giller, P.S., Good, J., Harris, R., Högberg, P., Huss-Danell, K., Jumpponnen, A., Koricheva, J., Leadley, P.W., Loreau, M., Minns, A., Mulder, C.P. H., O'Donovan, G., Otway, S.J., Palmborg, C., Pereira, J.S., Pfisterer, A.B., Prinz, A., Read, D.J., Schulze, E.-D., Siamantziouras, A.-S.D., Terry, A.C., Troumbis, A.Y., Woodward, F.I., Yachi, S., Lawton, J.H., 2005. Ecosystem effects of biodiversity manipulations in European grasslands. Ecological Monographs 75 (1), 37-63.

Ter Braak, C. J. F. and Šmilauer, P., 1997-2004. Canoco for Windows. Plant Research International, Wageningen.

Ter Braak, C. J. F., Šmilauer, P., 2002. Canoco reference manual an CanoDraw for Windows User's guide: Software for Canonical Community Ordination (version 4.5). Microcomputer Power, Ithaca, NY.

Tilman, D., Reich, P.B., Knops, J., Wedin, D., Mielke, T., Lehman, C., 2001. Diversity and productivity in a long-term grassland experiment. Science 294 (5543), 843-845.

Tilman, D., Wedin, D., Knops, J., 1996. Productivity and sustainability influenced by biodiversity in grassland ecosystems. Nature 379, 718-720.

Villéger, S., Mason, N.W. H., Mouillot, D., 2008. New multidimensional functional diversity indices for a multifaceted framework in functional ecology. Ecology 89 (8), 2290-2301.

Violle, C., Navas, M.-L., Vile, D., Kazakou, E., Fortunel, C., Hummel, I., Garnier, E., 2007. Let the concept of trait be functional! OIKOS 116, 882-892.

Wellstein, C., Schröder, B., Reineking, B., Zimmermann, N.E., 2011. Understanding species and community response to environmental change - A functional trait perspective. Agriculture, Ecosystems \& Environment 145 (1), 1-4. 
Wesche, K., Krause, B., Culmsee, H., Leuschner, C., 2012. Fifty years of change in Central European grassland vegetation: Large losses in species richness and animal-pollinated plants. Biological Conservation 150 (1), 76-85.

Westoby, M., Wright, I.J., 2006. Land-plant ecology on the basis of functional traits. Trends in Ecology \& Evolution 21 (5), 261-268.

Wilsey, B.J., Potvin, C., 2000. Biodiversity and ecosystem functioning: importance of species evenness in an old field. Ecology 81 (4), 887-892.

Wrage, N., Strodthoff, J., Cuchillo, H.M., Isselstein, J., Kayser, M., 2011. Phytodiversity of temperate permanent grasslands: ecosystem services for agriculture and livestock management for diversity conservation. Biodiversity Conservation 20 (14), 3317-3339.

Yang, Z., Ruijven, J., Du, G., 2011. The effects of long-term fertilization on the temporal stability of alpine meadow communities. Plant and Soil 345, 315-324. 


\section{Chapter 3}

Bringing biodiversity experiments to the real world: diversity versus management in a semi-natural grassland 


\section{Abstract}

Recent studies in the field of biodiversity and ecosystem functioning in temperate grassland systems reported a variety of results regarding the nature of the relationship between diversity and productivity. Findings supporting the positive effects of species diversity on productivity came mostly from experimental communities. Studies in natural and seminatural grassland communities, on the contrary, often reported weak or even no relationship between the two variables. These studies were, however, criticized for not including productive sites, confounded site and diversity effects, as well as low control of external factors. We present the results of a 5-year biodiversity experiment in a semi-natural grassland with a more than one-hundred-year-old history of extensive agricultural use. We managed to create three different sward types via removal of functional groups and a gradient of management intensity resulting from a combination of two cutting frequencies and nutrient input. In our study, overall species richness had no significant effect on the above-ground biomass production across the five study years. Sward type diversity had significant effects on the above-ground biomass production only in the experimental year with extremely dry weather conditions in the summer months before the peak standing crop, when control plots had larger yields than dicot- and monocot-reduced. While management intensification caused an increase in above-ground biomass production, changes in species numbers were not dramatic over the whole investigation period with increasing cutting frequency promoting establishing of more species. In our study existing species composition of the semi-natural grassland was highly resilient and four years after the removal of functional groups it regained a composition of grasses, herbs and legumes showing almost no differences among the sward types with larger shares of grasses being typical of fertilized plots and larger shares of herbs typical of frequent cutting. Shares of legumes were suppressed by fertilization, but were found in almost all plots by the end of the experimental period. We suggest that under appropriate agricultural management a semi-natural grassland might have a potential for sustainable forage production at the same time delivering multiple ecosystem services without significant species losses if management strategy is carefully chosen and without the need of being converted to arable land or reseeding it with diverse species mixtures. 


\section{Introduction}

A lot of grassland communities in Central Europe are nowadays characterized by a speciespoor composition of mowing-tolerant, $\mathrm{N}$-demanding competitive grasses and a decline of early-flowering species, especially insect-pollinated herbs (Wesche et al. 2012). Multifunctionality of grasslands, however, depends on the plant species diversity (Hector \& Bagchi 2007, Zavaleta et al. 2010) and promotes stability across levels of ecosystem organization (Isbell 2009, Proulx et al. 2010, Yang et al. 2012). But farmers and ecologists often have different views on the role of biodiversity for grassland production (Wrage et al. 2011) leading to a controversy concerning research priorities between the two groups. The need for agricultural production in Europe is still high, be it the primary source of forage for livestock or for bioenergy purposes. Species-rich grasslands are not perceived as an attractive source for agricultural production by farmers, but they are of focal interest for nature conservation. There have been attempts to restore diverse grasslands all over Europe, however, not all of them were successful (Critchley et al. 2003, Hodgson et al. 2005).

Due to this increasing interest in grassland biodiversity and the scarcity of land resources for agricultural production, two main strategies emerged: intensification of the use of diverse grassland or diversification of the existing species composition. The former may comprise grassland diversity, while the latter requires knowledge about the relationship between diversity and biomass production. Correspondingly, many studies addressed the problem of species losses and ecosystem functioning, as well as the nature of the relationship between diversity and biomass production (Chapin et al. 2000, Sala et al. 2000).

A large number of studies was conducted in order to examine the ecosystem functioning and the impacts of species losses on it. Biodiversity studies have often concentrated on the relationship between species diversity and productivity (Hector et al. 1999, Tilman et al. 2001, Roscher et al. 2005), but most of these studies took place in experimental grasslands sown with diverse species mixtures (Sanderson et al. 2004). Such studies (Tilman et al. 2001, Roscher et al. 2005, Reich et al. 2012) found mostly strong positive effects of species diversity on biomass production, which in long-running studies were also reported over time (Cardinale et al. 2007, Tilman et al. 2012). These results, however, were criticized for unnatural species abundances and artificial conditions, leading to the difficulty of scaling up or generalizing those findings (among others Loreau et al. 2001, Wilsey \& Polley 2004). 
Observational studies, conducted in natural and semi-natural grasslands, often reported weak or no relationship between species diversity and productivity (Huston et al. 2000, Adler et al. 2011, Assaf et al. 2011), but were considered to have a number of weaknesses, such as no defined biodiversity levels, confounded sites and diversity effects (Jiang et al. 2009, Kahmen et al. 2005) or low control of external factors (Diaz et al. 2003). Therefore, later generations of biodiversity studies, known as removal experiments, simulated the losses of certain species and functional groups and examined induced ecosystem responses emphasizing that these responses differ between natural and semi-natural grassland communities on the one hand and synthetic communities on the other (Wardle et al. 1999, Symstad \& Tilman 2001, McLaren \& Turkington 2010, Petersen et al. 2012).

Inconsistency of the findings from experimental and observational studies, as well as the challenges of transferring the results from synthetic communities to natural ecosystems and the need for long-term and large-scale studies have been on the agenda of many research projects as diversity loss was considered by many authors to be underestimated in synthetic communities compared to natural and semi-natural grassland systems (Diaz et al. 2003, Tylianakis et al. 2008). Thus, many scientists considered that research should focus on how biodiversity changes and biodiversity loss affect functioning of „real-world“ ecosystems (among others Schmid \& Hector 2004, Zavaleta \& Hulvey 2004, Naeem et al. 2012).

We present the results of a biodiversity experiment in an old semi-natural grassland in central Germany. By establishing a management gradient and creating three different sward types via removal of functional groups, we induced a change likely to affect ecosystem processes and functions. Thus, we could investigate not only the effect of the removal itself, but the functioning of the native species composition of this grassland ecosystem under disturbance resembling common levels of moderate intensification of grassland management and associated changes in yield production. Along with the herbicide treatment, we created a management gradient resulting in four management systems presented by a combination of fertilization and cutting frequency. The total of twelve established experimental treatments thus represented the combination of the three main experimental factors and matched common agricultural practices in Europe. We investigated the relationship between species diversity and productivity, as well as the changes in above-ground biomass production and vegetation diversity under management intensification. 


\section{Material and methods}

\section{Study site}

The study site is situated at the experimental farm of the University of Goettingen in the

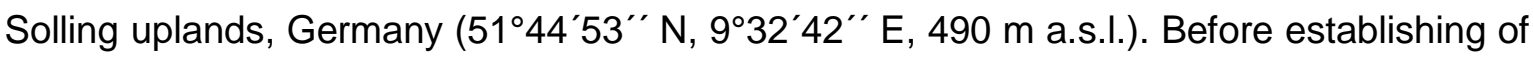
the experiment, the site was used in common farm management as pasture or for hay cutting. The mean annual temperature is $6.9^{\circ} \mathrm{C}$, mean annual precipitation $1100 \mathrm{~mm}$ (German Weather Service: DWD 1960-1990). The vegetation composition is characteristic of a nutrient-poor montane mesic-moist Lolio-Cynosuretum community with high shares of Festuca rubra and Agrostis capillaris. The soil is a haplic Cambisol with $\mathrm{pH} \mathrm{H}_{2} \mathrm{O}$ values of 5.2 - 5.6 .

\section{Experimental design}

In total, 72 plots, $15 \times 15$ m each, arranged in a Latin rectangle design consisting of six blocks and six rows, were set up in 2008 and resulted from the combination of the three experimental factors and their 6-times replication. The main experimental factors were sward type, fertilization, and cutting frequency. A change in sward diversity was achieved by the application of herbicides on July 31st 2008 to reduce the shares of grasses in the monocot-reduced (-Mon) sward (active component Clethodim $\left(0.5 \mathrm{I} \mathrm{ha}^{-1}\right)$ : Select 240 EC, Stähler Int., Stade, Germany; $0.5 \mathrm{I} \mathrm{ha}^{-1}$ ) and the share of herbs in the dicot-reduced (-Dic) sward (active components were Fluoroxypyr + Triclopyr and Mecoprop-P (3 I ha-1)). One third of the plots were left untreated (control sward). Fertilization (180-100-30 kg NPK ha-1 year $^{-1}(\mathrm{NPK})$ ) and cutting frequency (plots cut once a year (1x) and 3 times a year (3x) were two further management factors. As $\mathrm{N}$ fertilizer, we used calcium ammonium nitrate N27 (half of it applied in the beginning of April and half in the beginning of June), as P\&K fertilizer Thomaskali $(8 \%$ P2O5, 15\% K2O, 20\% CaO) in 2008-2009 and „PK fertilizer“ (12\% P2O5, $24 \% \mathrm{~K} 2 \mathrm{O}, 6 \% \mathrm{~S}, 21 \% \mathrm{CaO}$ ) in 2010-2012. Plots cut three times a year were harvested in the middle of May, middle of July, and late September. Plots cut once a year were harvested at July harvest. Harvesting of the plots was done using a Haldrup $\AA$ forage harvester by cutting of two stripes, each $1.5 \mathrm{~m}$ wide and $15 \mathrm{~m}$ long, on each plot, which was found to be a representative measurement technique for the plot size of $225 \mathrm{~m}^{2}$ and established as the standard measure of above-ground biomass production at the set-up of the experiment.

\section{Vegetation surveys}

Before the start of the experiment, the vegetation community was characterized and the minimum species area determined for defining the optimal vegetation survey size. Vegetation surveys were subsequently conducted twice a year in the beginning of May and 
in the end of August by recording species number and identity for each plot and estimating yield shares of each species, as well as functional groups' shares (grasses, herbs and legumes) according to Klapp \& Stählin (1936) in two $3 \mathrm{~m}$ × $3 \mathrm{~m}$ vegetation survey areas and $1 \mathrm{~m} \times 1 \mathrm{~m}$ quadrates per plot. The total species pool consisted of 73 species that were found over the whole vegetation period at the site. The mean overall species richness per plot was 25.3 species across all study years disregarding the differences in management system or sward type. Shannon evenness was calculated as $\mathrm{J}^{\prime}=\mathrm{H}^{\prime} / \log \mathrm{e}(\mathrm{n})$ and is hereafter referred to as evenness (where $\mathrm{H}^{\prime}$ is the Shannon diversity index (log e) and $\mathrm{n}$ is the number of species found on the corresponding plot).

\section{Data analyses}

Turboveg for Windows 2.91d (Alterra, Wageningen) was used for processing vegetation data and calculating diversity indices (Shannon diversity, Shannon evenness, Simpson diversity). Statistical analysis of the data was performed using the $\mathrm{R}$ software, Version 2.14 .0 (2012) with a significance level of $\alpha \leq 0.05$. The climate data was implemented in the models as year effects. We used linear and linear mixed effect models (Pinheiro \& Bates 2009) to explore the effects of the three main treatment factors on the relationship between species richness and productivity, as well as further diversity indices. The best fitting adequate minimum models including the significant predictive variables were selected by comparison of the Akaike Information Criteria (AIC) following the principle of marginality implying not deleting non-significant effects in presence of higher-order interactions of the corresponding factors. We used the maximum likelihood method to update the models and recalculated the final models with REML as we had spatial factors included as random effects. Residuals of the models were inspected for normality of distribution and homogeneity of variance in groups of according factors. Adjustments for non-linearity were performed if needed. If the models' residuals were heterogeneous, the variance was adjusted with the varldent structure for the corresponding factor. We used the autocorrelation function in the models for the dataset from the whole investigation period to account for temporal variation of the data. Models were simplified using an updated AICc procedure for small data-sets (Scherber 2011). Means (for grasses and herbs) and medians (for legumes) in the dicot-reduced and monocot-reduced swards were compared to the shares of corresponding functional groups in the control sward based on the linear models with block and row included as spatial factors using linear contrasts with the sward type as explanatory variable. 


\section{Results}

Overall species richness increased by the end of the experimental study period (from 23 species on average up to 25.7 species on average per plot) (Fig. 1). We successfully achieved the expected change in sward composition by the year following the herbicide treatment (Petersen et al. 2012). Compared to the set-up year, there were slightly higher numbers of species (on average 1.4 species more) in monocot-reduced plots than in the control sward and 1.6 species less in dicot-reduced plots than in control plots in 2009.

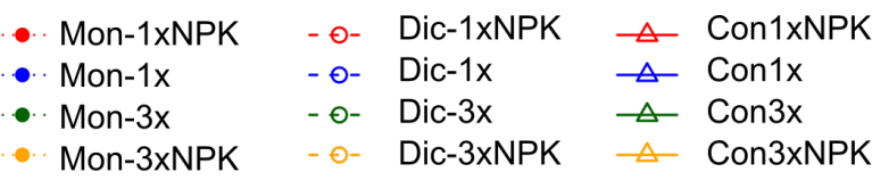

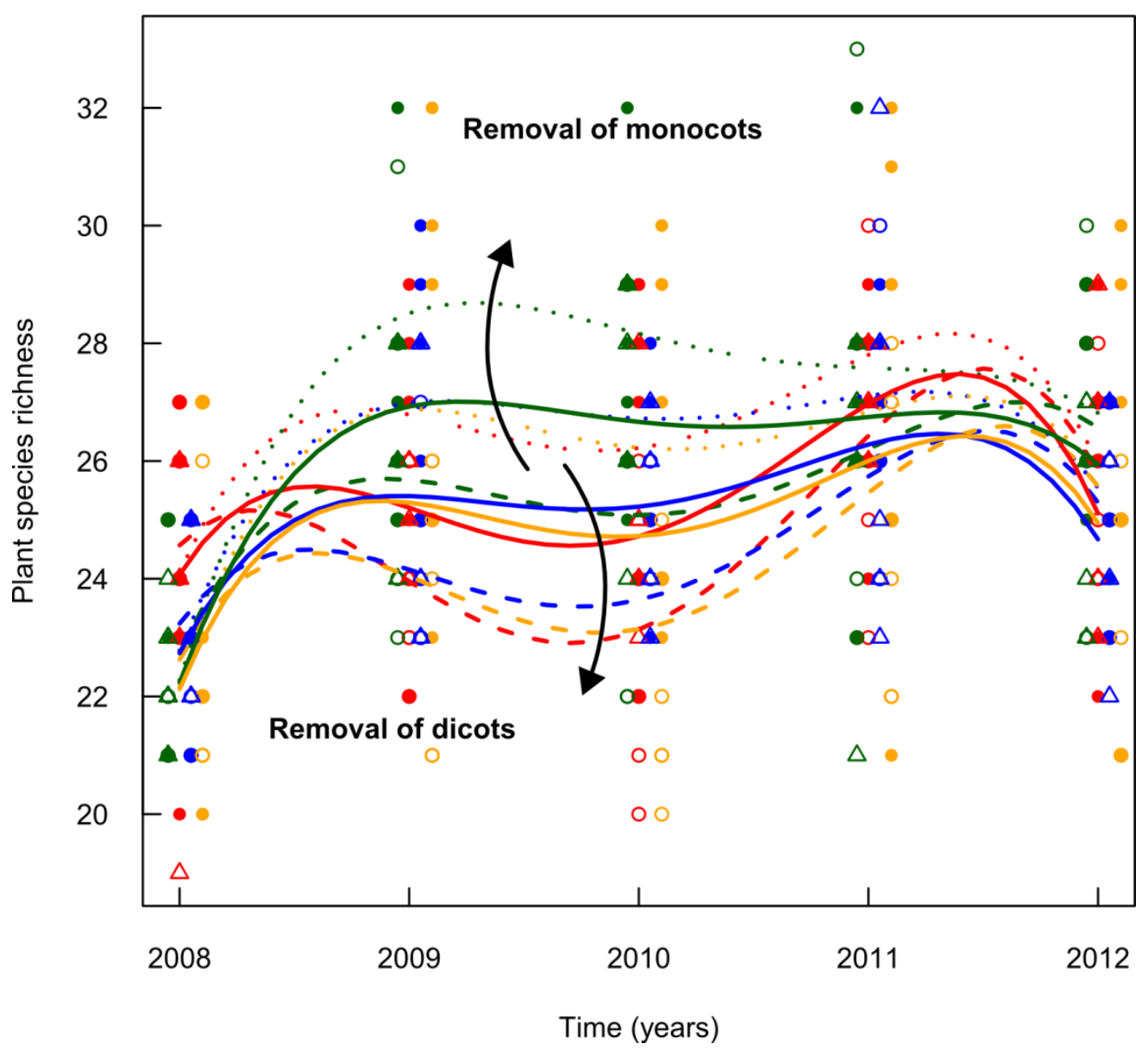

Fig. 1. Change in overall species numbers over time in 100-year-old grassland. Lines show predicted values from minimal adequate mixed effects models corrected for temporal autocorrelation and variance heterogeneity. Abbreviations of treatments are combinations of the following factors: Monstands for monocot-reduced sward, Dic- is dicot-reduced sward, Con stands for control sward. $1 \mathrm{x}$ stands for plots cut once a year, $3 \mathrm{x}$ - for plots cut three times a year; NPK - for fertilized plots.

In the last vegetation period (2012), recorded maximum species loss compared to the initial year was 3 species while the maximum number of species gained was 10 species per plot. 
Changes in species numbers were affected by the experimental year $(p<0.0001)$ and cutting frequency $(p<0.05)$ and the interactions of year and the following factors: sward type $(p<0.0001)$, cutting frequency $(p<0.001)$, as well as fertilization $(p<0.01)$.

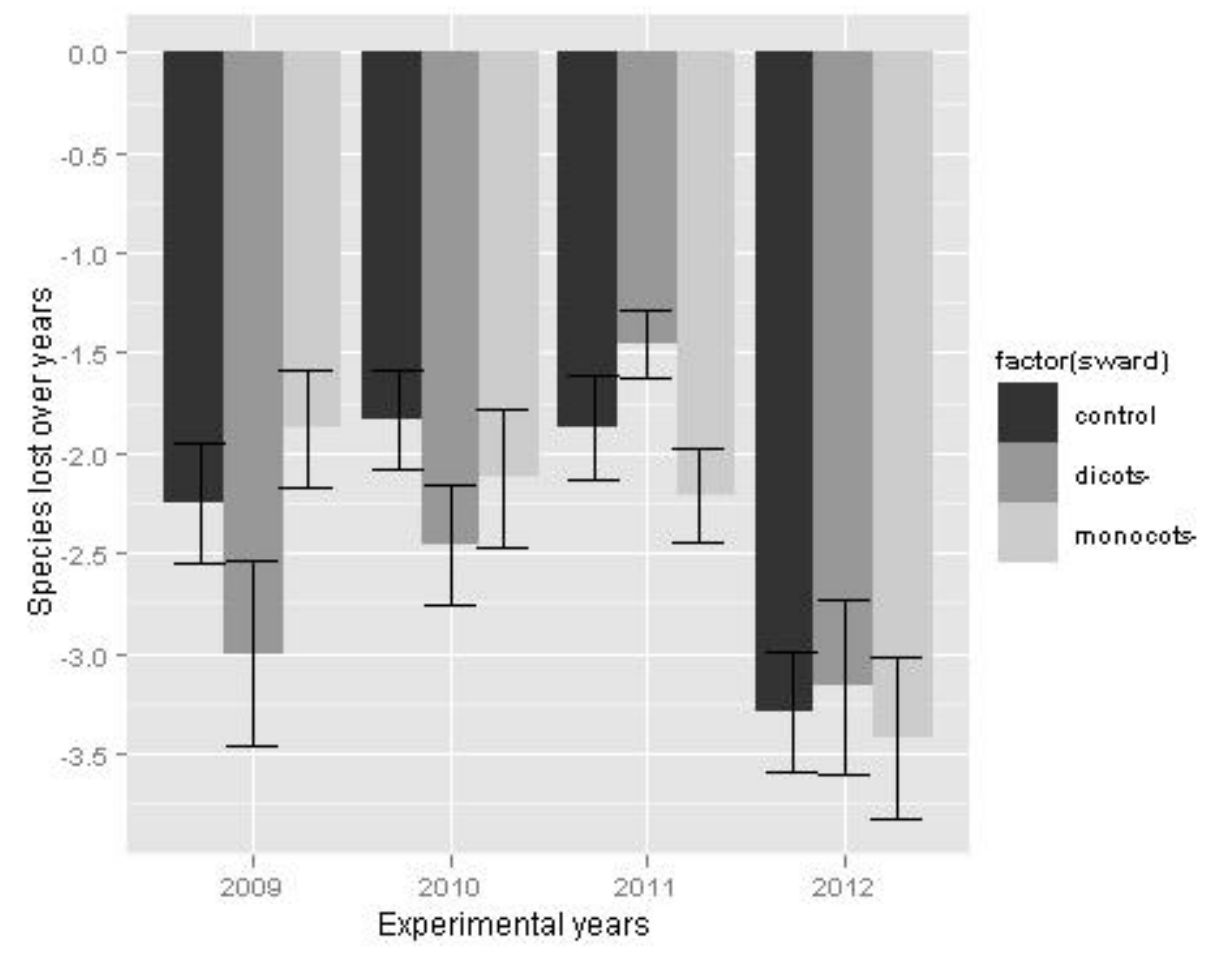

Fig. 2. Consecutive species losses of overall species richness in the three sward types (based on differences in species presence-absence data for consecutive years).

Species losses in all of the three sward types did not exceed 4 species per plot (Fig. 2). Along with the losses of species in swards that were treated with herbicides to manipulate the functional groups abundances, there was a natural dynamic of species present and absent in the control sward as well (Fig. 2 \& 3). In the year 2011, there was a significant effect of sward type on the number of species gained with higher number of species found in dicot-reduced plots (3.7 on average) while the effects of herbicide application were weakening (Fig. 3).

Regarding the effects of management intensification on species richness, in some of the years the change in species number and number of species gained compared to the previous year was found to be positively affected by cutting frequency $(p<0.05)$, whereas fertilization was not significant unless in combination with the experimental year $(p<0.01)$ with a trend in decreasing species numbers in fertilized compared to non-fertilized plots. In the year 2010, the change in species number, compared to the year 2009 was not affected by any of the main experimental factors, except for the combination of fertilization and cutting frequency $(p<0.02)$, with on average less than one species change over all 
management systems. In the fourth year after the set-up of the experiment, plots cut three times and not fertilized had on average 2.8 species more than control plots cut once a year and not fertilized $(p<0.01)$.

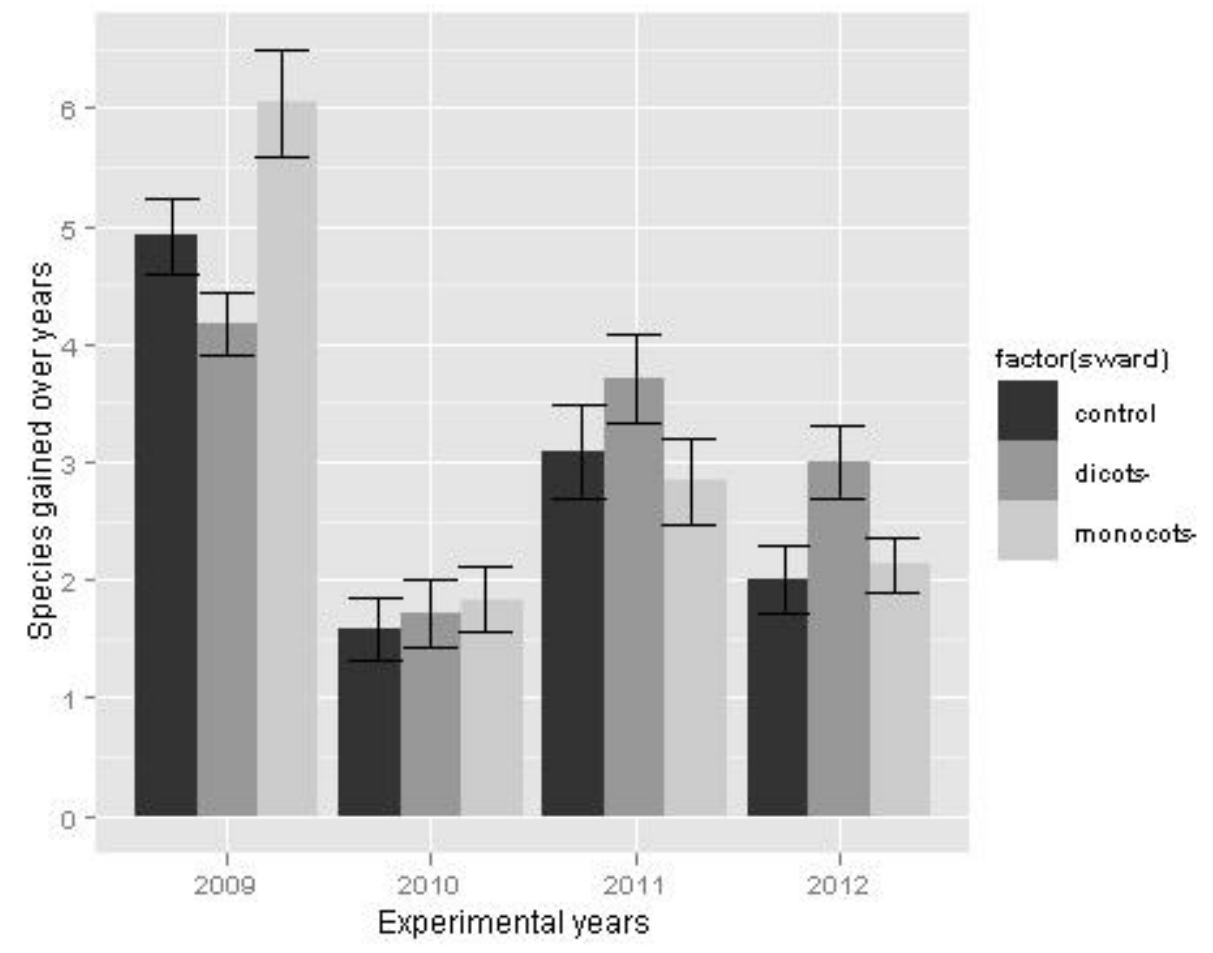

Fig. 3. Consecutive species gains of overall species richness in the three sward types (based on differences in species presence-absence data for corresponding years).

Species evenness was found to be significantly affected by all experimental factors and their influence varied across the years $(p<0.0001)$ (Figure 4$)$, sward types $(p<0.0001)$, cutting frequencies $(p<0.0001)$ and fertilization levels $(p<0.05)$. In the year following the herbicide application species evenness across all treatments was smaller compared to that of the initial species composition $(p<0.001)$.

In the two years following the herbicide application, species evenness was significantly different among the three sward types ( $p<0.0001$ in 2009; $p<0.001$ in 2010): in the control sward, species evenness was $10 \%$ higher than in the dicot-reduced sward while the highest evenness was found in the monocot-reduced sward $\left(\mathrm{J}^{\prime}=0.78\right)$ in 2009 . When the removal treatment effects were weakening in the year 2011 (Table 1), there were no significant differences found in the species evenness among the three swards ( $p=0.45)$ (Fig. 4, a). Fertilization tended to have a slightly significant effect on species evenness in the year 2009 $(p=0.07)$ (Fig. 4, b) and was found to affected species evenness in the year 2011 when the average species evenness in fertilized plots was $5 \%$ lower compared to non-fertilized plots $(p<0.001)$. Cutting frequency had significant effects on species evenness in all of the 
experimental years following the set-up year: in plots cut three times a year it was 3\% (2009, $p<0.05)$ to $7 \%(p<0.0001$ in 2010 and $p<0.0001$ in 2011) and $8 \%(2012, p<0.0001)$ higher compared to the plots cut once a year (Figure 4, b).
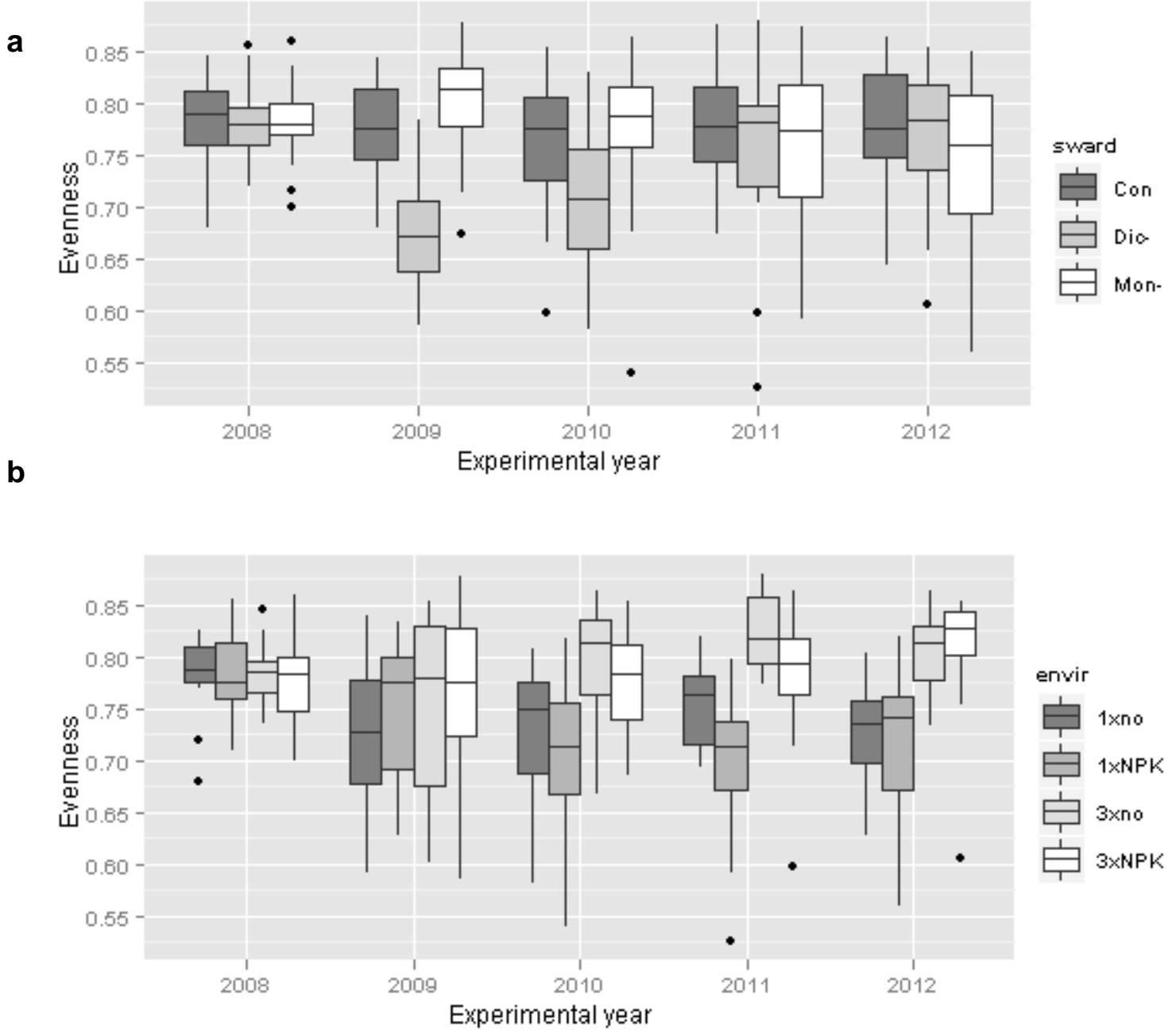

Fig. 4. Change in species evenness in three sward types $(a)$ ( $n=18$, average of vegetation surveys from May and September) and management systems $(b)(n=24$, average of vegetation surveys from May and September) in corresponding experimental years. Sward types are abbreviated here as following: Con stands for control sward, Dic- for dicot-reduced sward, Mon- for monocot-reduced swards.

The herbicide effects on sward composition lasted up to three years after the removal treatment (Table 1 \& Fig. 5) whereas in the last two experimental years we found that the functional group composition did not differ significantly between the sward types and came close to the initial composition of the set-up year (73\% grasses, $25 \%$ herbs and $1-2 \%$ legumes in 2012 versus $75.5 \%$ grasses, $21.7 \%$ herbs and $2.8 \%$ legumes, mean overall shares across all plots for corresponding year, for each group respectively). 
Table 1. Means (medians for legumes) and standard deviations (median deviations) for biomass shares (\%) of grasses, herbs and legumes in corresponding sward types. Asterisks indicate significant differences from the control sward with the following significance values: . $p<0.05$, * $p<0.01,{ }^{* *} p<0.001,{ }^{* * *} p<0.0001$.

\begin{tabular}{lllll}
\hline & Functional group & Control sward & -Dic sward & -Mon sward \\
\hline 2008 & Grasses & $74.8 \pm 4.8$ & $75.6 \pm 6.6$ & $76.2 \pm 4.5$ \\
& Herbs & $22.4 \pm .6$ & $21.6 \pm 4.5$ & $21.2 \pm 4.2$ \\
2009 & Legumes & $2.8 \pm 2.8$ & $2.8 \pm 0.2$ & $2.6 \pm 1.9$ \\
& Grasses & $69.9 \pm 7.1$ & $90.6 \pm 4.1^{* * *}$ & $43.6 \pm 7.7^{* * *}$ \\
& Herbs & $26.3 \pm 6.9$ & $9.3 \pm 4.0^{* * *}$ & $49.6 \pm 6.4^{* * *}$ \\
2010 & Legumes & $3.8 \pm 2.7$ & $0.1 \pm 0.1^{* * *}$ & $6.8 \pm 3.6^{* * *}$ \\
& Grasses & $65.7 \pm 7.8$ & $78.0 \pm 8.1^{* * *}$ & $49.3 \pm 8.6^{* * *}$ \\
& Herbs & $32.8 \pm 7.0$ & $21.8 \pm 7.7^{* * *}$ & $48.7 \pm 7.9^{* * *}$ \\
& Legumes & $1.5 \pm 1.9$ & $0.2 \pm 0.7^{* * *}$ & $2.0 \pm 3.1^{* * *}$ \\
& Grasses & $71.7 \pm 9.9$ & $75.0 \pm 10.7$. & $68.1 \pm 11.6^{*}$ \\
& Herbs & $26.9 \pm 9.0$ & $25.3 \pm 9.7$ & $29.9 \pm 10.1$. \\
& Legumes & $1.4 \pm 1.6$ & $0.5 \pm 1.0^{* *}$ & $2 \pm 2.4$ \\
& Grasses & $73.1 \pm 8.8$ & $71.8 \pm 10.4$ & $72.2 \pm 9.7$ \\
& Herbs & $25.3 \pm 8.6$ & $28.0 \pm 9.9$ & $25.9 \pm 9.1$ \\
& Legumes & $1.6 \pm 1.2$ & $0.6 \pm 0.9^{* *}$ & $1.9 \pm 1.9$
\end{tabular}

While in the first year after the removal treatment the shares of grasses, herbs and legumes were significantly different from those of the initial composition (Table 1), in the second year after herbicide application (2010) in the dicot-reduced sward type herbs gained about $12 \%$ compared to the shares in 2009 at the expense of the average shares of grasses, which were reduced by $12 \%$ compared to the year 2009 as well (Fig. 5, a, b and c).

Fertilization and cutting frequency had significant effects on the shares of grasses, herbs and legumes regarding the whole experimental period. Fertilization generally increased shares of grasses by $4.9 \%$ compared to unfertilized plots $(p<0.0001)$ and reduced the shares of herbs by $3.8 \%$ on average compared to unfertilized plots $(p<0.0001)$. Increasing cutting frequency promoted larger shares of herbs compared to the plots cut once a year by $2 \%$ on average $(p<0.0001)$ and decreased shares of grasses by $3.7 \%(p<0.001)$. There were on average $1 \%$ less legumes in the fertilized than unfertilized plots $(p<0.0001)$ and $1.6 \%$ more legumes on plots cut three times a year compared to the plots cut once a year $(p<0.0001)$. 

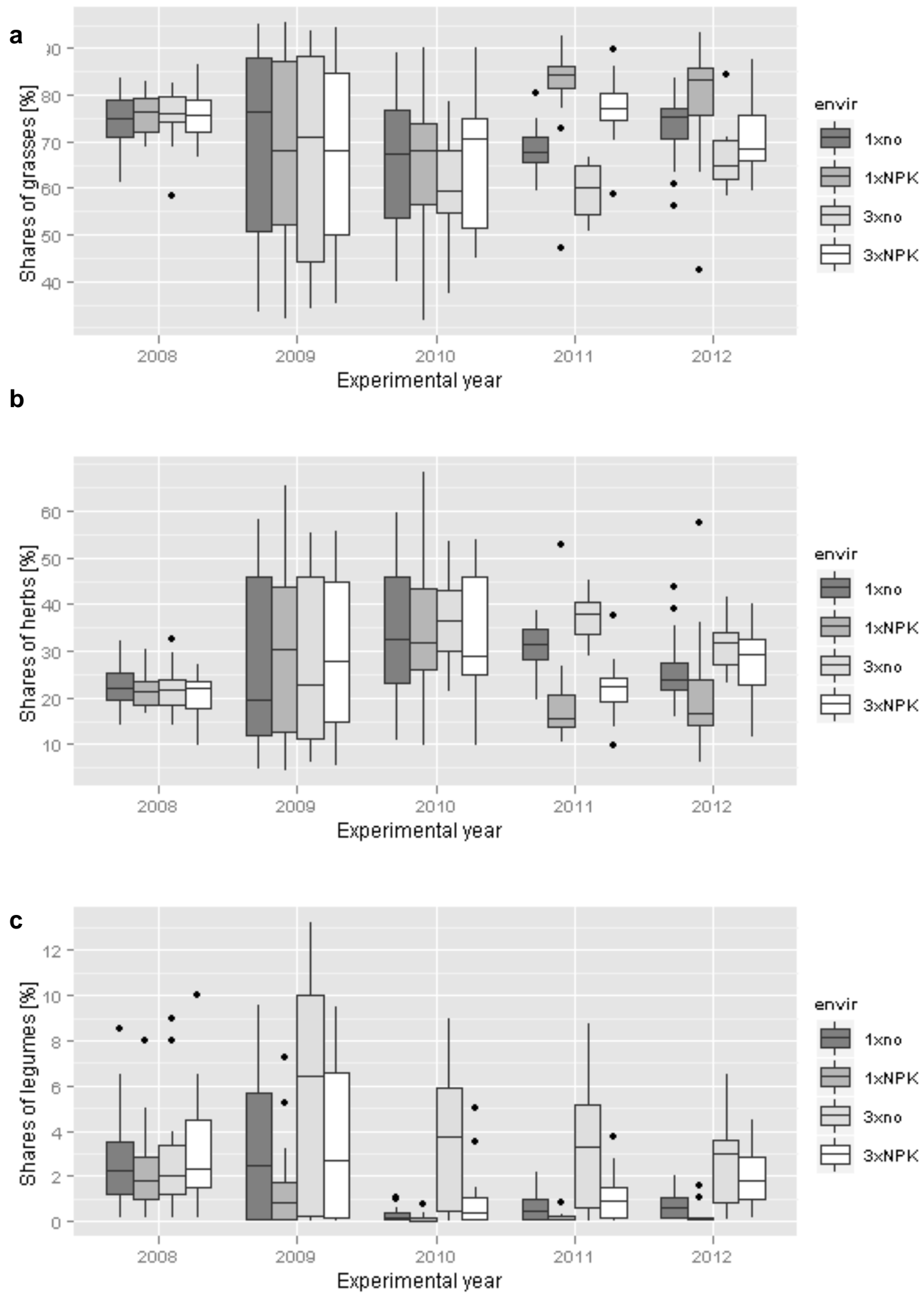

Fig. 5. Change in shares of functional groups (grasses (a), herbs (b) and legumes (c)) in corresponding management systems over the five experimental years.

Biomass production over the whole investigation period was not affected by overall species richness, except for a marginal effect of the interaction between species richness and sward 
type $(p<0.1)$. There was only a trend of a significant correlation found between the aboveground biomass production and the Shannon diversity index $(p=0.05)$. Species evenness was slightly positively correlated with productivity $(p<0.001)$, except for the year 2011 when the relationship between species evenness and productivity was significantly negative $(p<0.05)$. In presence of other experimental factors, however, species evenness was only marginally related to above-ground biomass production $(p=0.1)$.

The main factors determining the above-ground biomass production were fertilization and cutting frequency, as well as the combination of both factors. Increasing the fertilizer input and cutting frequency, we found an increase in biomass production (Table 2) irrespective of the sward types. Sward type was only a significant determinant of above-ground biomass production in the year 2010, when the summer conditions before the cutting event in July were characterized by particularly warm temperatures and scarce amounts of precipitation (Appendix 1 in this thesis).

Table 2. Percent variance in above-ground biomass production explained for the experimental years 2009-2012 based on linear models with block and row as spatial factors. Asterisks indicated significant levels as following: ${ }^{*} p<0.01,{ }^{* *} p<0.001,{ }^{* * *} p<0.0001$.

\begin{tabular}{|c|c|c|c|c|}
\hline Experimental factors & 2009 & 2010 & 2011 & 2012 \\
\hline Block & 1.67 & $3.96^{* *}$ & 1.36 & $1.45^{*}$ \\
\hline Row & 2.73 & $5.0 * *$ & 1.9 & $1.9^{*}$ \\
\hline Sward type & 0.19 & 2.34 ** & 0.16 & 0.19 \\
\hline Fertilization & $58.47^{\star \star \star}$ & $34.92 * \star \star$ & $81.26^{\star \star \star}$ & $41.89^{\star \star \star}$ \\
\hline Cutting frequency & $10.35^{\star \star \star}$ & $24.71^{* \star *}$ & $1.34^{\star}$ & $26.35^{\star \star \star}$ \\
\hline $\begin{array}{l}\text { Fertilization:Cutting } \\
\text { frequency }\end{array}$ & $8.62^{* * *}$ & 16.96 *** & $4.09^{\star \star \star}$ & $22.02^{\star \star \star}$ \\
\hline Residuals & 17.96 & 12.11 & 11.24 & 6.2 \\
\hline
\end{tabular}

Intensification of management had significant effects on the biomass production with the plots cut three times a year and fertilized having the highest dry matter yields in all of the experimental years following the set-up of the experiment (Fig. 6). In 2009 and 2011, we also found that the biomass yields of plots cut once a year and fertilized were significantly higher than in 2010 and 2012. 


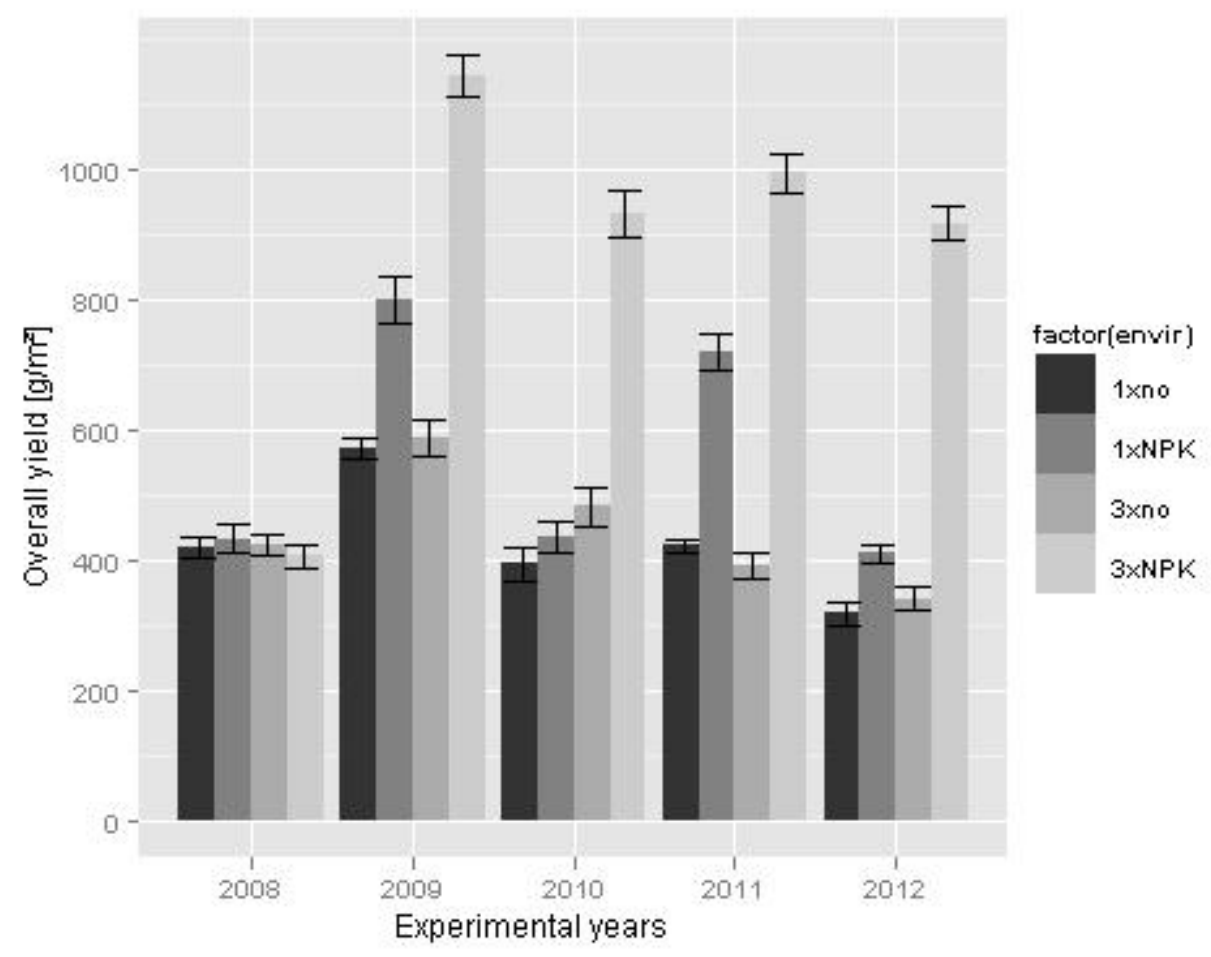

Fig. 6. Overall dry-matter yields (average of 24 plots) in four management systems (1xno, $1 \times$ NPK, $3 \times n$, 3xNPK) over the whole experimental period. 


\section{Discussion}

In the present study, we investigated the effects of diversity and management on aboveground biomass production in a semi-natural temperate grassland. We found that changes in sward composition associated with functional groups removal lasted for three years and affected the shares of grasses, herbs and legumes, as well as species evenness, while dynamics of species richness varied across the sward types and years. Overall species richness was not directly associated with an increase or loss of productivity regarding the whole experimental period while species evenness had a slight correlation with aboveground biomass production, direction and degree of which varied across the years. The primary determinants of an increase in biomass production were fertilization and cutting frequency with the highest dry matter yields characteristic for intensively managed plots. Sward type had a significant effect on above-ground biomass production only in the year with extremely dry summer conditions. After five years of establishing the experiment, the change in species numbers across the management systems of this grassland was not dramatic, but certain changes in vegetation composition were apparent.

\section{Changes in plant species richness}

Given the site characteristics, the experimental design represented the most typical management strategies in common temperate agriculturally-used grasslands. It was previously found that the major agricultural changes have occurred in the second half of the twentieth century and were diminishing after the 1990 (de Snoo et al. 2012, Wesche et al. 2012). We assume that the species composition of this semi-natural grassland was highly adapted to the local environmental factors at the set-up of the experiment and the changes mediated by the removal of functional groups, fertilization and cutting frequency could successfully reflect the dynamic of species changes in temperate grasslands under corresponding management intensification. While the dynamics of species gains and losses varied across all experimental years, the average species numbers recorded in the fifth year were higher than at the set-up of the experiment.

Depending on the state of the plant community and levels of nutrient input, it was found by some authors that fertilization can reduce the species number (Lepš 2004), but it may also have no significant effect on the species number and composition (Pavlů et al. 2012). While the overall species number fluctuated across the experimental years, some of the species that disappeared initially after the removal treatment were found again in the year 2011 as the herbicide effects were weakening. We also found the number of species to fluctuate slightly across the years in the control plots as well. In the study by Marini et al. (2007) both 
field management and soil fertility were along with topography the main determinants of vascular species richness. We suggest that the long history of use of this grassland for hay cutting and pasture was the primary determinant of the present species composition and the site conditions apparently allowed for the higher levels of above-ground biomass production than at the set-up year of the experiment (about $420 \mathrm{~g} / \mathrm{m}^{2}$ on average across all plots at the harvest in the end of June) without significant changes in species numbers. While in short-term synthetic communities biomass production may be affected by initial species abundances (Jiang et al. 2009), it seems that in real-world grasslands the natural variation of species dynamics is also important for above-ground biomass production. We conclude that at our study site changes in overall species numbers were not dramatic after five experimental years and fluctuations in species composition seemed normal. However, sward composition changes and changes in species evenness could be detected.

Changes in sward composition: functional groups shares and species evenness

Along with the changes in species numbers, the removal treatment proved to be successful regarding the shares of the three functional groups (for detailed description of the results see Petersen et al. 2012). While the immediate effects of removal of dicot- and monocotspecies on the shares of grasses and herbs were significant, three years after herbicide application the changes in sward composition were weakening and disappeared by the fourth year. Nevertheless, we found significantly larger shares of grasses in fertilized plots and significantly larger shares of herbs in plots cut three times even in the last observation period, suggesting that along with high natural resilience of this grassland's species composition, management matters for the sward diversity.

It was previously found that the productivity of plots within natural vegetation was related more to the relative composition of species (evenness) than to the number of species, with predominantly negative relationships between the two variables (Laird et al. 2003, Mulder et al. 2004). In our study, there was a significantly positive correlation between species evenness and productivity found, but the degree and the direction of this correlation varied across the years while the effects of the main experimental factors (fertilization, cutting frequency and sward type) had various effects on species evenness as well. We suggest that when a positive relationship was found between species evenness and productivity (e.g. in the years 2010 and 2012), the sward composition at our site became more even, productive species took advantage of an increased nutrient input, but not at the expense of limiting growth of the less-dominant species. It seems that in this grassland coexistence of the characteristic matrix of large productive grasses (Dactylis glomerata, Lolium perenne) and shorter sub-dominant grasses (Agrostis capillaris, Festuca rubra) and herbs (Veronica 
chamaedrys, Ranunculus repens) was possible also under increased fertilization levels. It was previously shown that species composition might be highly variable and change according to the environmental conditions while species richness stays within narrow limits (Brown et al. 2001). Interestingly, in our study the species composition of most plots did not differ significantly after five years compared to the initial composition suggesting that this grassland remained rather stable concerning the species richness reaction on mid-term (multivariate analysis of the vegetation composition performed with Canoco (ter Braak \& Šmilauer 1997-2004) revealed a short gradient of the variation of vegetation relevés in the dataset for the whole investigation period, data not shown).

\section{Diversity-productivity relationship in a real-world grassland}

Our results suggest that the absence of a direct effect of species richness on above-ground biomass production regarding the whole investigation time-period is the result of multiple direct and indirect effects of fertilization, sward composition and cutting frequency. In the year 2010, however, the sward diversity had an effect on the biomass production, and it might be due to combination of still pronounced differences in the sward diversity and better nitrogen use efficiency in the control sward (as shown by Keuter et al. 2012). Laird et al. (2003) considered that the absence of a relationship between diversity and productivity in an old field might have been due to competitive dominance causing deterministic structuring of the vegetation composition. Jiang et al. (2009) compared the findings from synthetic and natural communities and suggested that reduction in diversity in a natural community does not necessarily result in the reduced presence of productive species, thus a negative effect of reduced diversity on productivity may not apply. We could not find any consistent effects of diversity on productivity across the experimental years. While dominant species are the most important factors in determining ecosystem processes and properties (Grime 1998, Mokany et al. 2008), it seems that their contribution to the above-ground biomass production did not cause a reduction of the numbers of less-dominant species in this grassland and the effects of species richness on productivity were therefore not significant.

In line with the results reported by Assaf et al. (2011) who found that species richness poorly explained productivity in managed grasslands, we found that species number had no direct effects on the above-ground biomass production only and that sward diversity had a positive effect on biomass production in the year 2010 when the control swards had higher drymatter yields compared to the further two sward types. Keuter et al. (2012) found in the year 2010 a better $\mathrm{N}$-use efficiency in the control sward plots which may have improved biomass production under the exceptionally dry summer months. Bernhard-Römermann et al. (2011) investigated the effects of climate, species and functional diversity on the biomass yields in 
temperate environments and found that the importance of each factor depended on the nutrient status and management frequency of the system. In our study, fertilization and cutting frequency were the determining factors of productivity. We suppose that in the dry summer period 2010 the not disturbed shares of grasses, herbs and legumes in the control sward composition might have compensated in terms of yield production for the reduced effects of fertilizer under drought conditions.

\section{Need for more biodiversity experiments in real-world grasslands?}

On the one hand, the needs for agricultural production in Europe are still growing and large areas of temperate grasslands are needed as the primary source of forage for cattle and other grazing animals, which drives the attention to maximizing their production potential. Such grasslands, however, are mostly represented by relatively species-poor mixtures sown on highly fertilized arable land. On the other hand, species-rich grasslands often receive a special status of high biodiversity value and are not used for agricultural practices anymore. Changes in species diversity do not only directly influence the ecosystem processes but have also direct links to ecosystem services, resilience of the ecosystem and resistance to disturbance (Chapin et al. 2000). Managing for improved biodiversity and for conservation is particularly challenging in agriculturally used areas (Hopkins \& Holz 2006). And while experimental grasslands can on the one hand sometimes offer more insights into the functioning of the ecosystems (e.g. Spehn et al. (2000) who reported that in experimental grassland communities mixtures perform better than monocultures suggesting complementary resources use), effects of realistic species losses can be studies better in removal experiments (Diaz et al. 2003, Jiang et al. 2009). Therefore, it is particularly important to study the patterns of diversity effects on ecosystem functioning in the realworld ecosystems.

\section{Implications for agricultural land use}

Our results suggest that with proper management strategies, providing sufficient resources for the least-productive species, it is possible to maintain sustainable biomass production levels without losing many plant species. Increasing cutting frequency, for instance, promoted species gains over the years compared to the plots cut only once a year in our study. Previous work has indicated that extensification might not be an adequate measure to increase grassland diversity (Schmid 2002). The studied grassland ecosystem was quite resilient and after disturbance bounced back to the original state of its long-term well-tried functional group composition while an increase of above-ground biomass production was mainly achieved by an appropriate management without a trade-off of losing diversity. Weigelt et al. 2009, as well as Tilman et al. (2012) found recently that the use of diverse 
mixtures might be more effective in increasing grassland productivity of some crops than fertilization and may provide better ecosystem services. We found that at least on a midterm basis it was possible to improve productivity of an old grassland and even gain new species through management adapted to the site conditions without the need of reseeding it with diverse species mixtures. The high nature value of this really long-term grassland system might thus be even higher, especially regarding its capacity for carbon storage, for example, provided the soil is not disturbed by plowing activities. Still, further monitoring of vegetation diversity should not only include species number but also composition as it seems to react faster to changes in agricultural management.

\section{List of references}

Adler, P.B., Seabloom, E.W., Borer, E.T., Hillebrand, H., Hautier, Y., Hector, A., Harpole, S.W., O'Halloran, L.R., Grace, J.B., Anderson, M.T., Bakker, J.D., Biederman, L.A., Brown, C.S., Buckley, Y.M., Calabrese, L.B., Chu, C.-J., Cleland, E.E., Collins, S.L., Cottingham, K.L., Crawley, M.J., Damschen, E.I., Davies, K.F., DeCrappeo, N.M., Fay, P.A., Firn, J., Frater, P., Gasarch, E.I., Gruner, D.S., Hagenah, N., Lambers, J.H.R., Humphries, H., Jin, V.L., Kay, A.D., Kirkman, K.P., Klein, J.A., Knops, J.M.H., La Pierre, K.J., Lambrinos, J.J., Li, W., MacDougall, A.S., McCulley, R.L., Melbourne, B.A., Mltchell, C.E., Moore, J.L., Morgan, J.W., Mortensen, B., Orrock, J.L., Prober, S.M., Pyke, D.A., Risch, A.C., Schuetz, M., Smith, M.D., Stevens, C.J., Sullivan, L.L., Wang, G., Wragg, P.D., Wright, J.P., Yang, L.H., 2011. Productivity is a poor predictor of plant species richness. Science 333, 17501753.

Assaf, T.A., Beyschlag, W., Isselstein, J., 2011. The relationship between plant diversity and productivity in natural and in managed grasslands. Applied Ecology and Environmental Research 9 (2), 157-166.

Bernhardt-Römermann, M., Römermann, C., Sperlich, S., Schmidt, W., 2011. Explaining grassland biomass - the contribution of climate, species and functional diversity depends on fertilization and mowing frequency. Journal of Applied Ecology 48 (5), 1088-1097.

Brown, J.H., Ernest, M.S., Parody, J.M., Haskell, J.P., 2001. Regulation of diversity: maintenance of species richness in changing environments. Oecologia 126, 321-332.

Cardinale, B.J., Wright, J.P., Cadotte, M.W., Carroll, I.T., Hector, A., Srivastava, D.S., Loreau, M., Weis, J.J., 2007. Impacts of plant diversity on biomass production increase through time because of species complementarity. Proceedings of the National Academy of Sciences (PNAS) 104 (46), 18123-18128.

Chapin, S.F., Zavaleta, E.S., Eviner, V.T., Naylor, R.L., Vitousek, P.M., Reynolds, H.L., Hooper, D.U., Lavorel, S., Sala, O.E., Hobbie, S.E., Mack, M.C., Díaz, S., 2000. Consequences of changing biodiversity. Nature 405, 234-242.

Critchley, C.N. R., Burke, M.J. W., Stevens, D.P., 2003. Conservation of lowland semi-natural grasslands in the UK: a review of botanical monitoring results from agri-environment schemes. Biological Conservation 115 (2), 263-278.

de Snoo, G.R., Naus, N., Verhulst, J., van Ruijven, J., Schaffers, A.P., 2012. Long-term changes in plant diversity of grasslands under agricultural and conservation management. Applied Vegetation Science 15, 299-306.

Diaz, S., Symstad, A.J., Stuart Chapin, F., Wardle, D.A., Huenneke, L.F., 2003. Functional diversity revealed by removal experiments. Trends in Ecology \& Evolution 18 (3), 140-146. 
Foster, B.L., Khavin, I.S., Murphy, C.A., Smith, V.H., Ramspott M.E., Price, K.P., Kindscher, K. (2010) Transactions of the Kansas Academy of Science 113 (1/2), 103-119.

Gough, L., Osenberg, C.W., Gross, K.L. \& Collins, S.L. (2000) Fertilization effects on species density and primary productivity in herbaceous plant communities. OIKOS 89, 428-439.

Grime, J., 1998. Benefits of plant diversity to ecosystems: immediate, filter and founder effects. Journal of Ecology 86, 902-910.

Hector, A., Schmid, B., Beierkuhnlein, C., Caldeira, M.C., Diemer, M., Dimitrakopoulos, P.G., Finn, J.A., Freitas, H., Giller, P.S., Good, J., Harris, R., Högberg, P., Huss-Danell, K., Joshi, J., Jumpponen, A., Körner, C., Leadley, P.W., Loreau, M., Minns, A., Mulder, C.P.H., O'Donovan, G., Otway, S.J., Pereira, J.S., Prinz, A., Read, D.J., Scherer-Lorenzen, M., Schulze, E.-D., Siamantziouras, A.-S.D., Spehn, E.M., Terry, A.C., Troumbis, A.Y., Woodward, F.I., Yachi, S., Lawton, J.H., 1999. Plant diversity and productivity experiments in European grasslands. Science 286, 1123-1127.

Hector, A., Bagchi, R., 2007. Biodiversity and ecosystem multifunctionality. Nature 448 (7150), 188190.

Hodgson, J., Montserrat-Marti, G., Tallowin, J., Thompson, K., Diaz, S., Cabido, M., Grime, J., Wilson, P., Band, S., Bogard, A., Cabido, R., Cáceres, D., Castro-Diez, P., Ferrer P., Martinez, M., Pérez-Rontomé, M., Charles, M., Cornelissen, J., Dabbert, S., Pérez-Harguindeguy, N., Krimly, T., Sijtsma, F., Strijker, D., Vendramini, F., Guerrero-Campo, J., Hynd, A., Jones, G., Romo-Diez, A., Torres Espuny, L. de, Villar-Salvador, P., Zak, M., 2005. How much will it cost to save grassland diversity? Biological Conservation 122 (2), 263-273.

Hooper, D.U., Vitousek, P.M., 1997. The effects of plant composition and diversity on ecosystem processes. Science 277 (5330), 1302-1305.

Hopkins, A., Holz, B., 2006. Grassland for agriculture and nature conservation: production, quality an multi-functionality. Agronomy Research 4 (1), 3-20.

Huston, M.A., Aarsen, L.W., Austin, M.P., Cade, B.S., Fridley, J.D., Garnier, E., Grime, J.P., Hodgson, J., Lauenroth, W.K., Thompson, K., Vandermeer, J.H., Wardle, D.A., 2000. No consistent effect of plant diversity on productivity. Science 289 (5483), 1255a.

Jiang, L., Wan, S., Li, L., 2009. Species diversity and productivity: why do results of diversitymanipulation experiments differ from natural patterns? Journal of Ecology 97 (4), 603-608.

Kahmen, A., Perner, J., Buchmann, N., 2005. Diversity-dependent productivity in semi-natural grasslands following climate perturbations. Functional Ecology 19, 594-601.

Keuter, A., Hoeft, I., Veldkamp, E., Corre, M.D., 2012. Nitrogen response efficiency of a managed and phytodiverse temperate grassland. Plant and Soil 364: 193-206.

Klapp, E., Stählin, A., 1936. Standorte, Pflanzengesellschaften und Leistung des Grünlandes. Ulmer, Stuttgart.

Laird, R.A., Pither, J., Aarsen, L.W., 2003. Species evenness, not richness, has a consistent relationship with productivity in old-field vegetation. Community Ecology 4 (1), 21-28.

Lepš, J., 2004. What do the biodiversity experiments tell us about consequences of plant species loss in the real world? Basic and Applied Ecology 5, 529-534.

Loreau, M., Naeem, S., Inchausti, P., Bengtsson, J., Grime, J.P., Hector, A., Hooper, D.U., Huston, M.A., Raffaelli, D., Schmid, B., Tilman, D., Wardle, D.A., 2001. Biodiversity and Ecosystem Functioning: Current Knowledge and Future Challenges. Science 294 (5543), 804-808.

Marini, L., Scotton, M., Klimek, S., Isselstein, J., Pecile, A., 2007. Effects of local factors on plant species richness and composition of Alpine meadows. Agriculture, Ecosystems \& Environment 119 (3-4), 281-288.

McLaren, J.R., Turkington, R., 2010. Ecosystem properties determined by plant functional group identity. Journal of Ecology 98 (2), 459-469.

Mokany, K., Ash, J., Roxburgh, S., 2008. Functional identity is more important than diversity in influencing ecosystem processes in a temperate native grassland. Journal of Ecology 96 (5), 884893. 
Mulder, C.P.H., Bazeley-White, E., Dimitrakopoulos P.G., Hector, A., Scherer-Lorenzen, M., Schmid, B., 2004. Species evenness and productivity in experimental plant communities. OIKOS 107, 50-63.

Naeem, S., Duffy, E., Zavaleta, E., 2012. The functions of biological diversity in an age of extinction. Science 336, 1401-1406.

Pavlů, V., Gaisler, J., Pavlů, L., Hejcman, M., Ludvíková, V., 2012. Effect of fertiliser application and abandonment on plant species composition of Festuca rubra grassland. Acta Oecologica 45, 42-49.

Petersen, U., Wrage, N., Köhler, L., Leuschner, C., Isselstein, J., 2012. Manipulating the species composition of permanent grasslands-A new approach to biodiversity experiments. Basic and Applied Ecology 13 (1), 1-9.

Pinheiro, J., Bates, D., DebRoy, S., Sarkar, D., The R Core team, 2009. nlme: Linear and nonlinear mixed effects models. $R$ package version 3, 1-96.

Proulx, R., Wirth, C., Voigt, W., Weigelt, A., Roscher, C., Attinger, S., Baade, J., Barnard, R.L., Buchmann, N., Buscot, F., Eisenhauer, N., Fischer, M., Gleixner, G., Halle, S., Hildebrandt, A., Kowalski, E., Kuu, A., Lange, M., Milcu, A., Niklaus, P.A., Oelmann, Y., Rosenkranz, S., Sabais, A., Scherber, C., Scherer-Lorenzen, M., Scheu, S., Schulze, E.-D., Schumacher, J., Schwichtenberg, G., Soussana, J.-F., Temperton, V.M., Weisser, W.W., Wilcke, W., Schmid, B., Borevitz, J.O., 2010. Diversity promotes temporal stability across levels of ecosystem organization in experimental grasslands. PLOS ONE 5 (10), e13382.

R Development Core Team, 2011. R: A language and environment for statistical computing. $R$ Foundation for Statistical Computing, Vienna.

Reich, P., Tilman, D., Isbell, F., Mueller, K., Hobbie, S.E., Flynn, D.F. B., Eisenhauer, N., 2012. Function, developmental genetics, and fitness consequences of a sexually antagonistic trait. Science 336 (6081), 585-589.

Roscher, C., Temperton, V.M., Scherer-Lorenzen, M., Schmitz, M., Schumacher, J., Schmid, B., Buchmann, N., Weisser, W.W., Schulze, E.-D., 2005. Overyielding in experimental grassland communities - irrespective of species pool or spatial scale. Ecology Letters 8 (4), 419-429.

Sala, O.E., Chapin, S.F. III, Armesto, J.J., Berlow, E., Bloomfield, J., Dirzo, R., Huber-Sanwald, E., Huenneke, L.F., Jackson, R.B., Kinzig, A., Leemans, R., Lodge, D.M., Mooney, H.A., Oesterheld, M., Poff, L.N., Sykes, M.T., Walker, B.H., Walker, M., Wall, D.H., 2000. Global biodiversity scenarios for the year 2100. Science 287, 1770-1774.

Sanderson, M.A., Skinner, R.H., Barker, D.J., Edwards, G.R., Tracy, B.F., Wedin, D.A., 2004. Plant species diversity and management of temperate forage and grazing land ecosystems. Crop Science 44, 1132-1144.

Schaffers, A.P., 2002. Soil, biomass, and management of semi-natural vegetation. Part II. Factors controlling species diversity. Plant Ecology 158, 247-268.

Scherber, C., Ripley B.D., Venables, W.N., 2011. StepAICc procedure for Ime models. Adjusted to work for $\mathrm{Im}, \mathrm{glm}$ and Ime models.

Schmid, B., 2002. The species richness-productivity controversy. Trends in Ecology and Evolution 17 (3), 113-114.

Schmid, B., Hector, A., 2004. The value of biodiversity experiments. Basic and Applied Ecology 5 (6), 535-542.

Spehn, E.M., Joshi, J., Schmid, B., Diemer, M., Körner, C., 2000. Above-ground resource use increases with plant species richness in experimental grassland ecosystems. Functional Ecology 14, 326-337.

Symstad, A.J., Tilman, D., 2001. Diversity loss, recruitment limitation and ecosystem functioning: lessons learned from a removal experiment. OIKOS 92, 424-435.

Ter Braak, C. J. F., Šmilauer, P., 1997-2004. Canoco for Windows. Plant Research International, Wageningen.

Tilman, D., Reich, P., Knops, J., Wedin, D., Mielke, T., Lehman, C., 2001. Diversity and productivity in a long-term grassland experiment. Science 294 (5543), 843-845. 
Tilman, D., Reich, P.B., Isbell, F., 2012. Biodiversity impacts ecosystem productivity as much as resources, disturbance, or herbivory. Proceedings of the National Academy of Sciences 109 (26), 10394-10397.

Tylianakis, J.M., Rand, T.A., Kahmen, A., Klein, A.-M., Buchmann, N., Perner, J., Tscharntke, T., Loreau, M., 2008. Resource heterogeneity moderates the biodiversity-function relationship in real world ecosystems. Plos Biol 6 (5), e122.

Wardle, D.A., Bonner, K.I., Barker, G.M., Yeates, G.W., Nicholson, K.S., Bardgett, R.D., Watson, R.N., Ghani, A., 1999. Plant removals in perennial grassland: vegetation dynamics, decomposers, soil biodiversity, and ecosystem properties. Ecological Monographs 69 (4), 535-568.

Weigelt, A., Weisser, W.W., Buchmann, N., Scherer-Lorenzen, M., 2009. Biodiversity for multifunctional grasslands: equal productivity in high-diversity and low-productivity high-input systems. Biogeosciences 6, 1695-1706.

Wesche, K., Krause, B., Culmsee, H., Leuschner, C., 2012. Fifty years of change in Central European grassland vegetation: large losses in species richness and animal-pollinated plants. Biological Conservation 150 (1), 76-85.

Wilsey, B.J., Polley, W.H., 2004. Realistically low species evenness does not alter grassland species-richness-productivity relationships. Ecology 85 (10), 2693-2700.

Wrage, N., Strodthoff, J., Cuchillo, H.M., Isselstein, J., Kayser, M., 2011. Phytodiversity of temperate permanent grasslands: ecosystem services for agriculture and livestock management for diversity conservation. Biodiversity Conservation 20 (14), 3317-3339.

Yang, Z., van Ruijven, J., Du, G., 2011. The effects of long-term fertilization on the temporal stability of alpine meadow communities. Plant and Soil 345, 315-324.

Zavaleta, E.S., Hulvey, K.B., 2004. Realistic species losses disproportionately reduce grassland resistance to biological invaders. Science 306 (5699), 1175-1177.

Zavaleta, E.S., Pasari, J.R., Hulvey, K.B., Tilman, G.D., 2010. Sustaining multiple ecosystem functions in grassland communities requires higher biodiversity. Proceedings of the National Academy of Sciences (PNAS) 107 (4), 1443-1446. 


\section{General discussion}

The present work investigated several aspects of the relationship between diversity and productivity in a semi-natural grassland, including the effects of sampling scale, plant identity, and impacts of management. Biodiversity and ecosystem functioning were among the most intensively studied research topics lately, and a number of studies were conducted to investigate the different ecosystem processes, often including various methods and approaches. Nevertheless, there are more topics which need to be studied. Those include, for instance, the effects of biodiversity on ecosystem functioning in real-world species losses (Schmid \& Hector 2004) which might imply impacts on the state of ecosystem diversity and provision of ecosystem services. I will further discuss the findings of this study regarding recent work by other authors and relevance of the experimental results for the state of knowledge on semi-natural temperate grasslands, as well as the implications for agricultural management and multifunctional use of landscapes. I will primarily concentrate on the following questions. Does the spatial scale at which the relationship between diversity and productivity is investigated affect this relationship? Whether and how does plant functional diversity impact the relationship between biodiversity and above-ground biomass production and what is the role of agricultural management in the diversityproductivity relationship?

The first chapter of this thesis was aimed at investigating the effects of the scale of sampling on the relationship between species diversity and productivity. We found that harvesting at smaller spatial scales did not always reflect the relationship between diversity and productivity found at larger sampling scales. Species identity seemed to be important, on the other hand, particularly at small spatial scales. It is therefore important to include scale in future studies in natural and semi-natural grasslands particularly when those are characterized by patchy structure of the vegetation composition. It will allow not only to describe better vegetation diversity but will also ensure that the findings are not biased by the size of the vegetation relevé quadrats and species selection effects. Our results are in accordance with Grace et al. (2007) who reported that influence of small-scale diversity on productivity in mature communities can be a weak force. We often found non-significant relationships between diversity measures and productivity. In an observational study on multiple herbaceous communities in the Czech Republic Šimova et al. (2013) did not find any universal form of the relationship between species diversity and productivity. We could experimentally show that under different management regimes the relationship between 
diversity and productivity varied. While selection of the vegetation releve size of $1 \mathrm{~m}^{2}$ seems to be a reasonable choice in many studies (Dolnik \& Breuer 1998), biomass data collected from the plots of identical size might have a certain inaccuracy. In our study the largest variation of the data was typical at the spatial scale of $1 \mathrm{~m}^{2}$. The high variation in the data regarding harvested biomass might often be the case in the studies on natural and seminatural grasslands where vegetation composition might consist of patches of tall and productive grasses (Dactylis glomerata in our study) and short less productive grasses and herbs (Agrostis capillaris, Festuca rubra, Veronica chamaedrys in our study). Due to the natural heterogeneity of the vegetation cover and varying relationship between aboveground biomass production and diversity, it is therefore important to consider selection of an appropriate sampling scale for vegetation surveys and harvesting of biomass and to include scale variable in the models exploring the functioning of semi-natural grassland communities. The effects of management should also be studied further in detail as management tends to affect species composition in agricultural grasslands.

The second chapter of this thesis was dedicated to exploring the effects of management intensification on the diversity-productivity relationship with a focus on plant functional traits of dominant species and their role in this relationship. We concentrated on the dominant species diversity as several previous studies (among others Mokany et al. 2008) reported that the traits of dominant species influence ecosystem processes and properties. In our study, we did not only explore the effects of dominant species' traits on the above-ground biomass production, but also the impacts of management on changes in the functional diversity of dominant species. We found that fertilization led to decrease of different diversity measures (such as evenness, number and functional diversity of dominant species) whereas increasing cutting frequency positively affected these measures. Our results are in line with the findings by Flynn et al. (2009) who reported that land-use intensification leads to the reduction of functional diversity beyond changes in species richness. In our study, while overall species richness was not affected by the management intensification, at least on the mid-term, changes of the vegetation composition could be detected through evenness and functional traits. It seems therefore that it is important to include management aspects and multiple measures of diversity in future studies on semi-natural grasslands to understand better the link between management intensification and ecosystem processes in these systems. While overall species richness may not change dramatically due to management intensification, at least on short or mid-term basis, there still might be more benefits of swards with higher diversity which should not be overlooked. Many authors, among others de Bello et al. (2010), Balvanera et al. (2006), showed that high diversity is 
needed for many ecosystem processes. It is therefore important to monitor other diversity parameters, beyond species number only.

The last chapter of this thesis summarized the results of the whole experimental period regarding the diversity-productivity relationship and addressed such an important question as whether diversity is the main predictor of productivity in a semi-natural permanent grassland. It was highlighted by several authors that it is crucial to take biodiversity experiments to more "real-world" systems and consider long-term and large-scale effects of biodiversity on productivity in grasslands (Schmid \& Hector 2004, Lemaire et al. 2005). We found that species richness was a poor predictor of diversity while fertilization and cutting frequency were the main factors influencing the above-ground biomass production. In the study by Roemermann et al. (2011) contribution of species richness and functional diversity depended on nutrient status and management frequency. Our results, on one hand, support these findings as management variables were of primary importance for above-ground biomass production, but on the other hand, overall species richness in our study did not decrease dramatically with nutrient input compared to not fertilized swards in the investigation period but certain changes in species evenness and composition were detected. Sward type had significant effect on productivity only in the year 2010 which might be associated with particularly dry conditions in the summer months before July harvest, so that control sward performed better regarding overall dry-matter yield than monocot- and dicot-reduced swards. Interestingly, changes in overall species number were not significant over the whole investigation time period. Increasing cutting frequency even promoted establishing of new species on plots cut three times a year. In the study by Fenner \& Palmer (1998) the identity of species changed under addition of nutrients, but there were no consistent trends in species numbers. It seems that at our site vegetation composition reacted to management intensification with certain stability in overall species number. It may be argued that agriculturally used semi-natural grasslands are often rather speciespoor, but this fact may be due to the land use changes that have already taken place in European agricultural grasslands in the twentieth century. By reseeding permanent swards and increasing fertilization levels humans induced irreversible changes of biodiversity. Thus, our findings can be seen as a supporting idea for considering the use of permanent swards and not further reseeding them to provide sustainable yields, as suggested by Tilman et al. (2012) who showed recently that the use of diverse mixtures might be more effective in increasing productivity of some crops than fertilization and may provide better ecosystem services. Permanent grasslands can provide many other ecosystem services, beyond only biomass production and should therefore be viewed as multifunctional systems 
which play an important role in habitat provisioning, pollination services and carbon sequestration.

GrassMan project addressed biodiversity and ecosystem functioning issue from a rather new perspective. Taking the experimental approach to the "real-world" ecosystem seems to have given us new insights in the different aspects of the diversity-productivity relationship. Biodiversity can be both: externality of multifunctional land-use and its result at the same time, and can thus contribute to delivery of multiple ecosystem functions (Hopkins \& Holz 2006).

In our study we explored only some aspects of ecosystem functioning, such as aboveground biomass production and biodiversity relationship, but certainly addressing the issues of spatial scale, multiple measures of functional diversity and including management effects was an advantage of exploring this relationship in agriculturally used grassland using experimental approach. Our findings suggest that permanent swards are important for considering using them for optimising sustainable herbage production under appropriate management. While productivity of grasslands is dependent on balanced fertilization and cutting frequency selected for each particular site and environmental conditions, it should not be forgotten that other ecosystem services which are delivered by grassland system might require high species diversity (Isbell et al. 2011, MacDougall et al. 2013). Furthermore, preventing ploughing activities on old grasslands may affect their contribution to carbon storage and delivering other ecosystem services, such as soil microbial diversity or erosion control, more stable yields and further benefits.

\section{List of references}

Balvanera, P., Pfisterer, A.B., Buchmann, N., He, J.-S., Nakashizuka, T., Raffaelli, D., Schmid, B., 2006. Quantifying the evidence for biodiversity effects on ecosystem functioning and services. Ecology Letters 9 (10), 1146-1156.

Bernhardt-Römermann, M., Römermann, C., Sperlich, S., Schmidt, W., 2011. Explaining grassland biomass - the contribution of climate, species and functional diversity depends on fertilization and mowing frequency. Journal of Applied Ecology 48 (5), 1088-1097.

de Bello, F., Lavorel, S., Díaz, S., Harrington, R., Cornelissen, J.H.C., Bardgett, R.D., Berg, M.P., Cipriotti, P., Feld, C.K., Hering, D., Martins da Silva, P., Potts, S.G., Sandin, L., Sousa, J.P., Storkey, J., Wardle, D.A., Harrison, P.A., 2010. Towards an assessment of multiple ecosystem processes and services via functional traits. Biodiversity Conservation 19 (10), 2873-2893.

Dolnik, C. \& Breuer, M. (2008) Scale dependency in the species-area relationship of plant communities. Folia Geobotanica 43, 305-318. 
Fenner, M., Palmer, L., 1998. Grassland management to promote diversity: creation of a patchy sward by mowing and fertiliser regimes. Field Studies 9, 313-324.

Flynn, D.F.B., Gogol-Prokurat, M., Nogeire, T., Molinari, N., Richers, B.T., Lin, B.B., Simpson, N., Mayfield, M.M., DeClerck, F., 2009. Loss of functional diversity under land use intensification across multiple taxa. Ecology Letters 12 (1), 22-33.

Grace, J.B., Michael Anderson, T., Smith, M.D., Seabloom, E., Andelman, S.J., Meche, G., Weiher, E., Allain, L.K., Jutila, H., Sankaran, M., Knops, J., Ritchie, M., Willig, M.R., 2007. Does species diversity limit productivity in natural grassland communities? Ecology Letters 10 (8), 680-689.

Hopkins, A., Holz, B., 2006. Grassland for agriculture and nature conservation: production, quality and multi-functionality. Agronomy Research 4 (1), 3-20.

Isbell, F., Calcagno, V., Hector, A., Connolly, J., Harpole, W.S., Reich, P.B., Scherer-Lorenzen, M., Schmid, B., Tilman, D., van Ruijven, J., Weigelt, A., Wilsey, B.J., Zavaleta, E.S., Loreau, M., 2011. High plant diversity is needed to maintain ecosystem services. Nature 477 (7363), 199-202.

Lemaire, G., Wilkins, R., Hodgson, J., 2005. Challenges for grassland science: managing research priorities. Agriculture, Ecosystems \& Environment 108 (2), 99-108.

MacDougall, A.S., McCann, K.S., Gellner, G., Turkington, R., 2013. Diversity loss with persistent human disturbance increases vulnerability to ecosystem collapse. Nature 494 (7435), 86-89.

Mokany, K., Ash, J., Roxburgh, S., 2008. Functional identity is more important than diversity in influencing ecosystem processes in a temperate native grassland. Journal of Ecology 96 (5), 884893.

Schmid, B., Hector, A., 2004. The value of biodiversity experiments. Basic and Applied Ecology 5 (6), 535-542.

Šímová, I., Li, Y.M., Storch, D., 2013. Relationship between species richness and productivity in plants: the role of sampling effect, heterogeneity and species pool. Journal of Ecology 101 (1), 161170.

Tilman, D., Reich, P.B., Isbell, F., 2012. Biodiversity impacts ecosystem productivity as much as resources, disturbance, or herbivory. Proceedings of the National Academy of Sciences 109 (26), 10394-10397. 


\section{Summary}

Present study was aimed at examining the effects of spatial scale, plant identity and management on the relationship between diversity and productivity in an old semi-natural grassland in the Solling uplands, Germany. The study was conducted in the framework of the Grassland Management (GrassMan) experiment which is a part of the Excellence cluster „Functional Biodivesity Research“ at the University of Goettingen. The experimental field is a Lolio-cynosuretum semi-natural permanent grassland with more than a hundredyear old history of extensive agricultural use. The three experimental factors (sward composition, fertilization and cutting frequency) results in 12 different treatments and are set in Latin Rectangle, comprising 6 replications of each treatment. Experimental approach that we used, the so called "removal experiment", is aimed at studying the effects of removal itself and recovery of the vegetation after disturbance, as well as the different aspects of ecosystem functioning

In the first chapter we investigate the effects of sampling scale on the relationship between species diversity and productivity. So far, many observational studies, conducted in seminatural grasslands, explored the relationship between species diversity and productivity at the common size of vegetation surveys of $1 \mathrm{~m}^{2}$ or larger, selected according to the species minimum areal. Experimental studies, on the other hand, referred to the small-scale effects of diversity and productivity relationship which often caused the problem of extrapolating and generalizing of their results to more natural plant communities. We studied the effects of spatial scale on the biomass production and diversity relationship by selecting four spatial scales: small $\left(0.04 \mathrm{~m}^{2}\right.$ and $\left.0.16 \mathrm{~m}^{2}\right)$, medium $\left(1 \mathrm{~m}^{2}\right)$, large $\left(9 \mathrm{~m}^{2}\right)$, and very large $\left(225 \mathrm{~m}^{2}\right)$ and comparing the power of this relationship, including the effects of agricultural management. We found that the relationship between diversity and productivity of a seminatural grassland differed across the scales of sampling and that harvesting of the biomass at small spatial scales did not always fully reflect the relationship between the two variables (which often turned into insignificant at larger spatial scales). The most common size of plots for vegetation surveys, being $1 \mathrm{~m}^{2}$, in this study showed high variation, both in vegetation composition and harvested biomass. Management system established at the field seemed to play a role in the direction of this relationship (positive or negative). So, plots cut three times a year, becoming more homogeneous (more even) in vegetation composition showed a positive relationship between diversity and productivity. We suggest that selecting an appropriate spatial scale is therefore very important in heterogeneous natural grasslands, also those agriculturally managed. While in more homogeneous environments rather small spatial scale is adequate for describing the composition and 
many aspects of ecosystem functioning, in more heterogeneous habitats it is important to include this parameter in the analysis.

In the second chapter we present the results of a study on the effects of management intensification in a permanent grassland and the response of overall and dominant species diversity. A removal experiment in the Solling uplands, Germany (three sward types: control, dicot-reduced and monocot-reduced) employed four different levels of management intensity resulting from a combination of two factors: fertilization (no and 180-30-100 kg ha ${ }^{-1}$ year ${ }^{-1}$ of N-P-K, respectively) and cutting frequency (cut once and three times a year). This study was conducted over two years $(2010,2011)$, starting with a third year after introducing the management treatments. We defined species diversity by species number per plot as well as evenness and identified dominant species, making up about $80 \%$ share of the yield. We collected information on several plant functional traits for each of the dominant species: plant height, leaf dry matter content, stem dry matter content, leaf specific area, green leaves / total leaves ratio, stem specific density, and calculated additionally the ratio of stem specific density and plant height. Further measures of functional diversity included functional group shares, functional diversity index, defined as the total branch length of the traits-species cluster diagram, and aggregated plant functional traits for each plot. We found that management intensification did not affect the total species number, but affected species evenness and functional diversity of dominant species, including their number and identity. Correlations of above-ground biomass and several dominant species' traits were responsible for fertilization effects on above-ground productivity in this grassland. This indicates the importance of monitoring not only species richness but also other measures of diversity, as well as including management aspects in studies of plant functional traits in grasslands.

In the third chapter of the thesis we present the results from the whole investigation period and summarize the findings of the GrassMan experiment regarding the relationship between species richness and productivity, as well as the changes in species number over time and the main determinants of productivity. We analyzed the overall effects of species diversity expressed in species number, functional group composition and species identity effects on the above-ground biomass production. We found that the effects of species richness on the productivity were rather weak while the functional group diversity was a better predictor of productivity in some years. Intensifying the management, however, caused higher above-ground biomass production. It also affected species composition and evenness: increasing cutting frequency increased the evenness while increasing fertilization decreased it. We suggest that functional group richness might be important for better use of available resources. We conclude that existing species composition under 
appropriate agricultural management seems to have a potential for sustainable forage production without significant species losses, when not used and fertilized too intensively, and without the need of being converted to arable land or manipulating the species composition. The changes in species diversity should, however, be monitored, including not only species number but also other parameters, such as vegetation composition and functional group shares.

We finally discuss that our findings do not necessarily support the evidence from experimental studies on sown grasslands which often found that species richness had a defining role in biomass production. While overall species richness was of relatively less importance than management in this grassland, species composition was changing beyond just the number of species. We thus underline the importance of bringing biodiversity experiments to the "real-world“ ecosystems and suggest that thorough consideration of spatial aspects of the diversity-productivity relationship, as well as incorporating multiple measures of diversity in the experiments, conducted in agricultural grasslands under appropriate management strategies, might give better insights in their functioning and serve as motivation for farmers to conserve existing species diversity. Apart from the number of important ecosystem functions, providing fodder for herbivores and ruminants, conserving natural vegetation composition contributes to delivering further ecosystem services, which could support cultural and biodiversity benefits of the agricultural landscapes. 


\section{Acknowledgements}

This thesis was prepared in the framework of the Cluster of Excellence "Functional Biodiversity Research" and was supported by the Ministry of Science and Culture of Lower Saxony and the "Niedersächsisches Vorab".

I would first of all like to thank my supervisors: Prof. Dr. Johannes Isselstein and Prof. Dr. Nicole Wrage for their support throughout this time, inspiring discussions, sharing with me their knowledge of grassland systems and giving me all kind of advice.

Without thorough and reliable work of our vegetation experts over the whole experimental time period this work would not have been possible. Uwe von Borstel, Bernd Gehlken and Berit Greune supported us in conducting vegetation surveys despite cold, rain or unbearable heat. I would especially like to thank Berit Greune who helped me a lot in the last year of my Ph.D. studies and supported me in research activities at the field while I was busy preparing talks and posters in the office.

I am very thankful to Barbara Hohlmann for her support with the technical issues, assistance with coordination of the field activities and being ready to help me or even pick the whole group up from the field in all emergency cases. Machines are not humans and sometimes they did not care when we had our harvesting dates, but I was very lucky to have the support of our technical workers who helped with this kind of work and could even repair some of the equipment in the field.

An important role in managing general activities at the field site belongs to Arne Oppermann who was very patient with all the Ph.D. students from the project despite our "hilarious" fear of cows at the neighboring field.

I am thankful to Lars Köhler for help with formal activities in the framework of this project, to Christoph Scherber for his statistical advice, to other members of the Excellence cluster for interesting discussions during the meetings and to all of my GrassMan fellow Ph.D. students with whom we did not only share the field activities, but also had a nice time during our lunch breaks or meetings in Göttingen.

Interns and student workers of our department helped with sorting of numerous samples and were interested in being involved in the project which was very motivating for all of us.

I am thankful to my colleagues from the Grassland Institute with whom we also became friends, some of them have already finished their Ph.D. studies, some not, but I feel that I learned a bit from everybody and I am grateful for sharing walks and talks with them.

Last but not least I would like to thank my family and close friends for their support and cheering me up when I was staying late on weekends to scan an enormous amount of plant material collected in the field. And of course there are more people who inspired me a lot on the way, and their attitude and kindness motivated me a lot in pursuing this work. 


\section{Curriculum vitae \\ Date and Place of Birth}

\section{Email \\ Office Address}

May 2010 - May 2013

Oct. 2007 - Jan. 2010

Sep. 2002 - Jul. 2007

Sep. 1991 - Jun. 2002

April 2011

Sep. 2009

July 2013 - September 2014

April 2010 - June 2013

May 2009 - Jan. 2010

Sep. 2008 - March 2010

Dec. 2006 - May 2007

Jan. 2005 - Oct. 2007

Moscow

\subsubsection{4, Moscow}

\section{Contact information}

tfrom@gwdg.de

von-Siebold Str. 8, Faculty of Agricultural

Sciences, Department of Crop Science, 37075

Goettingen, Germany

\section{Educational Background}

Ph.D. Candidate at the Georg-August University of Goettingen, International Ph.D. Program for Agricultural Sciences

Master of Sciences in the International Master program "Environmental Management Management of Natural Resources" at the Ecology Center of the Christian-Albrecht's University of Kiel

Diploma in International Economy and Trade, Moscow

High school education at the Center of Education \# 1862, Moscow

\section{Additional Education and Courses}

Methods in Landscape Analysis (at the Leibniz Center for Agricultural Landscape Research in Muencheberg (ZALF))

Summer school "Management of water quality"

\section{Professional Experience}

Consultant at the Food and Agricultural Organization of the United Nations in Rome, Italy

Ph.D. candidate in the GrassMan project at the Department of Grassland Science, Georg-August University of Goettingen

Scientific work within the framework of the Coastal Futures project (master thesis)

Scientific assistant at the Department of Hydrology at the Ecology Center Kiel: assistance during the course Geographical Information Systems and organization of the Summer School

Internship at the Ministry of Economic Development and Trade of the Russian Federation, Department of Co-ordination of Economic Policy

Part-time job at the "Kelis Consulting" Company, 


\section{List of publications}

From T., Wrage N., Isselstein J., 2012. Exploring the relationship between diversity and productivity of a semi-natural permanent grassland using plant functional traits. Grassland Science in Europe. Vol. 17, 70-72 (peer-reviewed publication). Presented in a talk at the 24th General Meeting of the European Grassland Federation in Lublin, Poland (3-7 June 2012).

From, T., Isselstein, J., 2012. Produktivität und Futterqualität von bewirtschaftetem, naturnahem Grünland unterschiedlicher Phytodiversität. Mitteilungen der Arbeitsgemeinschaft Grünland und Futterbau 13, 67-71.

From T., Wrage N., Isselstein J., 2011. Does the scale of sampling affect the relationship between biodiversity and productivity of temperate grasslands? Presented as a poster at the International conference Functions and Services of Biodiversity in Goettingen, Germany (20-22 June 2011).

From T., Wrage, N., Isselstein, J., 2011. The relationship between biodiversity and productivity of temperate semi-natural grasslands - The effect of scale of sampling. Mitteilungen der Gesellschaft für Pflanzenbauwissenschaften 23, 176.

From, T., Petersen, U., Isselstein, J., 2011. Produktivität und Futterqualität von naturnahem Grünland unterschiedlicher funktioneller Diversität unter verschiedener Bewirtschaftungsintensität. Mitteilungen der Arbeitsgemeinschaft Grünland und Futterbau 12, 163-168. 


\section{Appendix}

Appendix 1. Supporting information for Chapter 1 (Supplementary table 1).

Precipitation and mean air temperatures (mean 1960-1990) at Silberborn, Solling Uplands (German Weather Service, 1960-1990) and at the GrassMan site at $2 \mathrm{~m}$ height (2009-2012, overall dataset for corresponding years available from 2009 onwards)

\begin{tabular}{llllllll}
\hline & April & May & June & July & Aug & Sep & Annual \\
\hline $\begin{array}{l}\text { Mean 1960-1990 } \\
\text { Precipitation }(\mathrm{mm})\end{array}$ & 77 & 84 & 108 & 97 & 85 & 78 & 1031 \\
$\begin{array}{l}\text { Temperature }\left({ }^{\circ} \mathrm{C}\right) \\
\mathbf{2 0 0 9}\end{array}$ & 6 & 11 & 14 & 15 & 15 & 12 & 7 \\
$\begin{array}{l}\text { Precipitation }(\mathrm{mm}) \\
\text { Temperature }\left({ }^{\circ} \mathrm{C}\right)\end{array}$ & 22 & 70.4 & 52.9 & 112.6 & 48.9 & 80.6 & 1000.6 \\
$\mathbf{2 0 1 0}$ & 11.6 & 11.8 & 12.5 & 16 & 17.3 & 13.5 & 7.8 \\
Precipitation $(\mathrm{mm})$ & 15 & 113 & 26 & 47 & 182 & 102 & 1110 \\
$\begin{array}{l}\text { Temperature }\left({ }^{\circ} \mathrm{C}\right) \\
\mathbf{2 0 1 1}\end{array}$ & 7.8 & 8.5 & 15.7 & 19.8 & 15.4 & 11.4 & 6.6 \\
Precipitation $(\mathrm{mm})$ & 41.8 & 23.3 & 61 & 110.9 & 125.3 & 54.8 & 724 \\
Temperature $\left({ }^{\circ} \mathrm{C}\right)$ & 11.3 & 12.7 & 15.2 & 14.5 & 16.6 & 14.8 & 8.9 \\
$\mathbf{2 0 1 2}$ & & & & & & & \\
Precipitation $(\mathrm{mm})$ & 45.3 & 59.3 & 104.6 & 112.3 & 49.6 & 29.4 & 810.1 \\
Temperature $\left({ }^{\circ} \mathrm{C}\right)$ & 6.7 & 13.1 & 13.2 & 15.7 & 17.4 & 12.3 & 8.6 \\
\hline
\end{tabular}


Appendix 2. Supporting information for Chapter 1 (Supplementary table 2).

Summary of linear models between productivity and species richness according to each management system (block and row included as fixed effects if their effects were found significant), $p$-value $(p)$ and $\mathrm{R}^{2} ; \mathrm{n}=18$. Small scale in 2010: $0.16 \mathrm{~m}^{2}$, in 2011: $0.04 \mathrm{~m}^{2}$. Further scale levels: medium: $1 \mathrm{~m}^{2}$, large: $9 \mathrm{~m}^{2}$, plot: $225 \mathrm{~m}^{2}$

\begin{tabular}{|c|c|c|c|c|c|c|c|c|}
\hline \multirow[b]{2}{*}{ Cut } & \multirow[b]{2}{*}{ Scale } & \multirow[b]{2}{*}{ Environment } & \multicolumn{3}{|c|}{2010} & \multicolumn{3}{|c|}{2011} \\
\hline & & & Slope & $p$ & $\mathbf{R}^{2}$ & Slope & $p$ & $\mathbf{R}^{2}$ \\
\hline \multirow[t]{8}{*}{ May } & small & $3 \times n o$ & + & 0.06 & 0.2 & - & 0.47 & 0.35 \\
\hline & & $3 \times N P K$ & + & 0.77 & 0.006 & + & 0.27 & 0.45 \\
\hline & medium & $3 \times n o$ & - & 0.37 & 0.05 & + & $<0.01$ & 0.40 \\
\hline & & $3 \times N P K$ & + & 0.13 & 0.14 & - & 0.28 & 0.21 \\
\hline & large & $3 \times n o$ & + & 0.54 & 0.04 & + & 0.13 & 0.14 \\
\hline & & $3 \times N P K$ & + & 0.68 & 0.01 & - & 0.07 & 0.60 \\
\hline & very large & $3 \times n o$ & - & 0.89 & 0.001 & + & 0.26 & 0.28 \\
\hline & & $3 x N P K$ & + & 0.96 & 0.001 & + & 0.59 & 0.02 \\
\hline \multirow[t]{16}{*}{ July } & small & $1 \times n o$ & - & 0.07 & 0.18 & - & 0.03 & 0.25 \\
\hline & & $1 \times N P K$ & - & 0.49 & 0.03 & - & 0.62 & 0.02 \\
\hline & & $3 \times n o$ & - & 0.71 & 0.009 & + & 0.87 & 0.002 \\
\hline & & $3 \times N P K$ & - & 0.03 & 0.26 & - & 0.96 & 0.002 \\
\hline & medium & $1 \times n o$ & + & 0.63 & 0.02 & + & 0.88 & 0.002 \\
\hline & & $1 \times N P K$ & - & 0.89 & 0.001 & - & 0.03 & 0.25 \\
\hline & & $3 \times n o$ & + & 0.37 & 0.05 & - & 0.95 & 0.003 \\
\hline & & $3 x N P K$ & - & 0.84 & 0.002 & + & 0.07 & 0.19 \\
\hline & large & $1 \times n o$ & + & 0.38 & 0.05 & + & 0.25 & 0.08 \\
\hline & & $1 \times N P K$ & + & 0.07 & 0.18 & - & 0.54 & 0.02 \\
\hline & & $3 \times n o$ & - & 0.18 & 0.11 & + & 0.8 & 0.004 \\
\hline & & $3 \times N P K$ & - & 0.20 & 0.10 & - & 0.20 & 0.10 \\
\hline & very large & $1 \times n o$ & + & 0.57 & 0.02 & + & 0.26 & 0.08 \\
\hline & & $1 \times N P K$ & + & 0.65 & 0.01 & - & 0.09 & 0.32 \\
\hline & & $3 \times n o$ & - & 0.9 & 0.001 & - & 0.65 & 0.01 \\
\hline & & $3 x N P K$ & - & 0.01 & 0.48 & - & 0.22 & 0.09 \\
\hline \multirow[t]{8}{*}{ Sep } & small & $3 \times n o$ & + & 0.03 & 0.66 & + & 0.12 & 0.14 \\
\hline & & $3 \times N P K$ & - & 0.96 & 0.002 & - & 0.47 & 0.03 \\
\hline & medium & $3 \times n o$ & + & 0.06 & 0.20 & - & 0.17 & 0.12 \\
\hline & & $3 x N P K$ & - & 0.41 & 0.04 & + & 0.76 & 0.07 \\
\hline & large & $3 \times n o$ & + & 0.08 & 0.51 & + & 0.33 & 0.06 \\
\hline & & $3 \times N P K$ & - & 0.62 & 0.02 & - & 0.62 & 0.02 \\
\hline & very large & $3 \times n o$ & + & 0.17 & 0.51 & - & 0.68 & 0.001 \\
\hline & & $3 x N P K$ & + & 0.08 & 0.17 & - & 0.62 & 0.02 \\
\hline
\end{tabular}


Appendix 3. Supporting information for the Chapter 1 (Supplementary table $3)$.

Summary of linear models between productivity and species evenness according to each management system (block and row included as fixed effects if their effects were found significant), $p$-value $(p)$ and $\mathrm{R}^{2} ; \mathrm{n}=18$. Small scale in 2010: $0.16 \mathrm{~m}^{2}$, in $2011: 0.04 \mathrm{~m}^{2}$. Further scale levels: medium: $1 \mathrm{~m}^{2}$, large: $9 \mathrm{~m}^{2}$, plot: $225 \mathrm{~m}^{2}$

\begin{tabular}{|c|c|c|c|c|c|c|c|c|}
\hline \multirow[b]{2}{*}{ Cut } & \multirow[b]{2}{*}{ Scale } & \multirow[b]{2}{*}{ Environment } & \multicolumn{3}{|c|}{2010} & \multicolumn{3}{|c|}{2011} \\
\hline & & & Slope & $p$ & $\mathbf{R}^{2}$ & Slope & $p$ & $\mathbf{R}^{2}$ \\
\hline \multirow[t]{8}{*}{ May } & small & $3 \times n o$ & + & 0.07 & 0.19 & - & 0.02 & 0.62 \\
\hline & & $3 x N P K$ & - & 0.01 & 0.32 & - & 0.72 & 0.03 \\
\hline & medium & $3 \times n o$ & - & 0.74 & 0.007 & - & 0.80 & 0.06 \\
\hline & & $3 x N P K$ & + & 0.12 & 0.14 & - & 0.87 & 0.04 \\
\hline & large & $3 \times n o$ & - & 0.70 & 0.01 & - & 0.10 & 0.15 \\
\hline & & $3 x N P K$ & + & 0.94 & 0.001 & + & 0.20 & 0.10 \\
\hline & very large & $3 \times n o$ & + & 0.14 & 0.13 & + & 0.01 & 0.16 \\
\hline & & $3 \times N P K$ & - & 0.30 & 0.07 & - & 0.85 & 0.002 \\
\hline \multirow[t]{16}{*}{ July } & small & $1 \times n o$ & - & 0.55 & 0.02 & - & 0.17 & 0.12 \\
\hline & & $1 \mathrm{xNPK}$ & - & 0.54 & 0.02 & - & 0.56 & 0.02 \\
\hline & & $3 \times n o$ & - & 0.13 & 0.14 & + & 0.87 & 0.002 \\
\hline & & $3 x N P K$ & - & 0.07 & 0.27 & + & 0.08 & 0.18 \\
\hline & medium & $1 \times n o$ & + & 0.82 & 0.003 & + & 0.82 & 0.006 \\
\hline & & 1xNPK & + & 0.79 & 0.004 & - & 0.16 & 0.12 \\
\hline & & $3 \times n o$ & - & 0.84 & 0.003 & - & 0.09 & 0.32 \\
\hline & & $3 \times N P K$ & - & 0.12 & 0.17 & - & 0.87 & 0.002 \\
\hline & large & $1 \times n o$ & - & 0.35 & 0.05 & + & 0.69 & 0.01 \\
\hline & & 1xNPK & - & 0.68 & 0.01 & - & 0.04 & 0.23 \\
\hline & & $3 x n o$ & - & 0.09 & 0.10 & - & 0.10 & 0.15 \\
\hline & & $3 x N P K$ & - & 0.09 & 0.17 & - & 0.24 & 0.09 \\
\hline & very large & $1 \times n o$ & - & 0.79 & 0.005 & - & 0.31 & 0.06 \\
\hline & & $1 \mathrm{xNPK}$ & + & 0.04 & 0.25 & - & 0.12 & 0.14 \\
\hline & & $3 \times n o$ & + & 0.09 & 0.13 & + & 0.03 & 0.27 \\
\hline & & $3 x N P K$ & - & 0.5 & 0.02 & - & $<0.001$ & 0.52 \\
\hline \multirow[t]{8}{*}{ Sep } & small & $3 \times n o$ & - & 0.62 & 0.38 & + & 0.64 & 0.01 \\
\hline & & $3 \times N P K$ & - & 0.66 & 0.01 & - & 0.55 & 0.02 \\
\hline & medium & $3 x n o$ & - & 0.02 & 0.14 & - & 0.05 & 0.23 \\
\hline & & $3 \times N P K$ & - & 0.93 & 0.002 & - & 0.20 & 0.10 \\
\hline & large & $3 \times n o$ & + & 0.18 & 0.11 & + & 0.04 & 0.26 \\
\hline & & $3 x N P K$ & + & 0.35 & 0.05 & + & 0.82 & 0.003 \\
\hline & very large & $3 \times n o$ & + & 0.64 & 0.01 & + & 0.09 & 0.23 \\
\hline & & $3 \times N P K$ & + & 0.49 & 0.03 & + & 0.87 & 0.002 \\
\hline
\end{tabular}

